\title{
Childhood respiratory health in the Dutch-German borderland
}

Citation for published version (APA):

Mommers, M. A. H. (2005). Childhood respiratory health in the Dutch-German borderland. [Doctoral Thesis, Maastricht University]. Maastricht University. https://doi.org/10.26481/dis.20050414mm

Document status and date:

Published: 01/01/2005

DOI:

10.26481/dis.20050414mm

Document Version:

Publisher's PDF, also known as Version of record

\section{Please check the document version of this publication:}

- A submitted manuscript is the version of the article upon submission and before peer-review. There can be important differences between the submitted version and the official published version of record.

People interested in the research are advised to contact the author for the final version of the publication, or visit the DOI to the publisher's website.

- The final author version and the galley proof are versions of the publication after peer review.

- The final published version features the final layout of the paper including the volume, issue and page numbers.

Link to publication

\footnotetext{
General rights rights.

- You may freely distribute the URL identifying the publication in the public portal. please follow below link for the End User Agreement:

www.umlib.nl/taverne-license

Take down policy

If you believe that this document breaches copyright please contact us at:

repository@maastrichtuniversity.nl

providing details and we will investigate your claim.
}

Copyright and moral rights for the publications made accessible in the public portal are retained by the authors and/or other copyright owners and it is a condition of accessing publications that users recognise and abide by the legal requirements associated with these

- Users may download and print one copy of any publication from the public portal for the purpose of private study or research.

- You may not further distribute the material or use it for any profit-making activity or commercial gain

If the publication is distributed under the terms of Article $25 \mathrm{fa}$ of the Dutch Copyright Act, indicated by the "Taverne" license above, 
Childhood Respiratory Health in the Dutch-German borderland 
ISBN 9052784558

Lay-out: MAH Mommers

Cover illustration: enlarged from the Euregio Maas-Rijn map, Euregio Maas-Rijn / Interreg

Production: Datawyse, Universitaire Pers Maastricht

2005 MAH Mommers

All rights reserved. No part of this thesis may be reproduced or transmitted in any form or by any means, electronic or mechanical, including photocopying, recording or any information storage or retrieval system, without permission in writing from the author, or, when appropriate from the publishers of the publications. 


\title{
Childhood Respiratory Health in the Dutch-German borderland
}

\author{
PROEFSCHRIFT
}

ter verkrijging van de graad van doctor

aan de Universiteit Maastricht, op gezag van de Rector Magnificus,

Prof. mr. G.P.M.F. Mols, volgens het besluit van het College van Decanen, in het openbaar te verdedigen op donderdag 14 april 2005 om 16.00 uur

door

Monique A.H. Mommers

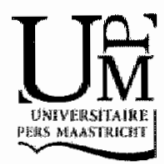




\section{Promotor:}

Prof dr. C.P. van Schayck

\section{Co-promotores:}

Dr. G.M.H. Swaen

Dr. M. Weishoff-Houben (RWTH-Aachen, Duitsland)

\section{Beoordelingscommissie:}

Prof. dr. ir. P.A. van den Brandt (voorzitter)

Dr. Q. Jöbsis

Prof. dr. T. Kraus (RWTH-Aachen, Duitsland)

Dr. G.J. Wesseling

The Dutch-German study on childhood respiratory health was financially supported by the European Union, the Euregio Maas-Rhine (Interreg II project EMR.INT2.96.09.V.039), the Land Northrhine-Westphalia, the Province of Limburg and the counties of Heinsberg, Midden-Limburg and Westelijke Mijnstreek. 


\section{CONTENTS}

1. Introduction

2a. Changing prevalence of respiratory symptoms and treatment in Dutch school children:1989-1997

2b. Trends in prevalence of respiratory symptoms and treatment in Dutch children over a 12 year period: results of the fourth consecutive survey

3. Differences in asthma diagnosis and medication use in children living in Germany and the Netherlands

4. Infant immunisation and the occurrence of atopic disease in Dutch and German children: a nested case-control study

5. Childhood infections and risk of wheezing and allergic sensitisation at age $7-8$ years

6. Indoor environment and respiratory symptoms in children living in the Dutch-German borderland

7. Different risk factor patterns for asthmatic symptoms in atopic and non-atopic Dutch and German children

8. General Discussion 101

Summary

Samenvatting

Appendices

Dankwoord

Curriculum Vitae 



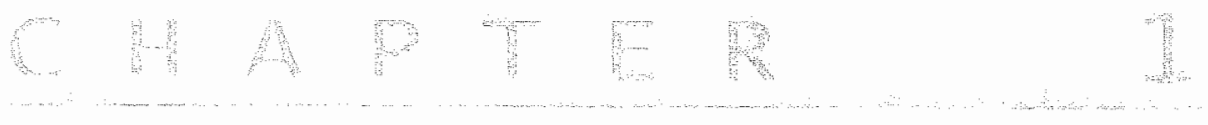

Introduction 
8 | Chapter 1 


\section{BACKGROUND}

Asthma is a chronic inflammatory disorder of the airways, associated with airway hyperresponsiveness, airflow limitation, and respiratory symptoms [1]. Asthma is a common chronic disease in children and there is ample evidence that the prevalence of asthma has increased over the last decades $[2,3]$. Furthermore, results from the International Study of Asthma and Allergies in Childhood (ISAAC) and the European Community Respiratory Health Study (ECRHS) conducted among adults, revealed large variations in prevalence rates between countries $[4,5]$, with the highest asthma symptom prevalence rates reported for Australia, New Zealand and England. Causes for these temporal and geographical differences are at present still unclear. Indoor as well as outdoor environmental factors have been investigated extensively, and many factors appear to be involved in the development of childhood asthma and in the precipitation of asthma exacerbations. With the results from the ISAAC-study [4] and the German East-West-studies [6] it became clear that the role of outdoor air pollution was limited in explaining the geographical and temporal variations of asthma symptom prevalence. Changes in lifestyle and housing conditions have been thought more likely to explain these differences.

The role of allergen exposure as a secondary cause for asthma has been well established [7-9], and may in particular be relevant for progression to clinically manifest disease $[10,11]$. From their review Murray and co-workers recently concluded that, although biologically plausible, the evidence for allergen exposure as a primary cause of asthma is weak [12]. However, primary prevention trials on allergen avoidance are still ongoing, and, with the exception of the Isle of Wight study, so far clinical outcomes have been reported at age 2 years or younger (reviewed by Simpson and Custovic [13]). For the longest ongoing study (Isle of Wight study) results have been reported up to the age of 8 years, at which age a large reduction in sensitisation to mite had been achieved in the intervention group, as well as a significantly smaller proportion of participants suffering from current wheeze [14]. On the other hand, allergic sensitisation and a family history of atopic diseases have since long been recognised as major risk factors for the development of asthma. Recent results from the German Multicentre Allergy Study (MAS) have challenged this concept by indicating allergic sensitisation as an intermediate step in the development of asthma and not as a causal risk factor inevitably resulting in asthma [15]. Expanding on the results of the MAS-study, von Mutius concluded that the predisposition to become sensitised rather than elevated allergen exposure drives the development of asthma, rendering other factors than allergen exposure important contributors in asthma development [16].

As childhood asthma begins very early in life, factors acting in utero or in early infancy have attracted special interest. Following the observation that having older siblings protects against atopic disease, in 1989, Strachan formulated the so-called "hygiene hypothesis" which proposes a protective effect of early childhood infections on atopic disease $[17,18]$. Results from many studies since have supported this theory, using indicators of infectious burden such as day-care attendance $[19,20]$, number of siblings or birth order [21-24], or studying specific 
infections [25-27]. A biological basis for the hygiene hypothesis is represented by the T-helper(Th)1/Th2-balance, which is thought to remain skewed towards a neonatal Th2-profile in atopic children, whereas normal maturation of the immune system would comprise proliferation of Th1-type lymphocytes. Early life events, such as certain infections, may shift the Th1/Th2 balance towards a Th1 response, and by doing so may suppress the development of atopic disease. Other factors acting early in life, such as breastfeeding [28] and exposure to pets in the home or to life-stock in a farming environment [29-35] have likewise been thought to protect against atopic manifestations. Recently, a number of studies have found that early exposure to pets reduces the risk of allergic sensitisation [35] or of asthma-like symptoms $[33,34]$ later in childhood.

The exact role of most factors implicated in asthma development is at present still unclear and both protective and harmful influences of factors such as pet keeping, infections, and breastfeeding have been reported in literature $[25,26,34,36-44]$. Although the hygiene hypothesis provides a reasonable explanation for many of these findings, in their recent editorial van Schayck and Knottnerus [45] consider "confounding by behaviour" as an alternative explanation, based on their observation that all indications in favour of the hygiene hypothesis stem from observational studies. Also, the role of the Th1/Th2 balance in explaining the increased prevalence of atopic disorders is still controversial [46]. Moreover, it might be an oversimplification [47,48] and an alternative explanation (reduced immune suppression) has recently been emphasized [46].

A universally accepted strategy for asthma prevention is still far off, not in the least caused by the lack of a clear understanding of the natural history of asthma [49]. Little is still known about the pathogenesis of asthma and it becomes more and more clear that the "asthma" definition holds a heterogeneity of syndromes with different aetiologies and prognoses. Differences in risk factor patterns for atopic asthma and non-atopic astinma have been suggested [50-52], and differences in genetic background have been thought to mediate the effect of environmental stimuli on atopic outcome $[32,53]$. Moreover, a German study pointed out a dissociation between mechanisms involved in the pathogenesis of asthma and factors operating in the development of allergy [54].

Against this background, the Dutch-German study on childhood respiratory health and environment was initiated, to gain more insight into prevalence of and risk factors for respiratory symptoms in the Dutch-German borderland.

\section{DUTCH-GERMAN STUDY}

\section{ON CHILDHOOD RESPIRATORY HEALTH AND ENVIRONMENT}

In the early nineties, the Dutch Municipal Health Services Westelijke Mijnstreek and Midden-Limburg identified childhood respiratory symptoms (asthmatic symptoms and cough) as an important health issue in their region. This awareness together with lack of information and incomparable results from previous studies, urged German (Kreis Heinsberg) and Dutch (Westelijke Mijnstreek and Midden- 
Limburg) Municipal Health Services and the Institute for Hygiene and Environmental Medicine (RWTH-Aachen) to conduct a large longitudinal study on childhood respiratory health in the Dutch-German borderland (Fig. 1).

Questionnaire survey $(\mathrm{N}=7201)$
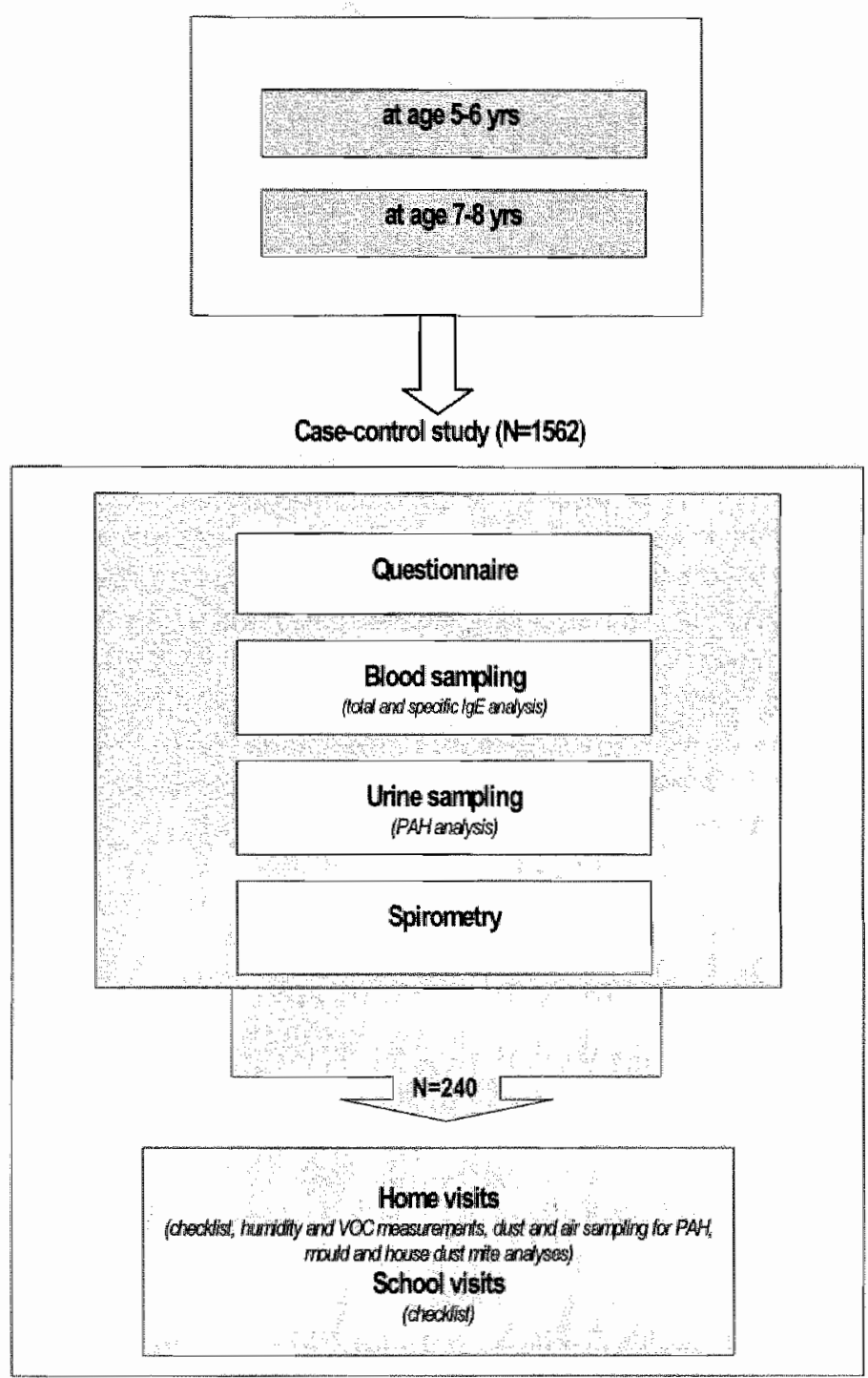

Fig. 1. Study design 
As a first step, prevalence of respiratory symptoms and diagnosis was studied in two consecutive surveys conducted in 1995 and 1997. All 7201 children living in the study area who were born between November $30^{\text {th }} 1989$ and December $1^{\text {st }} 1990$ were included in the study. Their parents were asked to complete a respiratory symptom questionnaire for the child, when the children were aged 5-6 years (1995) and again at $7-8$ years of age.

Ensuing these surveys, in a case-control setting, we investigated risk factors for childhood respiratory symptoms, "in particular for asthmatic symptoms. All 781 children with respiratory symptoms and an equal number of control children were invited to participate in the case-control study.

It was of importance to the Municipal Health Services to identify preventable risk factors for respiratory symptoms, modifiable at an age the Municipal Health Services have access to the chilldren, to use the resources of the Health Services to study prevalence of and risk factors for respiratory symptoms, and eventually to implement or improve prevention measures on a population levell. As described above, from literature, many factors appear to play a role in the development of atopic disease and for some factors (i.e., pets) it is not yet clear what their exact mechanism of action is. Also, at the time hardly any information was available on risk factors for developing respiratory symptoms in children, specific to the DutchGerman borderland. For these reasons it was decided to approach the issue from a broad perspective, with a study covering indoor environment at home, as well as at school, and also perinatal and early life events that could easily be assessed in the Health Service setting.

In addition to an elaborate questionnaire and a physical examination, in a subsample of 240 children, homes were investigated in more detail, including the collection of dust and air samples. We used checklists for a visual inspection of the homes and schools of these children.

\section{QUESTIONNAIRES AND DEFINITIONS USED IN THE THESIS}

In the present thesis, results from two studies, i.e., the Westelijke Mijnstreek periodic surveys and the Dutch-German study on respiratory health and enviroument are presented.

The first survey in the Westelijke Mijnstreek was conducted in 1989, using the "Regio-lijst"-questions on childhood respiratory symptoms (Appendix 1)[55]. The "Regio-lijst" includes validated questions on wheeze, shortness of breath, and cough, for which good reproducibility has been reported [56]. For comparison reasons the Municipal Health Service Westelijke Mijnstreek has continued to use this respiratory symptom questionnaire for their periodical surveys until 2001.

The first survey of the Dutch-German study was conducted in 1995, using respiratory symptom questions derived from the WHO-questionnaire (Appendix 2) [57]. The 1997 survey used the exact same questionnaire as the 1995 survey. During the eighties and early nineties, both the "Regio-lijst" and the WHO- 
questionnaire have been widely used in the Netherlands [58] and, with the exception of chronic cough, were found to yield comparable results for determining prevalence of respiratory symptoms [59].

For participation in the case-control study, children with respiratory symptoms (cases) as well as controls were selected based on the answers given in the 1995 and 1997 surveys. Respiratory symptoms were defined as reported wheezing in the last 12 months and attacks of shortness of breath with wheeze in the last 12 months (asthmatic symptoms), or, reported coughing in the morning or during the day or evening in the autumn and winter and coughing daily for about 3 months a year (coughing), in 1995 or 1997 (Table 1). Control children had negative answers to all questions about respiratory symptoms in the 1995 survey as well as in the 1997 survey. Resulting from their differing pathophysiology, asthmatic symptoms and cough have been suspected to have different risk factor patterns [60].

Table 1. Definitions for respiratory symptoms, diagnosis, and allergic sensitisation as used in the DutchGerman study on respiratory health and environment

Respiratory symptoms

WHO

Asthmatic symploms

WHO

Recent asthmatic symptoms at age $5-6$ years

Recent asthmatic symptoms at age $7-8$ years

Persistent asthmatic symptoms

Coughing

Recent wheeze

Atopic/Allergic sensitisation

Sensitised against house dusi mite

Sensitised against grasses
Reported wheezing in the last 12 months and attacks of shortress of breath with wheeze in the last 12 moniths, or reported coughing in the morning or during the day or ewening in the autumn and winter and coughing daily for about 3 months a year, in 1995 or 1997

Reported wheezing in the last 12 months and attacks of shortness of breath with wheeze in the last 12 months, in 1995 or 1997

WHO Asthmatic symploms (as defined above) present in 1995

WHO Asthmatic symptoms (as defined above) present in 1997

WHO Asthmatic symploms (as defined above) in one surwey and reporlsd wheezing in the last 12 months andior attacks of shortness of breath with wheeze in the last 12 months in the other survey

WHO Reported coughing in the marning or during the day or evening in the autumm and winter and coughing daily for about 3 months a year, in 1995 or 1997

WHOISAAC Asthmatic cases with a positive answer to the ISAAC question "Has your child had wheezing or whistling in the chest in the last 12 months"

At least one specific IgE (Dermatophagoides pteronysisinus; Dermatophagoides farinas, Cladosporium herbarum. Aspergillus fumigatus, Alternaria tenuis, chicken eggl, cow's milk, cat and dog epilthelium, or a mix of grasses) $\geq 0.35 \mathrm{ku}$ at 7-8 years of age

Specific lge against Dermatophagoides pteronyssinus or Dermatophagoides farinae $\geq 0.35 \mathrm{kU} /$ at 7.8 years of age Specific lgE against a mix of grasses $20.35 \mathrm{~kJ} / \mathrm{l}$ at $7-8$ years of age 
As we intended to study risk factors for asthmatic symptoms and cough separately, our definition of respiratory symptoms includes, besides asthmatic symptoms, also coughing. The definition of asthmatic symptoms in our study comprises wheeze, as it is the most common clinical expression of asthma, although not all wheeze may necessarily be asthma-related. Therefore we also included shortness of breath with wheeze in our definition of asthmatic symptoms; for which high sensitivity as well as high specificity in relation to physician-diagnosed asthma had been reported among school-aged children [56]. Table 1 further shows the various subdivisions for asthmatic symptoms that are used in the present thesis.

For cases participating in the Dutch-German case-control study, recent wheeze was defined using an extra criterion; a positive answer to the question "Has your child had wheezing or whistling in the chest in the last 12 months". This question was included in the detailed questionnaire used in the case-control study, which was partly based on the ISAAC-questionnaire (Appendix 3)[61]. Around the time the Dutch-German case-control study was conducted, the first ISAAC-study results became available, and using the ISAAC questionnaire had the advantage that, besides standardised information on diagnosis and treatment, information on severity of wheeze could also be obtained.

Atopy and allergic sensitisation were defined using measurements of specific Immunoglobulin $\mathrm{E}$ ( $\mathrm{IgE}$ ) at age 7-8 years. A child was considered atopic (sensitised) if the level of at least one specific IgE tested was $\geq 0.35 \mathrm{kU} / 1$ (Table 1). In Table 1, definitions for sensitisation against house dust mite and sensitisation against grasses are also presented.

\section{AIMS AND OUTLINE OF THE THESIS}

The study had two main aims: (1) to assess prevalence rates of respiratory symptoms, asthma diagnosis, and treatment in German and Dutch children and (2) to investigate subsequently, risk factors for allergic sensitisation and respiratory symptoms (asthmatic symptoms and cough) in 7-8-year-old German and Dutch children.

For the children from the Westelijke Mijnstreek (the Netherlands) we additionally studied changes in prevalence rates of respiratory symptoms and treatment over a time period of 12 years, based on periodical surveys that were conducted by the Municipal Health Service Westelijke Mijnstreek, to monitor the prevalence of respiratory symptoms in children between 1989 and 2001 . In Chapters $2 a$ and $2 b$ trends in childhood respiratory symptom prevalence and treatment are presented. Chapter 3 compares diagnosis and treatment in German and Dutch children aged 56 years and again two years later at the age of $7-8$ years.

In light of the hygiene hypothesis [17], both vaccination and infections have been implicated in the development of atopic disease. Differences in German and Dutch vaccination programme and vaccination coverage resulted in variation in vaccination and infection rates between the two countries, thus presenting an 
opportunity to study the role of immunisation (Chapter 4) and childhood infections (Chapter 5) in the development of atopic manifestations.

As asthma is a multifactorial disease, and indoor as well as outdoor environmental factors have been suggested to play a role in the aetiology of asthma, in Chapter 6 , we studied the association between indoor environmental risk factors and respiratory symptoms in German and Dutch children. It has become routine to describe asthma as an atopic disease although epidemiological evidence suggests that the population-based proportion of asthma cases attributable to atopy is less than half [62]. Therefore, in Chapter 7 we compare risk factors for asthmatic symptoms in atopic and non-atopic children. In Chapter 8 the results are discussed and recommendations for further research are made.

\section{REFERENCES}

1. Global Initiative for Asthma (GINA). Global strategy for asthna mangigement and prevention. National Institutes of Health. National Heart, Lung, and Blood Institute. NVH Publication No. 02-3659, Revised 2002.

2. Peat JK, van den Berg RH, Green WF, Mellis CM, Leeder SR, Woolcock AJ. Changing prevalence of astluma in Australian children. BMJ 1994;308(6944):1591-6.

3. Anderson HR, Butland BK, Strachan DP. Trends in prevalence and severity of childhood asthma. BMJ 1994;308(6944):1600-4.

4. ISAAC Steering Committee. Worldwide variation in prevalence of symptoms of asthma, allergic rhinoconjunctivitis, and atopic eczema: ISAAC. The linternational Study of Asthma and Allergies in Childhood (ISAAC) Steering Committee. Lancer 1998;351 (9111):1225-32.

5. European Community Respiratory Health Survey. Variations in the prevalenee of respiratory symptoms, self-reported asthma attacks, and use of asthma medication in the European Community Respiratory Health Survey (ECRHS). Eur Respir J 1996;9(4);687-95.

6. von Mutius E, Fritzsch $\mathrm{C}$, Weiland $\mathrm{SK}$, Roll G, Magnussen H. Prevalence of asthma and allergic disorders among children in united Germany: a descriptive comparison. BMJ 1992;305(6866):1395-9.

7. Platts-Mills TA, Ward GW, Jr, Sporik R, Gelber LE, Chapman MD, Heymann PW. Epidemiology of the relationship between exposure to indoor allergens and asthme. W Arch Allergy Appl Imomunol 1991:94(1-4):339-45.

8. Platts-Mills TA, Carter MC. Asthma and indoor exposure to allergens. $N$ Engl J Med $1997 ; 336(19): 1382-4$

9. Custovic A, Simpson A, Chapman MD, Woodcock A. Allergen avoidance in the treatment of astlhma and atopic disorders. Thorax 1998;53(1):63-72.

10. Cloosterman SG, Hofland ID, Lukassen $\mathrm{HG}$, Wieringa MH, Folgering HT, van der Heide $\mathrm{S}$ et al. House dust mite avoidance measures improve peak flow and symptoms in patients with allergy but without asthma: a possible delay in the manifestation of clinical asthma? J Allergy Clin Immuno 1997;100(3):313-9.

11. Cloosterman SG, van Schayck OC. Control of house dust mite in managing asthma. Effectiveness of measures depends on stage of asthma. BMJ 1999;318(7187):870.

12. Murray CS, Woodcock A, Custovic $A$. The role of indoor allergen exposure in the development of sensitization and asthma. Curr Opin Allergy Clin Immunol 2001; (5) 407-12.

13. Simpson A, Custovic A. Allergen avoidance in the primary prevention of asthma. Curr Opin Allergy Clin Inmmol 2004; $4(1): 45-51$.

14. Arshad SH, Bateman B, Matthews SM. Primary prevention of asthma and alopy during childhood by allergen avoidance in infancy: a randomised controlled study. Thorax $2003 ; 58(6): 489-93$. 
15. Illis, von Mutius $\mathbb{E}$, Lat 3 , Nickel $R$, Niggemann $B$, Sommerfeld $C$ et al. The pattem of atopic semsitization is associated with the development of asthma in childhood. I Ahergy Chn Immunol 2001;108(5):709-14.

16. won Mutius E. Enwironmertal factors influencing the development and progression of pediatric asthma. $J$ Aller gy Clin Immumol 2002; 109 (6 Suppl):525-32.

17. Strachan DP. Hay fever, hygiene, and household size. BMJ 1989;299(6710):1259-60.

18. Strachan DP. Fanily size, infection and atopy: the first decade of the "hygiene hypothesis". Thorax 2000,55 Suppl 1:2-10.

19. Kramer U, Heinich J, Wjst M, Wichmann HE Age of entry to day nursery and allergy in later childhood. Lancet $1999 ; 353(9,151): 450-4$.

20. Ball TM, Castro-Rodriguez $\mathrm{J}$, Griffith KA, Holberg CJ Martinez FD, Wright AL. Siblings, day-care attendance, and the risk of asthma and wheezing during childhood. $N$ Engl J Med $2000 ; 343(8): 538-43$.

21. Karmaus $W$, Botezan $C$. Does a higher number of siblings protect against the development of allergy and asthma? A review. J Epidemiol Commwity Heallh 2002;56(3):209-17.

22. Koppellman GH, Jansen DF, Schouten JP, van der Heide S, Bleecker ER, Meyers DA et al. Sibling effect on atopy in children of patients with asthma. Cin Exp Allergy 2003;33(2):170-5.

23. Rasatuen $M$, Laitinen $T$, Kaprio J, Koskenvuo M, Laitinen LA. Hay fever, asthma and number of older siblings--a twin study. Clin Exp Allergy 1997;27(5):515-8.

24. McKeever TM, Lewis SA, Snith C, Collins J, Heatlie $H_{4}$ Frischer $M$ et al. Siblings, multiple births, and the incidence of allergic disease: a birth cohort study using the West Midlands. general practice research database. Thor ax 2001;56(10):758-62.

25. Matricardi PM, Rosmini F, Riondino $S$, Fortini M, Ferrigno L, Rapicetta $M$ et al. Exposure to foodborne and orofecal microbes versus airborne viruses in relation to atopy and allergic asthma: epidemiological study. BMJ 2000;320(7232):412-7.

26. Shaheen SO, Aaby P, Hall AJ, Barker DJ, Heyes CB, Shiell AW et al. Measles and atopy in Guinea-Bissau. Lancet 1996;347(9018):1792-6.

27. Illi $\mathrm{S}$, won Mutius E, Lau S, Bergmann R, Niggemann B, Sommerfeld C et al. Early childhood infectious diseases and the development of asthma up to school age: a birth cohort study. $B M J$ $2001 ; 322(7283): 390-5$.

28. Dell $S$, To T. Breastfeeding and asthma in young children: findings from a population-based study. Arch Pediatr Adolesc Med 2001;155(11):1261-5.

29. Riedler J, Braun-Fahrlander C, Eder W, Schreuer $M$, Waser $M$, Maisch $S$ et al. Exposure to farming in early life and development of asthma and allergy: a cross-sectional survey. Lancet $2001 ; 358(9288): 129-33$.

30. Johnson $\mathrm{CC}$. Alford SH. Do animals on the farm and in the home reduce the risk of pediatric atopy? Cur Opin Allergy Clin Immunol 2002;2(2):133-9.

31. Braun-Fahrlander C. Environmental exposure to endotoxin and other microbial products and the decreased risk of childhood atopy: evaluating developments since April 2002. Curr Opin Allergy Clin Imwnonol 2003;3(5):325-9.

32. Piats-Mills T, Vaughan J, Squillace $S$, Woodfolk J, Sporik R. Sensitisation, asthma, and a modified Th2 response in children exposed to cat allergen: a population-based cross-sectional study. Lancet $2001 ; 357(9258): 752-6$.

33. Remes ST, Castro-Radriguez JA, Holberg Cl, Martinez FD, Wright AL. Dog exposure in infancy decreases the subsequent risk of frequent wheeze but not of atopy. I Allergy Clin lownunol $2001 ; 108(4) ; 509-15$.

34. Celedon JC, Litonjua AA, Ryan L, PlatsuMills T, Weiss ST, Gold DR. Exposure to cat allergen, maternal history of asthma, and wheezing in first 5 years of life. Lancet $2002 ; 360(9335): 781-2$.

35. Ownby DR, Johnson CC, Peterson EL. Exposure to dogs and cats in the first year of life and risk of allergic sensitization at 6 to 7 years of age. JAMA 2002;288(8):963-72.

36. Simpson A, Custovic A. Early pet exposure: friend or foe? Cum Opin Allergy Chin Immunol $20033(1): 7-14$ 
37. Apelberg BJ, Aoki Y, Jaakkola JJ. Systematio review: Exposwe to pets and risk of asthma and asthma like symptoms. J Allergy Chin thmand $2001 ; 107(3): 455-60$.

38. Ini $S$, won Mutius $E$, Lau $S$, Bergmann $R$, Niggemann B, Sommerfeld $C$ et all Early childhood infectious diseases and the development of asthma up to school age: at birth cohort strdy. BMI $2001 ; 322(7283): 390-5$.

39. Renz $\mathrm{H}$, Herz $\mathrm{U}$. The bidirectional capacity of bacterial antigens to modulate allergy and asthmia, Eur Respir J 2002;19(J):158-71.

40. Lewis SA, Britton IR. Measles infection, measles vaccination and the effect of birth order in the aetiology of hay tever. Clin Exp Allergy 1998;28(12):1493-500.

41. Paunio M, Heinonen OP, Virtanen M, Leinikki P, Patja A, Pelitola $H$. Measles bistory and atopic diseases: a population-based cross-sectional study. JAMA 2000;283(3):343-6.

42. Bodner C, Anderson WJ, Reid TS, Godden DJ. Childhood exposture to infection and risk of adult onset wheeze and atopy. Thorax 2000;55(5):383-7.

43. Farooqi IS, Hopkin JM. Early childhood infection and atopic disorder. Thonax $1998 ; 53(11): 927-32$.

44. Sears MR, Greene JM, Willan AR, Taylor DR, Flannery EM, Cowan JO et al. Long-term relation between breastfeeding and development of atopy and asthma in children and young adults: a longitudinal study. Lancet 2002;360(9337):901-7.

45. van Schayck CP, Knottnerus AJ. Can the 'hygiene hypothesis' be explained by confounding by behaviour? I Clin Epidemiol 2004;57(5):435 7 .

46. Romagnani S. Immunologic influences on allergy and the TH1/TH2 balance. I Allergy Chm Immunol 2004; $113(3): 395-400$.

47. Renz $H$, von Mutius E, llli S, Wolkers $\mathbb{F}$, Hirsch $T$, Weiland SK. T(H)1/T(H)2 immune response profiles differ between atopic children in eastern and western Germany. J Allergy Chin Imwmunol $2002 ; 109(2): 338-42$.

48. Sheikh $\mathrm{A}$, Smeeth $\mathrm{L}$, Hubbard $\mathrm{R}$. There is no evidence of an inwerse relationship between TH2mediated atopy and THI-mediated autoimmune disorders: Lack of support for the hygiene hypothesis. J Allergy Clin Immunol 2003:1111(1):131-5.

49. Martinez FD. Toward asthma prevention--does all that really matters happen before we learn to read? $N$ Engl J Med 2003;349(15):1473-5.

50. Ronmark E, Jonsson E, Platts-Mills T, Lundback B. Different paitern of risk factors for atopic and nonatopic asthma among children--report from the Obstructive Lung Disease in Northerm Sweden Study. Allergy 1999;54(9):926-35.

51. Court CS, Cook DG, Strachan DP. Comparative epidemiology of atopic and non-atopic wheeze and diagnosed asthma in a national sample of English adults. Thorax 2002;57(11):951-7.

52. Halonen M, Stern DA, Lolvman C. Wright AL, Brown MA, Martinez FD. Two subphenotypes of childhood asthma that differ in maternal and paternal influences on asthma risk. Am J Respir Crit Care Med 1999;160(2):564-70.

53. Smit JJ, wan Loveren $H$, Hoekstra MO, Karimi $K$, Folkerts $\mathrm{G}_{4}$, Nijkamp FP. The Slcllal (Nrampl) gene controls efficacy of mycobacterial treatment of allergic asthma. I Imwanol 2003:171(2):754-60.

54. von Mutius $\mathbb{E}_{\mathrm{r}}$ Weiland $\mathrm{SK}$, Fritzsch $\mathrm{C}$, Duhme $\mathrm{H}$, Keil $\mathrm{U}$. Increasing prevalence of hay fever and atopy among cliildren in Leipzig, East Germany. Lancet 1998;351(9106):862-6.

55. Werkgroep CARA bij jeugdigen. De Regio's studie deel I en deel II. Adelingem jeugdgezondheidszorg DGD voor Flevoland, DGD Noordoost Friesland, GGD Midden-Holland en Vakgroep Sociale Geneeskunde en Epidemiologie Rijksuniversiteit Groningen, 1988.

56. Verkerk $\mathrm{PH}$, Rijcken $\mathrm{B}$. Evaluatie van een vragenlijst naar respiratoire symptomen en do maatschappelijke gevolgen hiervan in een open populatie. TSoc Gezondheidsz 1988;66:102-5.

57. Florey C du V, Leeder SR. Methods for colhort studies of chronic ainflow limitation. WHO Regional Publications European Series No. 12. London, United Kingdom. 1982.

58. van der Wal MF, Uitenbroek DG, Verhoeff AP. Toegenomen percentage basisschoolkinderen met astmatische klachten in Nederland, 1984/85-1994-95; een literatuuronderzoek. Ned Tijdschr Geneeskd 2000; $144(37) ; 1780-5$. 
$18 \mid$ Chapter 1

59. Steenbekkers $\mathrm{A}$, de Boer A, Brunekreef B, Hoek $\mathrm{G}$, Rjjcken B, Groot B. Een vergelijking van twee vragenlijgten naar luchtwegsymptomen bij kinderen. 1. Vergelijking van prewalenties. Tijdschr Soc Gezondheidszorg 1990;68:478-82.

60. Wright $\mathrm{AL}$, Holberg $\mathrm{CJ}$, Morgan WI, Taussig LM, Hallonen M, Martinez FD. Recurrent cough in childiood and its telation to asthma. Am f Respir Crit Core Med 1996;153(4 Pa 1):1259-65.

61. Asher MI, Keil U, Anderson HR, Beasley R, Crane J, Martinez F et al. International Study of Asthma and Allergies in Childhood (ISAAC): rationale and methods. Eur Respir $J$ 1995;8(3):483-91.

62. Pearce $\mathrm{N}$, Pekkanen $\mathrm{J}$, Beasley $\mathrm{R}$. How much asthma is really attributable to atopy? Thorax $1999 ; 54(3): 268-72$. 


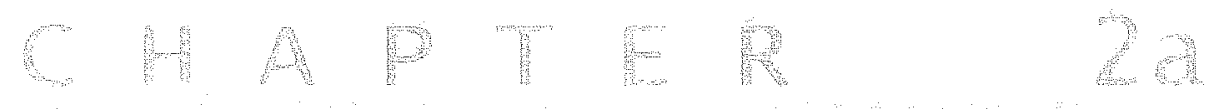

Changing prevalence of respiratory symptoms and treatment in Dutch school children: 1989-1997

\author{
M MOMMERS ${ }^{12}$ \\ RMH DERKX \\ GMH SWAEN \\ CP VAN SCHAYCK'
}

\footnotetext{
'DEPARTMENT OF GENERAL PRACTICE: CAPHARI, MAASTRICHT UNVERSITH, THE NETHERLANDS "MUNICIPAL HEALTH SEFVICE WIETELIJHE MIJNSTREEK, GELEEM, THE NETHERLANDS

DEPARTMENT OF EPIDEMIOLOGY, CAPHRI, MAASTPICHT UNIMERSITY, THE NETHERLANDS
} 


\section{A B STRACT}

AIM: To investigate whether the prevalence of respiratory symptoms, physician visits, medication use and school absence in Dutch children changed between 1989 and 1997, and whether respiratory symptoms are related to changed exposure to tobacco smoke and pets.

METHODS: Parents of children eligible for a routine physical examination in 1989, 1993 or 1997, were asked to complete a questionnaire about respiratory symptoms for their child.

RESULTS: Response rates were almost $100 \%$, in 1989 parents of 3176 children, in 1993 of 3491 children, and in 1997 of 4776 children participated. Between 1989 and 1997 the prevalence of shortness of breath increased from $7.4 \%$ to $9.3 \%$ $(p=0.056)$ in 5-6-year-olds, whereas the prevalence of wheezing decreased (from $22.1 \%$ to $18.3 \%, p=0.002$ ). The same trend was seen in $8-9$-year-old children. The proportion of asthmatic children consulting their physician or using medication increased (from $55.9 \%$ to $63.3 \%$ and from $38.7 \%$ to $47.4 \%$, respectively), whereas cigarette smoking (from $60.8 \%$ to $48.5 \%$ ) and pet ownership (from $55.1 \%$ to 47.0\%) decreased.

CONCLUSION: Our findings support other reponts of an increasing prevalence of asthma and treatment. However, this could not be explained by increased exposure to cigarette smoke or pets. 


\section{INTRODUCTION}

Respiratory symptoms are a major health burden; for Dutch school children it was reported that of the children with asthmatic complaints $38 \%$ were using medication and $22 \%$ had missed school for at least a week in the past year [1].

Large geographic differences in asthma symptom prevalence have been reported, with the highest prevallence rates in Anglo-Saxon countries [2,3]. Also, shortly after the reunification of East and West Germany, a higher prevalence of atopic sensibilisation, asthma and hay fever was found in former West German children compared to East German children [4]. Regional differences in asthma symptom prevalence have also been reported for the Netherlands [5]. As in other countries [68], a rising asthma symptom prevalence has also been observed in the Netherlands in recent years $[5,9]$. The causes of these geographical and temporal differences remain largely unexplained.

The aim of the present study was to investigate whether the prevalence of respiratory symptoms, physician visits, medication use and school absenteeism due to respiratory complaints, in Dutch school children, changed between 1989 and 1997. In addition, we studied whether respiratory symptoms were associated with changed exposure to tobacco smoke and pets, in order to explain underlying mechanisms of possible changes in asthma prevalence.

\section{METHODS}

\section{Study area and population}

The Westelijke Mijnstreek is located in the southern part of the Netherlands (Limburg) and has approximately 170,000 inhabitants.

The survey was performed among children that were eligible for their routine physical examination by the Youth Health Care Section of the Municipal Health Service in 1989, 1993 or 1997. Figure 1 shows that children were invited according to year of birth. For example, from October 1988 through March 1989 all 546-yearolds, born in 1983 were invited, followed by 8-9-year-olds born in 1980 (invited between April 1989 and September 1989). Consequently, this approach ensured enrolment of all 8-9-year-olds born in 1980 and 5-6-year-olds born in two consecutive years (i.e., 1983 and 1984) in the survey of 1989. In 1997 we extended the recruitment through March 1998 to include all 5-6-year-olds born in 1992 in the study (the study year 1997-1998 will further be denoted as 1997).

\section{Questionnaive}

In 1989,1993 and $\llbracket 997$ the same validated questionnaire was used $[10,11]$. This questionnaire has been used widely in the Netherlands and included questions on respiratory symptoms, which were derived from internationally used standard children's questionnaires. Questions were asked about chronic cough (coughing 5 days a week for more than 3 months), coughing with phlegm (coughing with phlegm for more than 3 weeks a year), wheezing, shortness of breath, and shortness 
of breath with wheezing. Additional questions were asked about physician visits, medication use, school absenteeism, and indoor environment.
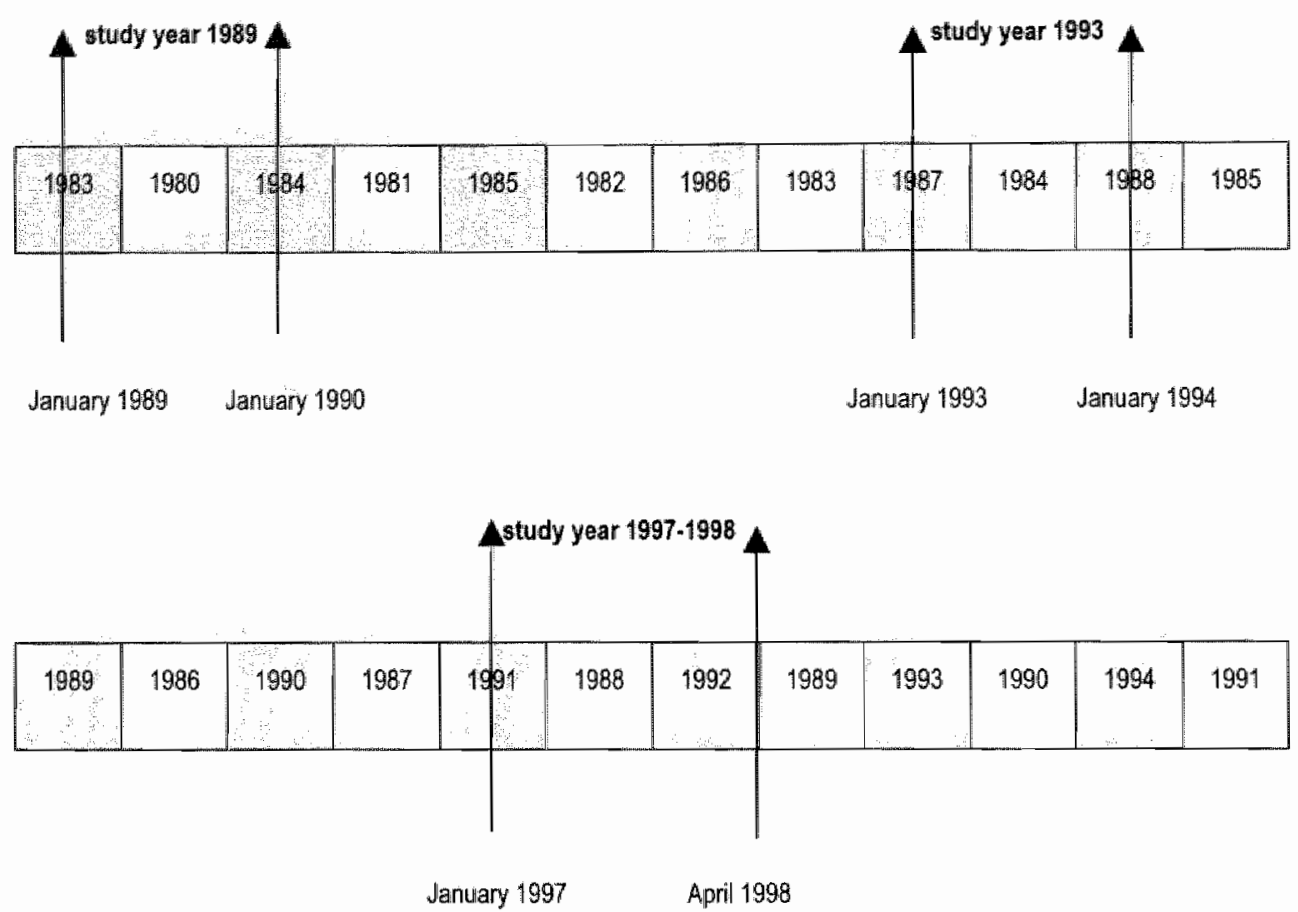

Fig. 1. Outline of the study. Grey and white areas represent the time periods in which 5-6-year-olds (grey areas: October through March) and 8-9-year-olds (while areas; April through September) respectively, were invited for a rouline physical examination. The year mentioned in the grey and white areas represents the year of birth of the children.

\section{Data analysis}

For each of the respiratory symptoms, the prevalence was calculated by dividing the number of positive responses to each question by the total number of responses to that question. To restrict the number of questions, respiratory symptoms were subdivided into asthmatic symptoms (one or more positive answers to the questions about recent wheezing, shortness of breath and shortness of breath with wheezing) and coughing (a positive answer to one or both questions about coughing). Questions on wheezing and shortness of breath were previously found to be more discriminative, when using the history by a doctor as an independent criterion, than were questions asking about coughing [11].

Data are presented by age group and study year. Mantel-Haenszel's Chi-square test for linear association was used to test differences in prevalence rates between the three study years for linear association. 


\section{RESULTS}

By combining the survey with the physical examination routinely performed on school children, high response rates were attained. In 1989 the questionnaire was completed for $3176(97.3 \%)$ children, in 1993 for $3491(97.5 \%)$ children, and in 1997 for 4776 children. Due to a technical problem the list of children invited in 1997 could not be completely retrieved. Therefore, the response rate could only be calculated for 2032 of the invited children; for $97.7 \%$ of these children the questionnaire was completed. The boys to girls ratio was similar for the three study years (Table 1). In 1989 the proportion of 5-6-year-olds was somewhat lower within the 4-7 age group as was the proportion 8-9-year-olds within the 8-12 age group, compared to 1993 and 1997.

Wheezing was the most frequently reported complaint in both age groups, followed by shortness of breath and shortness of breath with wheezing (Table 2). Chronic cough was the least prevalent respiratory symptom.

In all three years of observation the prevalence of respiratory symptoms was generally higher at the age of 5-6 years than at the age of 8-9 years. In both age groups, the prevalence of recent shortness of breath and recent shortness of breath with wheezing increased during the study period. Also, the prevalence of chronic cough showed a small, statistically nonsignificant increase. At the same time the prevalence of recent wheezing decreased; which reached statistical significance in the younger age group.

The frequency of school absence decreased during the study period, although in 8 9-year-old children the decline was not seen until 1993. The prevalence of school absence due to respiratory symptoms was virtually the same in 1989 and 1997, but was higher in 1993.

Ta ble 1. Sex and age distribution of the participating children in 1989,1993 and 1997

\begin{tabular}{|c|c|c|c|c|c|}
\hline \multicolumn{2}{|c|}{1989} & \multicolumn{2}{|c|}{1993} & \multicolumn{2}{|c|}{$1997^{*}$} \\
\hline ו" & $\%$ & $n$ & $\%$ & $n$ & $\%$ \\
\hline
\end{tabular}

4-7-year-old children:

$\begin{array}{lcccccc}4 \mathrm{yr} & 146 & 10.6 & 127 & 6.6 & 33 & 1.1 \\ 5-6 \mathrm{yr} & 1229 & 88.9 & 1790 & 93.0 & 2860 & 98.8 \\ 7 \mathrm{yr} & 7 & 0.5 & 8 & 0.4 & 1 & 0.03\end{array}$

8-12-year-old children:

$\begin{array}{ccccccc}8.9 \mathrm{yr} & 1576 & 87.8 & 1488 & 99.6 & 1607 & 99.8 \\ >9 \mathrm{yr} & 218 & 12.2 & 6 & 0.4 & 3 & 0.2\end{array}$

Sex:

$\begin{array}{lllllll}\text { Male } & 1610 & 50.7 & 1809 & 51.8 & 2447 & 51.3 \\ \text { Female } & 1566 & 49.3 & 168.2 & 48.2 & 2326 & 48.7\end{array}$


The proportion of children consulting their physician or using medication for respiratory complaints remained unchanged between 1989 and 1997.

In children who coughed, as well as in asthmatic children, the prevalence of physicians visits and medication use increased from 1989 to 1997 (Fig. 2).

During the same time period, the prevalence of pet keeping and smoking indoors decreased. The same trend was seen for asymptomatic children. In asymptomatic children exposure to cigarette smoke in the home decreased from $57.2 \%$ in 1989 to $43.9 \%$ in 1997. Pet ownership decreased from $56.0 \%$ in 1993 to $49.6 \%$ in 1997.

Table 2. Prevalence of respiratory symptoms, physicians visits and school absence in the past 12 months and medication use in the past month by age group and year of study

\begin{tabular}{|c|c|c|c|c|}
\hline & \multicolumn{4}{|c|}{ 5-6-year-olds } \\
\hline & 1989 & 1993 & $1997^{*}$ & p-walue ${ }^{* *}$ \\
\hline Wheezing & $305(22.1)$ & $402(20.6)$ & $559(18.3)$ & 0.002 \\
\hline Shoriness of breath with wheezing & $102(7.4)$ & $159(8.1)$ & $281(9.1)$ & 0.044 \\
\hline Shorthess of breath & $102(7.4)$ & $477(9.1)$ & $283(9.3)$ & 0,056 \\
\hline Coughing with phlegm & $109(7.9)$ & $142(7.3)$ & $221(7.3)$ & 0.532 \\
\hline Chronic cough & $55(4.0)$ & $88(4.5)$ & $137(4.5)$ & 0.502 \\
\hline \multicolumn{5}{|l|}{ General: } \\
\hline Physician visits & $1049(75.9)$ & $1531(78.8)$ & $2300(75.3)$ & 0.279 \\
\hline Medication use & $415(30.0)$ & $662(34.2)$ & $891(29.1)$ & 0.152 \\
\hline School absence: & $547(39.6)$ & $685(35.0)$ & $868(28.3)$ & 0.000 \\
\hline \multicolumn{5}{|l|}{ For respiratory complaints: } \\
\hline Physician visits & $314(22.7)$ & $459(23.6)$ & $664(21.8)$ & 0.340 \\
\hline Medication use & $193(14.0)$ & $288(14.9)$ & $453(14.8)$ & 0.555 \\
\hline School absance & $119(8.5)$ & $262(13.4)$ & $293(9.5)$ & 0.902 \\
\hline
\end{tabular}

Data are presented as number of positive responses with percentages between parentheses

* Study years 1997-1998

* Mantel-Haenszel's Chi-square test for linear association

\section{DISCUSSION}

The results of the present study are consistent with other reports of a rising trend in asthma prevalence in the Netherlands and other countries worldwide $[5-8,12,13]$. The increase in recent wheezing and the large increase in the prevalence of chronic cough previously described in Dutch children [5], could not be confirmed by our results. In the present study the prevalence of recent wheeze decreased in 5-6-yearolds from $22.1 \%$ in 1989 to $18.3 \%$ in 1997 , whereas the prevalence of chronic cough increased only slightly. 
The exact causes of the increasing asthma prevalence remain largely unexplained. When trying to explain this time trend, different factors should be considered, such as changes in indoor and outdoor environmental factors, diagnostics and the possibility of an artefactual finding. Considering the spatial pattern of asthma prevalence, outdoor air pollution is probably not a major factor [2]; for regions with a high level of air pollution the lowest rates of asthma prevalence were reported, whereas some regions with the lowest degrees of air pollution had high asthma prevalences [2].

Table 2 continued

8-9-year-olds

\begin{tabular}{|c|c|c|c|}
\hline 1989 & 1993 & $1997^{*}$ & p-value ${ }^{* *}$ \\
\hline $240(13.4)$ & $203(13.3)$ & $198(1+.9)$ & 0.216 \\
\hline $103(5.7)$ & $113(7.4)$ & $131(7.9)$ & 0.0113 \\
\hline $196(6.5)$ & $121(7.9)$ & $138(8.3)$ & 0.037 \\
\hline $70(3.9)$ & $67(4.4)$ & $62(3.8)$ & 0.852 \\
\hline $37(2.1)$ & $31(2.0)$ & $45(2.7)$ & 0.198 \\
\hline $1043(58.1)$ & $983(64.6)$ & $937(57.4)$ & 0.771 \\
\hline $351(19.6)$ & $368(24.4)$ & $318(19.3)$ & 0.912 \\
\hline $398(22.2)$ & $369(24.2)$ & $230(13.9)$ & 0.000 \\
\hline $226(12.6)$ & $219(A 4.4)$ & $497(11.9)$ & 0.594 \\
\hline $169(9.4)$ & $169(11.2)$ & $474(10.5)$ & 0.268 \\
\hline $86(4.8)$ & $120(7.9)$ & $64(3.9)$ & 0.288 \\
\hline
\end{tabular}

The Westelijke Mijnstreek has an airport, a large chemical industry, and heavy traffic, which could have had some influence on the prevalence rates in the present study.

The association between indoor risk factors such as environmental tobacco smoke, pet ownership and presence of dampness or moulds and respiratory symptoms has been established in several studies [14-16]. However, the increased prevalence of wheezing found in an English study could not be explained by change in indoor factors [17]. Exposure to environmental tobacco smoke or pet allergens was also unlikely to explain the increased prevalence of respiratory symptoms found in the present study. Because the same trend in smoking behaviour and pet ownership was 
also seen in asymptomatic children, information bias is unlikely to explain this finding.

Increased frequency of asthma diagnoses has been reported $[5,13]$. Correspondingly, in the present study physician visits and medication use increased in symptomatic children. Better diagnostics of asthmatic children probably only partly explain the increase in asthma prevalence [7]. Better treatment may however reduce asthma morbidity. In the present study no questions on severity of asthma symptoms were included.

Another possible explanation may lie in an increased recognition and tendency to report symptoms as a consequence of rising publicity and professional concern in recent years [12]. The decreasing prevalence of wheezing and at the same time increasing prevalence of shortness of breath, might be explained in terms of labelling differences between the study years. This is however unlikely, since the proportion of wheezy children additionally reporting shortness of breath, also increased from 1989 to 1997.
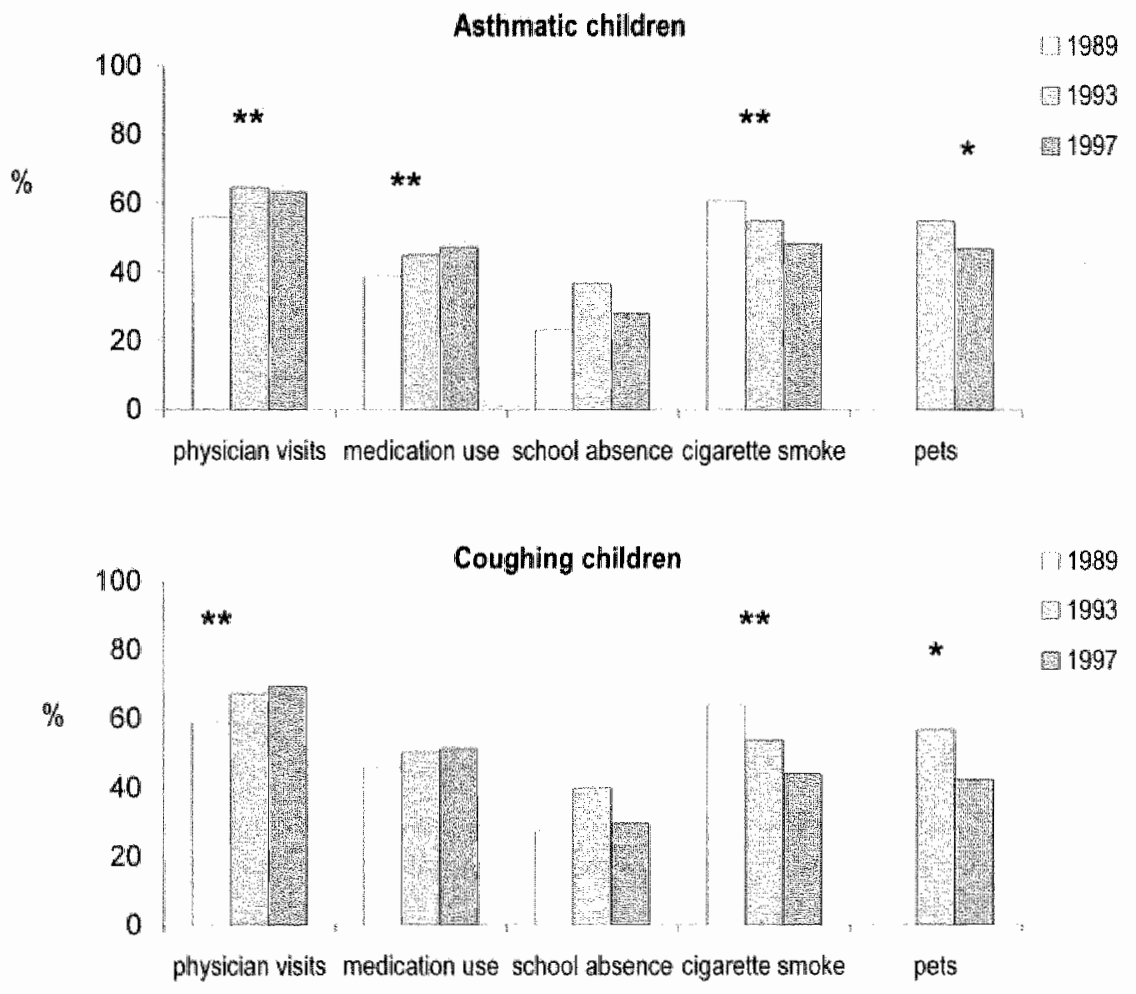

Fig. 2. Prevalence of physicians visits and school absence in the past year, medication use in the past month, smoking and pet keeping indoors in children with asthmatic symptoms and in children with coughing

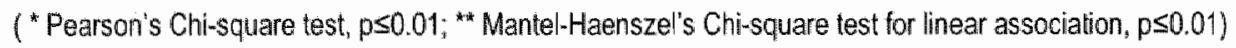


Therefore, the increase in shortness of breath with wheezing can probably be explained in terms of an increased prevalence of shortness of breath. Furthermore, considering the increased frequency of medication use it is likely that the severity of illness has increased.

In the present study no objective measures were included to ascertain whether the observed trend was a true one. The results from the few studies that have used more clinical diagnostic methods support a true increase in asthma prevalence $[13,18]$, as was also concluded for the increasing asthma prevalence in the Netherlands [9].

Because the survey was performed in the same standardised way in all three study years the results are highly comparable between the study years. In view of the high response rates, selective non-response is not likely. In Table 2 we presented 22 tests of significance, with seven reaching statistical significance. We should however be aware that in view of the $95 \%$ confidence limits we assumed when performing the tests, we accepted the probability that five out of 100 confidence intervals miss their true value. Therefore when performing 22 tests, one is expected to be a false positive result (Type I error).

In conclusion, our findings are in line with earlier reports of a rising trend in asthna prevalence and treatment. These changes however, cannot be explained in terms of changed exposure to cigarette smoke or pets. We were unable to determine whether increased treatment resulted in lesser morbidity in symptomatic children.

The Municipal Health Service Westelijke Mijnstreek will continue to monitor the prevalence of respiratory symptoms in their region, and in the fourth survey (in $2001)$ the questionnaire was extended with items on severity of symptoms.

\section{ACKNOWLEDGEMENTS}

The authors wish to thank the members of the Youth Health Care Section of the Municipal Health Service Westelijke Mijnstreek for their cooperation in the study and Cindy Gielkens for reading the manuscript.

\section{REFERENCES}

1. Spee-van der Wekke J, Meulmeester JF, Radder JJ, Verloove-Vanhorick SP. School absence and treatment in school children with respiratory symptoms in the Netherlands: data from the Child Health Monitoring System. J Epidemiol Commutrity Heahh 1998;52(6):359-63.

2. ISAAC Steering Committee. Worldwide variation in prevalence of symptoms of asthma, allergic rhinoconjunctivitis, and atopic eczema: ISAAC. Lancet $1998 ; 351(9111): 1225-32$.

3. European Community Respiratory Health Survey. Variations in the prevalence of respiratory symptoms, self-reported asthma attacks, and use of asthma medication in the European Community Respiratory Health Survey (ECRHS). Eur Respoir d 1996;9(4):687-95.

4. von Mutus E, Martinez FD, Fritzsch C. Nicolai T, Roell G, Thiemann HH. Prevallence of asthma and atopy in two areas of West and East Germany. Am $J$ Respir Crit Care Med $1994 ; 149(2 \mathrm{Pt} 1): 358-64$. 
5. Wan der Wal MF, Uitenbroek DG, Verhoeff AP. Toegenonwen percentage basisschoolkinderen met astmatische klachten in Nederland, 1984/"85-1994/"95; een literatuuronderzoek. Ned Tijdsch Geneeskd 2000;144(37):1780-5.

6. Wetss KB, Gergen PJ, Wagener DK. Breathing better or wheezing worse? The changing epideniology of asthma morbidity and mortality. Annw Rev Publ Health 1993;14:491-513.

7. Nystad W, Magnus P., Gulsvik A, Skarpaas U, Carlsen KH. Changing prevalence of asthma in school children: evidence for diagnostic changes in asthma in two surveys 13 yrs apart. Eur Respir J 1997:10(5):1046-51.

8. Omrail M, Russell $G$. Continuing increase in respiratory symptoms and atopy in Aberdeen schoolchildren. BMJ 1996;312(7022):34.

9. Tirmaina $\mathrm{PR}$, wan Schayck $\mathrm{CP}$, den Otter JJ, van Weel $\mathrm{C}$, van Herwaarden $\mathrm{CL}$, van den Boom $O$ et at. Prevalence of asthma and COPD in general practice in 1992: Has it changed since 1977? Br.J Gen Praci 1996; 46(406):277m81.

10. Werkgroep CARA bij jeugdigen. De Regio's studie deel II en deel II. Afdelingen jeugdgezondheidszorg DGD voor lilevoland, DGD Noordoost Friesland, GGD Midden Holland en Vakgroep Sociale Geneeskunde en Epidemiologie Rijksuniversiteit Groningen, 1988.

11. Verkerk $\mathrm{PH}, \mathrm{Rijcken} \mathrm{B}$. Evaluatie van een vragenlijst naar respiratoire symptomen en de maatschappelijke gevolgen hiervan in een open populatie. T Soc Gezondheidsz 1988;66:102-5.

12. Amderson HR, Butland BK, Strachan DP. Trends in prevalence and severity of childhood asthma, $B M J 1994 ; 308(6944): 1600-4$.

13. Downs SH, Marks GB, Sporik R, Belosouva EG, Car NG, Peat JK. Continued increase in the prevalence of asthma and atopy. Arch Dis Child 2001;84(1):20-3.

14. Cook DG, Strachan DP. Health effects of passive smoking. 3. Parental smoking and prevalence of respiratory symptoms and asthma in school age children. Thorax 1997;52(12):1081-94.

15. Burr ML, Anderson HR, Austin JB, Harkins LS, Kaur B, Strachan DP et al. Respiratory symptoms and home environment in children: a national survey. Thor $0 x$ 1999;54(1):27-32.

16. Dijkstra L, Houthuijs D, Brunekreef B, Akkerman I, Boleij JS. Respiratory health effects of the indoor environment in a population of Dutch children. Am Rev Respir Dis 1990;142(5):1172-8.

17. Butland BK, Strachan DP, Anderson HR. The home environment and asthma symptoms in childhood: two population based case-control studies 13 years apart. Thorax 1997;52(7):61824.

18. Peat JK, van den Berg RH, Green WF, Mellis CM, Leeder SR, Woolcock AJ. Changing prevallence of asthma in Australian children. BMJ 1994;308(6944): 1591-6. 


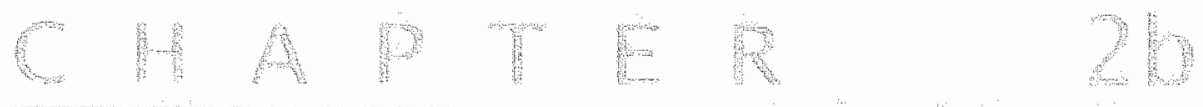

Trends in prevalence of respiratory symptoms and treatment in Dutch children over a 12 year period: results of the fourth consecutive survey

\author{
MOMMERS \\ C GIELKENS-SIJSTERMANS ${ }^{2}$ \\ GMH SWAEN ${ }^{3}$ \\ CP VAN SCHAYCK'
}

\footnotetext{
"DEPARTMENT OF GENEFAL PRACTICE, CAPHH, MAASTAICHT UNIVERSITY, THE NETHERLAMDS "MUNicipal MEALTH SERVICE WESTELHKE MIJNSTREEK, GELEEN, THE NETHERLANDS

"DEPARTMENT OF EFIDEMIOLOGY, CAFHIRI, MAASTRICHT UNIVERSITY, THE NETHERLANDS
} 


\section{A BSTRACT}

BACKGROUND: Although there is considerable evidence that the prevalence of childhood asthma has increased over the last decades, it is not clear if this trend is still ongoing. A study was undertaken to investigate whether previousiy observed trends in the prevalence of respiratory symptoms, physician visits, medication use and school absence for 8-9-year-old Dutch school children persisted in 2001.

METHODS: Parents of 1154 8-9-year-old children eligible for a routine physical examination in 2001 , were asked to complete a questionnaire on the respiratory health of their child.

RESULTS: In 2001, 1102 children (95.5\%) participated in the survey. Similarly high response rates were obtained in the surveys of 1989,1993 and 1997 , with 1794 , 1526 and 1670 8-9-year-old children participating in the respective surveys.

The decreasing trend previously observed for recent wheeze between 1989 and 1997 persisted into 2001, particularly in boys. After increasing between 1989 and 1997, the prevalence of shortness of breath with wheeze decreased between 1997 and $200 \%$. The proportion of wheezy children using medication increased between 1989 and 2001 in boys $(42.9 \% \vee 64.8 \% ; \mathrm{p}=0.003)$, but the increase was not statistically significant in girls $(34.0 \% v 45.7 \% ; \mathrm{p}=0.096)$.

CONCLUSION: The prevalence of recent wheeze in Dutch school children has declined steadily since 1989. The rising prevalence of medication use in symptomatic children over time may reflect better asthma control, and, therefore, may partly explain the concurrently decreasing trend in prevalence of asthma symptoms in our study population. 


\section{INTRODUCTION}

Although there is considerable evidence that the prevalence of childhood asthma has increased over the last decades [1], it is not clear whether or not this increase is still ongoing. In the US the number of annual physician visits related to asthma has remained stable since 1991 [2] and in the UK, new episodes of asthma reported to the general practitioner were found to have declined since 1993 [3]. Very recently a Swiss study and an Australian study have reported no further increase in the prevalence of asthma in children $[4,5]$.

Since 1989 the Municipal Health Service of the "Westelijke Mijnstreek" (in the south-east of the Netherlands) has monitored the prevalence of respiratory symptoms in their region every 4 years, using the same validated screening instrument in each survey. By combining the survey with the physical examination routinely performed on school children, each survey reached response rates of over $95 \%$. We have previously reported that, for children living in this area, the prevalence of recent wheeze decreased between 1989 and 1997 ; at the same time the prevalence of recent shortness of breath increased [6].

In 2001 the fourth consecutive survey was conducted, again among 8-9-year-old children. The aim of the present study was to investigate whether the previously observed trends in prevalence of respiratory symptoms, physician visits, medication use, and school absence in Dutch school children persisted in 2001.

\section{METHODS}

In 2001 the fourth consecutive survey was conducted among 8-9-year-old children in the "Westelijke Mijnstreek" located in the south-eastern part of the Netherlands. Identical surveys were conducted in 1989, 1993 and 1997, with 1794, 1526 and 1670 8-9-year-old children participating in the respective surveys. Detailed descriptions of these previous surveys have been reported elsewhere [6].

In brief, in 2001 the parents of all 1154 8-9-year-old children eligible for a routine physical examination by the Youth Health Care Section of the Municipal Health Service were asked to complete a questionnaire on respiratory health for their child. In all four surveys identical questions were used. Respiratory symptoms were defined using validated questions on chronic cough (coughing 5 days a week for more than 3 months), coughing with phlegm (coughing with phlegm for more than 3 weeks in the past 12 months), wheeze (wheezing in the past 12 months), shortness of breath (shortness of breath in the past 12 months when playing or climbing the stairs), and shortness of breath with wheeze (attacks of shortness of breath with wheeze in the past 12 months). Additional questions were asked about physician visits (general practitioner) and school absence (for I week or more) in the past year, and medication use (prescribed by general practitioner or specialist) in the past month. 
Pearson"s Chi-square test was used to test the statistical significance of differences between two study years (that is, 1997 and 2001), Mantel-Haenszel's Chi-square test for linear association was used to investigate trends in prevalence rates over the study period. To test whether the time trend for respiratory symptoms, physician visits, medication use or school absence was modified by the sex of the child, logistic regression models including the interaction term (sex*study year) were used.

A p-value of $<0.05$ was considered statistically significant.

Table 1. Respiratory symptorns, physician visits, medication use, and school absence in 8-9-year-old children, by sex and year of study

\begin{tabular}{ccccc} 
All & & \\
\hline 1989 & 1993 & 1997 & 2001 & $\begin{array}{c}\text { p- } \\
\text { value* }^{*}\end{array}$ \\
\hline
\end{tabular}

All children

Wheezing (past year)

Shorthess of breath (past year)

$n=1794 \quad n=1526 \quad n=1670 \quad n=1102$

Shorthess of breath with wheeze (past year)

$240(13.4)$

$203(13.3)$

$198(11.9)$

$100(9.1)$

0.001

$116(6.5)$

$121(7.9)$

$138(8.3)$

$87(7.9)$

0.077

Coughing with phlegm (past year)

$103(5.7)$

$113(7.4)$

$131(7.9)$

$60(5.5)$

0.641

Chronic cough

$70(3.9)$

$67(4.4)$

$62(3.8)$

$33(3.0)$

0.210

Any respiratory symptom*t

$37(2.1)$

$31(2.0)$

$45(2.7)$

$21(1.9)$

0.696

$313(17.4)$

260 (17.1)

$259(161)$

$146(13.5)$

0.007

Cliildran with racent wheeze

Physician visits (past year)t

Medication use (past month).t

School absence (past year)ף

$\begin{array}{ccccc}n=240 & n=203 & n=198 & n=100 & \\ 136(56.7) & 132(65.0) & 120(61.9) & 50(50.0) & 0.589 \\ 94(39.2) & 110(54.7) & 107(54.3) & 56(56.0) & 0.001 \\ 57(23.8) & 75(37.3) & 42(21.6) & 11(11.1) & 0.011\end{array}$

Data are presented as number of positive responses with percentages between parentheses

For the study year 1997, information on sex was not available for one child

Due ta missing observations, numbers do not always add up to total

* Mantel Haenszel's Chi-squuare lest for trend

*Any one or more of the respiratory symptoms (wheezing, shortness of breath, shortness of breath with wheezing,

coughing with phlegm, chronic cough) reported

+ General practitioner

\$ Prescribed by general practitioner or specialist

If School absence for 1 week or more (at least once) in the past year 


\section{RESULTS}

In 2001 the response rate was $95.5 \%(1102 / 1154)$; response rates for the three previous surveys were also over $95 \%$ [6]. Of the 1102 children participating in $2001,51.2 \%$ were male and $99.1 \%$ were born in 1992; the sex and age distributions were similar to the distributions reported for the previous surveys [6].

The results from the 2001 survey showed a continued decrease of recent wheeze in 8-9-year-old Dutch children; from $13.4 \%$ in 1989 to $9.1 \%$ in $2001(\mathrm{p}=0.001)$. This decrease was seen in both boys and girls, but only reached statistical significance in boys (Table 1).

Table 1 continued

\begin{tabular}{|c|c|c|c|c|c|c|c|c|c|}
\hline \multicolumn{5}{|c|}{ Boys } & \multicolumn{5}{|c|}{ Girls } \\
\hline 1989 & 1993 & 1997 & 2001 & $\begin{array}{c}\text { pp- } \\
\text { value" }\end{array}$ & 1989 & 1993 & 1997 & 2001 & $\begin{array}{c}p- \\
\text { value }\end{array}$ \\
\hline
\end{tabular}

$\begin{array}{cccccccccc}n=895 & n=777 & n=851 & n=564 & & n=899 & n=749 & n=818 & n=538 & \\ 140(15.6) & 114(14.7) & 111(13.1) & 54(9.6) & 0.001 & 100(11.1) & 89(11.9) & 87(10.7) & 46(8.6) & 0.144 \\ 73(8.2) & 63(8.1) & 77(9.1) & 53(9.4) & 0.304 & 43(4.8) & 58(7.8) & 61(7.5) & 34(6.4) & 0.139 \\ 64(7.2) & 59(7.6) & 75(8.9) & 34(6.0) & 0.898 & 39(4.3) & 54(7.2) & 56(6.9) & 26(4.9) & 0.413 \\ 45(5.0) & 33(4.3) & 33(3.9) & 19(3.4) & 0.117 & 25(2.8) & 34(4.5) & 29(3.6) & 14(2.6) & 0.886 \\ 21(2.3) & 15(1.9) & 25(3.0) & 12(2.2) & 0.759 & 16(1.8) & 16(2.11) & 20(2.5) & 9(1.7) & 0.815 \\ 177(19.8) & 139(18.0) & 14(117.3) & 83(15.0) & 0.022 & 136(15.1) & 121(16.2) & 118(14.9) & 63(11.9) & 0.119\end{array}$

$\begin{array}{cccccccccc}n=140 & n=114 & n=111 & n=54 & & n=100 & n=89 & n=87 & n=46 & \\ 84(60.0) & 74(64.9) & 72(66.7) & 30(55.6) & 0.961 & 52(52.0) & 58(65.2) & 48(55.8) & 20(43.5) & 0.437 \\ 60(42.9) & 61(54.0) & 63(57.3) & 35(64.8) & 0.003 & 34(34.0) & 49(55.7) & 44(50.6) & 21(45.7) & 0.096 \\ 35(25.0) & 36(31.9) & 25(23.1) & 2(3.7) & 0.008 & 22(22.0) & 39(44.3) & 17(19.8) & 9(20.0) & 0.353\end{array}$

The effect of study year on the prevalence of wheeze did not differ significantly by $\operatorname{sex}\left(p_{\text {sex }}\right.$ study year $\left.=0.270\right)$.

The increase in prevalence of recent shortness of breath and recent shortness of breath with wheeze between 1989 and 1997 [6], was not continued in 2001; for shortness of breath the increase levelled off $(8.3 \%$ in 1997 and $7.9 \%$ in 2001 ; $p=0.708$ ), while shortness of breath with wheeze decreased from $7.9 \%$ in 1997 to 
$5.5 \%$ in 2001 ( $\mathrm{p}=0.014)$. Table 1 shows that the prevalence of any one or more respiratory symptoms also decreased between 1989 and 2001, which was statistically significant for boys.

For children with recent wheeze the prevalence of physician visits did not show a significant trend between 1989 and 2001 (Table 1). School absence in boys was higher in 1997 than in $2001(23.1 \% \vee 3.7 \% ; \mathrm{p}=0.002)$. The prevalence of school absence in girls remained stable during the study period, with the exception of a high prevalence of school absence in 1993. The proportion of wheezy children using medication steadily increased between 1989 and 2001, especially for boys (Table 1). The effect of study year on medication use did not differ statistically

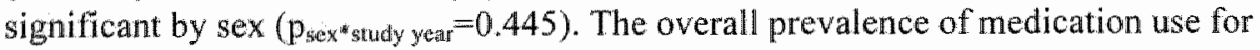
respiratory symptoms remained unchanged between $1989(9.4 \%)$ and $2001(9.2 \%)$.

\section{Discussion}

Our findings suggest that the decrease in recent wheeze, previously reported for school children living in the south-east of the Netherlands [6], persisted in 2001. Others observed an increasing prevalence of wheeze in preschool children until the late nineties [7], but very recently the first signs indicating that the rising trend in asthma prevalence might have come to an end have been observed, at least for Australian and Swiss children $[4,5]$. In the present study, the declining prevalence of recent wheeze was paralleled by increased medication use in wheezy boys, while the prevalence of physician visits remained relatively stable over this study period. Also, there was little change in the overall prevalence of medication use for respiratory symptoms (9.4\% in 1989 and $9.2 \%$ in 2001$)$. However, it is likely that medication use in wheezy children has increased proportionally, but the number of wheezy children needing medication has remained unchanged or has decreased.

Potential explanations for the decreasing prevalence of asthma symptoms include, a true decrease in prevalence, influence of improved identification and treatment, and changes in environmental influences such as indoor environmental factors, outdoor air pollution, infectious burden in early childhood, and lifestyle changes such as shorter duration of breastfeeding. We have previously found that changed exposure to environmental tobacco smoke or pets did not explain our results [6]. Likewise, the Swiss study found that none of a series of known risk factors had a significant influence on the observed time trends [4].

Our results are more in line with the second view, namely, that the decreasing prevalence of asthma symptoms might reflect improved diagnostics followed by appropriate treatment. Moreover, the significant decrease in the prevalence of wheeze and shortness of breath with wheeze seen between 1997 and 2001, coincided with the introduction of the revised guidelines in 1998 in which the importance of corticosteroids in asthma management was stressed [8], and might be viewed as an indication in favour of improved treatment.

Our data are consistent with recent reports from the UK and the US $[2,3]$ indicating no further increase in asthma visits since the early $1990 \mathrm{~s}$, and probably reflect 
improved asthma control [2]. Diagnostic changes as well as changes in underlying prevalence have been thought to play a part in the increasing prevalence of asthma symptom seen over the last decades. The decreasing prevalence found in the present study may likewise be the resultant of a number of opposing forces, which cannot be disentangled here. Although improved identification and treatment of asthmatic children is a likely explanation for our results, the finding that the prevalence of wheezy children not using medication also declined, may suggest that improved treatment alone does not explain the whole decrease. Also, among children not reporting wheeze in the past year, the prevalence of medication use remained fairly constant $(4.8 \%$ in 1989 and $4.3 \%$ in $2001 ; p=0.545)$.

The 2001 survey was conducted in the same standardised way as the three previous surveys, using the same study design and questionnaire. The study population consisted of all 8-9-year-old children living in the study area, excluding age as a confounder. Selection bias is unlikely to explain our results given the high response rates of more than $95 \%$ achieved in all surveys. However, questionnaire surveys may be subject to information bias.

In conclusion, the prevalence of recent wheeze has decreased steadily since 1989 in school children لiving in the south-east of the Netherlands, with the decline being especially prominent in boys. The rising prevalence of medication use in symptomatic children over time may reflect better asthma control, and, therefore, may partly explain the concurrently decreasing trend in the prevalence of asthma symptoms in our study population.

\section{ACKNOWLEDGEMENTS}

The authors wish to thank Ron Derkx and the members of the Youth Health Care Section of the Municipal Health Service Westelijke Mijnstreek for their cooperation in the study.

\section{REFERENCES}

1. Woolcock AJ, Peat.JK. Evidence for the increase in asthma worldwide. Ciba Found Symp 1997;206: 122-39.

2. Stafford RS, Ma J, Finkelstein SW, Haver K, Cockburn 1. National trends in asthma visits and asthma pharmacotherapy, 1978-2002. J Allergy Clin Immonol 2003;1 11(4):729-35.

3. Fleming DM, Sundertand R, Cross KW, Ross AM. Declining incidence of episodes of asthma: a study of trends in new episodes presenting to general practitioners in the period 1989-98. Thorax 2000;55(8):657-61.

4. Braun-Fahrliander C, Gassner M, Grize L, Takken-Sahli K, Neu U, Stricker T et al. No further increase in asthma, hay fever and atopic sensitisation in adolescents liwing in Switserland. Eur Respir $J 2004 ; 23(3): 407-13$.

5. Toelle $\mathrm{BG}, \mathrm{Ng} \mathrm{K}$, Belousova E, Salome $\mathrm{CM}$, Peat $J \mathrm{~K}$, Marks GB. Prewalence of asthma and allergy in schoolchildren in Belmont, Australia: three cross sectional surveys over 20 years. BMJ 2004;328(7436):386-7. 


\section{$36 \mid$ Chapter $2 b$}

6. Mommers $M$, Derk $R$, Swaen $G$, van Schayck $C P$. Changing prevalence of respiratory symptorns and treatmeni in Dufch school children: 1989-1997. Priw Care Resp J $2002 ; 11(2) ; 38-41$.

7. Kuchni CE, Davis A. Brooke AM, Siwerman M. Are all wheezing disorders in wery young (preschool) children increasing in prevalence? Lancer 2001;357(9271):1821-5.

8. Dirksen WJ, GejJer RM, De Haan M, De Koning G, Flikween S, Kolnaar B. NHG-Standaard Astma bij Kinderen (eerste herziening). Huisarts Wet 1998;41(3):130-43. 


\section{Differences in asthma diagnosis and medication use in children
(1) ing living in Germany and the Netherlands}

M MOMMERS ${ }^{1,2}$

GMH SWAEN

M WEISHOFF-HOUBEN"

W DOTT"

CP VAN SCHAYCK

'INSTITUE FOR HYGIENE AND ENVIRONMENTAL MEDICINE, FWTH AACHEN, GIEMMANY

"DEPARTMENT OF GENEFAL PRACTSE, CAPHRI, MAASTRICHT UNIWERSITY, THE NETHERLANDS

'DEPARTMENT OF EPIDEMIOLOGY, CAPHRI, MAAGTRICHT UNIVERSITY, THE NETHEFLANDS

PRIM CARE RESPJ $2005,14: 31-7$ 


\section{ABSTRACT}

AIM: To compare diagnosis and treatment between German and Dutch children with asthmatic symptoms at the age of 5-6 and 7-8 years, and the use of anti-asthma medication at 7-8 years of age.

METHODS: Parents of 4462 children participated in two surveys, in 1995 and in 1997. All 465 children identified with recent asthmatic symptoms at the age of 5-6 (May 1995) or at 7-8 years of age (May 1997) were sent a third more detailed questionnaire (October 1997).

RESUI.TS: Asthma diagnosis was more prevalent in Dutch children with recent asthmatic complaints (50-60\%), whereas over $90 \%$ of the German children with recent asthmatic complaints had been diagnosed with bronchitis. Inhaled $\beta_{2}$ agonists were more frequently used by Dutch children compared to German children $(67.3 \%, 45.6 \% ; \mathrm{p}<0.01)$ as were inhaled steroids $(38.9 \% v 7.0 \% ; p<0.01)$. Instead, German children more often used sodium cromoglycate or nedocromil as anti-inflammatory medication as compared with Dutch children $(42.1 \% v 11.5 \%$; $\mathrm{p}<0.01)$.

CONCLUSIONS: Differences in diagnosis rates for asthma and bronchitis between German and Dutch children most likely resulted from differential labelling of complaints, and probably lead to differences in treatment practice, indicating possible undertreatment of German children with inhaled steroids. 


\section{INTRODUCTION}

Asthma is a common disease in childhood with a large social and economic burden. Developed countries might expect to spend an estimated one to two percent of their total healthcare expenditures on asthma [1]. In children, asthma is an important cause for school absence. School absence in the past year due to asthma was reported for $40-50 \%$ of German and Dutch children [2]. Early diagnosis and appropriate treatment are vital to reduce the burden asthma puts on society and on the individual.

Several national and international guidelines for the diagnosis and management of asthma have been published in recent years $[1,3-6]$. Current recommendations stress the early introduction of anti-inflammatory agents because asthma is considered a chronic inflammatory disorder. Although some earlier guidelines recommended the use of sodium cromoglycate as maintenance treatment for children with moderate asthma $[3,4]$ more recent guidelines stress the importance of inhaled corticosteroids $[1,5]$. Inhaled steroid use has been shown to improve symptom control and lung function [7] and to reduce the risk of hospital admission [8]. A recent study reported substantial underuse of preventive therapy, specifically inlaled steroids [9]. The use of inhaled anti-inflammatory medication remains low even for children using large amounts of inhaled $\beta_{2}$-agonists [10]. A large European survey concluded that the current level of asthma control falls far short of the goals for long-term asthma management as put forward in current guidelines [11].

The incorporation of the guideline recommendations into daily medical practice may depend on factors such as organisation of healthcare, health insurance system, and costs of medical treatment, but probably (and most importantly) it may well depend on doctors' views on asthma diagnosis and management. Many of these factors differ between Germany and the Netherlands, and it is possible that asthma care between German and Dutch children differs likewise. In the Dutch system, general practitioners serve as gate keepers, whereas in Germany patients have open access to physicians or specialists. Moreover, asthma symptom prevalence rates in the Dutch borderland regions were among the highest in the Netherlands [12]; given the lack of information about respiratory health in the adjoining German region, this led the local health authorities to conduct a large Dutch-German study on respiratory health, diagnosis, treatment and risk factors, involving Municipal Health Services and Universities from both countries. The present study represents the first part of this Dutch-German study, aiming to gain more insight into diagnosis and prescription of anti-asthma medication in German and Dutch children. We investigated whether differences existed in prevalence rates of diagnosis and treatment between Dutch and German children with recent asthmatic symptoms. Whereas most studies on asthma control are cross-sectional, our data presented the opportunity to study diagnosis and treatment in the same group of children at different ages. Early recognition of asthmatic symptoms, early diagnosis, and early treatment might prevent disease progression, and willingness to diagnose asthma at an early age might differ between Germany and the Netherlands. Moreover, the design of the study enabled a more accurate assessment of asthmatic status 
(asthmatic symptoms present on more than one occasion) for studying medication use in these children.

This study therefore compares the prevalence rates of diagnosis and treatment between German and Dutch children with asthmatic symptoms at the age of 5-6 years and again at 7-8 years, and the use of anti-asthma medication at 7-8 years of age.

\section{METHODS}

Respiratory symptoms; diagnosis and treatment were assessed at 3 different time points in a period of 2.5 years, among children living in the Dutch-German borderland (Fig. 1). This region covers the geographic area consisting of the municipal health regions Kreis Heinsberg (Germany), Midden-Limburg and the Westelijke Mijnstreek (the Netherlands). Together, the two Dutch regions have approximately 380,000 inhabitants, while Heinsberg has approximately 250,000 inhabitants.

In May 1995, the parents of all 7201 children living in the study area who were born between November $30^{\text {th }} 1989$ and December $1^{\text {st }} 1990$ were invited to complete a questionnaire that included the WHO questions about respiratory symptoms [13] and questions about allergies, diagnosis and treatment. Parents of 5692 children $(79.0 \%)$, who turned 5-6 years in the study year, participated in 1995. In spring 1997, it was possible to trace 5459 of these children for participation in the second survey, using the same parental questionnaire; the remaining 233 children had moved out of the study area or their forwarding address was unknown.

We studied differences in diagnosis and treatment rates among German and Dutch children with reported recent asthmatic symptoms. Recent asthmatic symptoms were defined as reported wheezing and attacks of shortness of breath with wheezing in the respective year preceding the surveys of 1995 and 1997. For the purpose of defining recent asthmatic symptoms in the present study we used what is, to our knowledge, an unvalidated definition. Although our definition of recent asthmatic symptoms--positive response to both questions about wheezing and shortness of breath with wheezing in the past 12 months--had not been validated in this combination, each question separately was found to have both high sensitivity and specificity in relation to clinical asthma [14]. In all, 465 children had recent asthmatic symptoms either at 5-6 years of age (in May 1995) or at 7-8 years of age (in May 1997), or at both ages. In October (from September $29^{\text {th }}$ to November $7^{\text {th }}$ ) 1997, the parents of these 465 children were asked to complete a third, more detailed questionnaire, which included ISAAC questions on occurrence and severity of wheezing [15] (different questions regarding wheezing or whistling in the child's chest number of attacks of wheezing, sleep disturbance due to wheezing and wheezing severe enough to limit the child's speech to only one or two words at a time between breaths) and management (questions regarding medication use (tablets, sprays etc.) against wheezing or asthma in the last 12 months, number of visits to a general practitioner, pulmonologist, paediatrician or hospital emergency 
department for a regular asthma check-up or acute attack of wheezing or asthma in the last 12 months), as well as questions on indoor environment. Questionnaires were checked for completeness by an assistant of the Municipal Health Service in the presence of one or both parents. Because of the time frame of the study (from May 1995 through to October 1997) for some children recent astlmatic symptoms had only been reported in 1995, whereas for others recent asthmatic symptoms had been reported in May 1997. For the purpose of describing medication use in the past 12 months in children with recent symptoms, we used the question 'Has your child had wheezing or whistling in the chest in the last 12 months?' from the third, more detailed questionnaire to identify children with recent symptoms in October 1997. The study was approved by the medical ethics committee of the "Arztekammer Nordrhein" in Germany.

\section{Statistical analysis}

Prevalence rates were calculated by dividing the number of positive responses to each question by the total number of responses to that question. Data are presented stratified by country and age group. Chi-square tests were used to analyse differences in prevalence rates between the two countries. Fisher's exact test was used when the expected frequency of any cell was less than 5 .

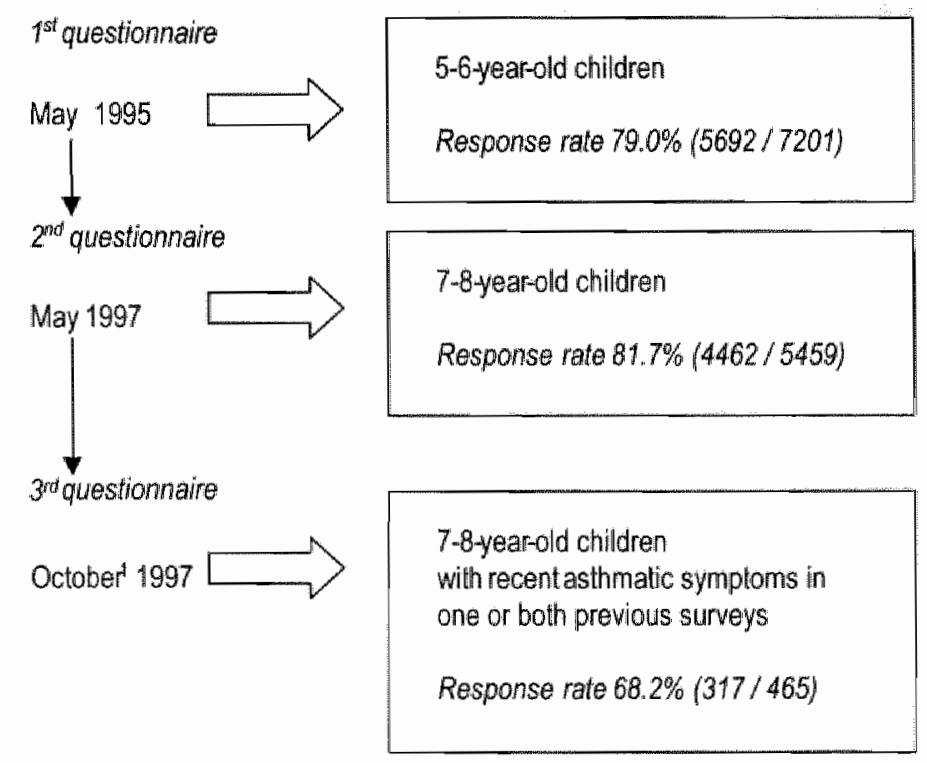

Fig. 1. Response rates of the different parts of the study

'from September $2 g^{\text {th }}$ to November $7^{\text {th }}$ 


\section{RESULTS}

\section{Response rates}

The overall response rates of the study are outlined in Figure 1. In 1997, 1402 $(74.8 \%)$ German and $3060(85.4 \%)$ Dutch participants of the 1995 survey took part in the second survey. The proportion of boys was slightly larger in the German compared to the Dutch region: $52.9 \%$ versus $51.0 \%$ respectively.

Table 1. Prevalence of diagnosis and treatment for asthma, bronchilis and allergies in children with recent asthmatic symptoms at different ages by country

\begin{tabular}{|c|c|c|c|c|c|c|}
\hline & \multicolumn{3}{|c|}{ 5-6-year-olds $(n=341)$} & \multicolumn{3}{|c|}{$7-8$-year-oids $(n=240)$} \\
\hline & $\begin{array}{c}\text { German } \\
n(\%) \\
\end{array}$ & $\begin{array}{l}\text { Dutch } \\
\mathrm{n}(\%)\end{array}$ & p-value & $\begin{array}{c}\text { German } \\
n(\%)\end{array}$ & $\begin{array}{l}\text { Dutch } \\
n(\%)\end{array}$ & p-walue \\
\hline $\begin{array}{l}\text { Physician-diagnosed as thma } \\
\text { (lifetime) }\end{array}$ & $21(21.2)$ & $117(52.2)$ & $<0.01$ & $32(37.2)$ & $89[59.7)$ & $<0.01$ \\
\hline $\begin{array}{l}\text { Physician-diagnosed bronchilis } \\
\text { (lifetime) }\end{array}$ & $99(95.2)$ & $15 \|(65.7)$ & $<0.01$ & $83\{93.3\}$ & $83(56.5)$ & $<0.01$ \\
\hline $\begin{array}{l}\text { Physician-diagnosed allergies } \\
\text { (all): }\end{array}$ & $38(37.6)$ & $128(54.2)$ & 0.01 & $47(57.3)$ & $93(65.5)$ & 0.22 \\
\hline House dust mite allergy & $16(18.0)$ & $68(32.5)$ & 0.01 & $27(40.3)$ & $64(52.5)$ & 0.11 \\
\hline Grass/pallen allergy & $17(19.3)$ & $48(24.0)$ & 0.38 & $37(48.7)$ & $49(45.0)$ & 0.62 \\
\hline Cow's millk allergy & $5(5.9)$ & $47(23.4)$ & $<0.01$ & $2(3.5)$ & $27(26.0)$ & $<0.01$ \\
\hline Chicken egg allergy & $4(4.8)$ & $21(10.9)$ & 0.10 & $2(3.6)$ & $21(20.2)$ & $<0.01$ \\
\hline Mould allergy & $4(4.8)$ & $11(5.9)$ & 11.00 & $11(19.0)$ & $9(10.3)$ & 0.14 \\
\hline Pet allergy & $15(17.2)$ & $66(32.0)$ & 0.01 & $23(34.3)$ & $57(47.1)$ & 0.09 \\
\hline Other allergies & $13(14.9)$ & $47(23.9)$ & 0.09 & $24(36.4)$ & $33(34.7)$ & 0.83 \\
\hline $\begin{array}{l}\text { Treatment (by a specialist) for } \\
\text { asithma in the past } 12 \text { months }\end{array}$ & $19(19.4)$ & $61(27.5)$ & 0.12 & $25(29.8)$ & $45(30.2)$ & 0.94 \\
\hline $\begin{array}{l}\text { Treatment (by a specialist) for } \\
\text { bronchitis in the past } 12 \text { months }\end{array}$ & $93(89.4)$ & $61(27.0)$ & $<0.01$ & $68(78.2)$ & $28(19.2)$ & $<0.01$ \\
\hline
\end{tabular}

Of the 4462 children participating in both surveys, 341 children $(7.6 \%)$ had recent asthmatic symptoms at the age of 5-6 years (in 1995) and $240(5.4 \%)$ had recent asthmatic symptoms at the age of 7-8 (in 1997); 465 children had recent symptoms either at 5-6 years of age or at 7-8 years of age, or at both ages. The additional questionnaire was completed for $68.2 \%(317 / 465)$ of these children, showing minimal differences in response rates between German (67.7\%) and Dutch children $(68.4 \%)$. Again, the proportion of German boys $(68.5 \%)$ was slightly larger than for Dutch boys $(64.6 \%)$. 
Diagnosis rates in German and Dutch children with recent asthmatic sympioms Among 5-6-year-olds with recent asthmatic symptoms, proportionally more Dutch than German children were diagnosed with asthma (Table 1). Two years later, this difference was still present but somewhat smaller: $59.7 \%$ for Dutch and $37.2 \%$ for German children $(p<0.01)$. Among 7-8-year-old children diagnosed with asthma, $77.3 \%$ of the Dutch children and $31.0 \%$ of the German children already had an asthma diagnosis at the age of 5-6 $(\mathrm{p}<0.01)$. Bronchitis was diagnosed in more than $90 \%$ of the German children with recent asthmatic complaints (Table 1). On the other hand, more than $40 \%$ of the German children without any reported respiratory symptom at 5-6 years of age as well as at 7-8 years of age, were also reported to have ever been diagnosed with bronchitis.

Allergies were diagnosed more often in Dutch compared to German children with asthmatic complaints, especially at the age of 5-6 years (Table 1).

\section{Anti-asthma medication use in German and Dutch children with recent asthmatic symptoms}

We identified 175 children with recent asthmatic symptoms at the third assessment of the study for describing severity of symptoms (Table 2) and anti-asthma medication use in the past year (Table 3). Wheezing attacks were more frequently reported for Dutch children, whereas speech-limiting wheeze was more prevalent in German children with recent asthmatic symptoms (Table 2).

Overall, for $80 \%$ of the 7-8-year-old German and Dutch children with recent asthmatic symptoms, any medication use for their complaints in the past 12 months was reported (Table 3). Anti-asthma medication, as listed in Table 3, had been used by $63.8 \%$ of the German children and by $72.6 \%$ of the Dutch children. Inhaled $\beta_{2}-$ agonists were used by more of the Dutch children compared to German children as were inhaled steroids. Instead, German children more often used sodium cromoglycate or nedocromil as anti-inflammatory medication compared with Dutch children. Inhaled $\beta_{2}$-agonists were used by $15.8 \%$ of the German children and by $26.5 \%$ of the Dutch children as monotherapy (Table 4). In combination with inhaled $\beta_{2}$-agonists German children most frequently used sodium cromoglycate or nedocromil, whereas in Dutch children inhaled $\beta_{2}$-agonists were more frequently combined with inhaled steroids.

Table 2. Frequency of wheezing attacks, sleep disturbance due to wheeze and speech-limiting wheeze in the past year in children with recent asthmatic symptoms by country

\begin{tabular}{lccc}
\hline & \multicolumn{2}{c}{$7-8$-year-old children with asthmatic complaints $(\mathrm{n}=175)$} \\
\cline { 2 - 4 } & $\begin{array}{c}\text { German } \\
\mathrm{n}(\%)\end{array}$ & $\begin{array}{c}\text { Dutch } \\
\mathrm{n}(\%)\end{array}$ & $\mathrm{p}$-value \\
\hline Wheezing attacks $(\geq 1)$ & $52(89.7)$ & $114(97.4)$ & 0.06 \\
Sleep disturbance due to wheeze & $33(60.0)$ & $78(68.4)$ & 0.28 \\
Speech-Himiting wheeze & $21(36.8)$ & $25(21.9)$ & 0.04 \\
\hline
\end{tabular}




\section{DISCUSSION}

The results of the present study show differences between German and Dutch asthmatic children with respect to diagnosis and treatment. Almost all German children had been diagnosed with bronchitis. Asthma diagnosis was more frequent in Dutch than in German children.

Inhaled $\beta_{2}$-agonists and inhaled steroids were more frequently used by Dutch children, whereas more German children used inhaled sodium cromoglycate or nedocromil.

Diagnosis rates differ between German and Dutch children with recent asthmatic symptoms

The large difference in diagnosis rates by country probably originated from differential labelling of respiratory symptoms. German physicians may have preferred the label bronchitis because (in the parents view) it is a less threatening and stigmatising diagnosis than asthma. In Germany the label bronchitis seems to encompass respiratory symptoms ranging from mild coughing symptoms to more severe asthmatic symptoms. In line with this, the variation in prevalence rates for allergy diagnoses by country might well reflect differences in diagnostics rather than a real difference in atopic predisposition.

Table 3. Medical care use in the past year in children with recent asthmatic symploms by country

7-8-year-old children with asthmatic complaints $(n=175)$

\begin{tabular}{ccc}
\hline German & Dutch & p-value \\
$n(\%)$ & $n(\%)$ & \\
\hline
\end{tabular}

Medication use in the past 12 manths

$46(80.7)$

$92(80.0)$

0.91

Inhaled $\beta_{2}$ agonists

$26(45.6)$

$76(67.3)$

$<0.01$

Inthaled anticholinergic agents

$2(3.5)$

$7(6.2)$

0.72

Inthaled corticosteroids

$4(7.0)$

$44(38.9)$

$<0.01$

Sodium cromoglycate / nedocromil

$24(42.1)$

$13(11.5\rangle$

$<0.01$

Oral Bragonists

$5(8.8)$

- $\quad<0.01$

Theophyline

$1(1.8)$

0.34

Ketolifen

$3(5.3)$

0.04

Corticosteroids (oral)

$4(7.0)$

$1(0.9)$

0.04

Corticosteroids (rectal)

$10(17.5)$

$<0.01$

Physician's visit for acute asthmatic

$45(84.9)$

$79(72.5)$

0.08

problems in the past 12 months

Physician's visit for a regular asthma

$18(38.3)$

$5.2(49.1)$

0.22 


\section{Therapeutic regimes differ between German and Dutch children with recent asthmatic symptoms}

Fewer German than Dutch children with recent asthmatic symptoms reported the use of anti-asthma medication in the past year. The rate of anti-asthma medication use in German children $(64 \%)$ was similar to the rate previously reported for German children [16]. Most guidelines recommend the use of $\beta_{2}$-agonists in children with mild asthma [3-6]. Our results indicate that $\beta_{2}$-agonists were used more frequently in Dutch children than in German children. Also, proportionally more Dutch than German children used $\beta_{2}$-agonists as monotherapy. It is possible that Dutch physicians adhered more strictly to the guidelines and prescribed $\beta_{2}$ agonists to children with mild intermittent asthmatic symptoms (step one in the GINA guidelines [1]). Another explanation could be that among Dutch children mild asthmatic symptoms are more prevalent than among German children, or that parents of Dutch children more readily report their child's complaints to a physician. The latter is less likely because underpresentation of respiratory symptoms to the general practitioner is a large problem among Dutch adult asthmatic patients [17].

In addition, more of the Dutch children used inhaled steroids as maintenance treatment, whereas most German children in this study used sodium cromoglycate or nedocromil. Our results are consistent with recent reports of lower use of inhaled steroids in Germany [16,18] and in other countries [2,9]. Low steroid use in German children may have resulted from parent's or physician's fear of side effects of treatment with steroids, or from different recommendations in national guidelines. For instance, the 1998 German national guidelines [6] recommend the use of sodium cromoglycate as an alternative to inhaled steroids in children with mild asthma whereas the 1998 Dutch guidelines recommend inhaled steroids as the prophylactic treatment of first choice [5]. The use of steroids largely depends on the degree of asthma severity. As our definition of asthmatic symptoms was based solely on questionnaire reports and did not include more objective clinical diagnostic methods, it was not possible to determine accurately the severity of the asthmatic symptoms. It is therefore possible that most of the children in this study only had mild complaints which did not require treatment with steroids. However, we studied medication use among children who had had at least two periods of wheezing or attacks of shortness of breath with wheezing at two different time points. In about half of these children asthma had been diagnosed.

Adequate treatment may have affected the frequency and improved the severity of symptoms in these children. We have no information on compliance to treatment, but low compliance has been reported worldwide and is, on average, not strongly influenced by disease severity [1.9]. In children with asthma, adherence rates to prescribed treatment regiments are often below 50\% [20]. 
Table 4. Percentage of Geman and Dutch children with recent asthmatic symptoms using Bz-agonists as monotherapy or in combination with anti-inflammatory medication

7-8-year-old children with asthmatic complaints $(n=175)$

\begin{tabular}{|c|c|c|c|}
\hline & \multirow[b]{2}{*}{$\begin{array}{c}\text { German } \\
n(\%)\end{array}$} & \multirow[b]{2}{*}{$\begin{array}{l}\text { Dutch } \\
n(\%) \\
\end{array}$} & \multirow{2}{*}{ p-value } \\
\hline & & & \\
\hline Bacagonists as monotherapy & $9(15.8)$ & $30(26.5)$ & 0.12 \\
\hline B-agonists wilh inhaled corticosteroids & $1(1.8)$ & $38(33.6)$ & $<0.01$ \\
\hline Bragonists with sodium cromoglycate / nedocromil & $15(26.3)$ & $7(6.2)$ & $<0.01$ \\
\hline $\begin{array}{l}\text { Bamgonists with inhaled corticosteroids and sodium } \\
\text { cromoglycate / nedocromil }\end{array}$ & $1(1.8)$ & $1(0.9)$ & 1.00 \\
\hline
\end{tabular}

\section{Possible limitations of the study}

We cannot address a possible responder bias because we have no information on the children who did not participate in both 1995 and 1997. It is possible that parents of children with symptoms were more likely to participate than parents of children without symptoms, leading to overrepresentation of symptomatic children in our study. In line with this, children with asthmatic symptoms whose parents had completed the third, more detailed questionnaire were more frequently found to have reported symptoms in the second survey (in 1997) than non-participants for the third questionnaire. Since we only selected children with recent asthmatic symptoms for the analysis of treatment, this differential response probably did not influence the main outcomes of this study. However, based on our data, we cannot irrefutably exclude a real difference in prevalence of asthmatic symptoms between the two countries but it seems likely that different diagnostic labelling plays a major role in explaining these data.

\section{Conchusions}

The study results show differences in diagnostic labelling of asthmatic symptoms between countries, possibly leading to the observed differences in asthma management. In Dutch children asthmatic symptoms were more often labelled as asthma whereas in German children they were more often labelled as bronchitis. Although this did not result in large differences in prevalence of overall anti-asthma medication use between German and Dutch children living in the study area, differences in the use of specific anti-asthma medication were found. Most Dutch children used inhaled steroids as anti-inflammatory treatment, whereas only a minority of German children used inhaled steroids. Most German children were treated with sodium cromoglycate or nedocromil, possibly indicating undertreatment of German children with steroids. It seems feasible that German physicians have to overcome their reluctance to diagnose children with asthma symptoms as having asthma, in order to increase the use of inhaled corticosteroids 
as the most appropriate treatment in respect to the underlyng pathophysiology of this disease.

\section{ACKNOWLEDGEMENTS}

The authors wish to thank Ron Derkx, Gonnie Jongmans-Liedekerken, Paul Mertens and Bernd Ziemer for their cooperation in the study. The study was financially supported by the European Union, the Euregio Maas-Rhine (Interreg II project EMR.INT2.96.09.V.039), the Land Northrhine-Westphalia, the Province of Limburg and the counties of Heinsberg, Midden-Limburg and Westelijke Mijnstreek.

\section{REFERENCES}

1. Global Initiative for Asthma (GINA). Global strategy for asthma management and prevention. Nationall Institutes of Health, National Heart, Lung, and Blood Institute. NIH Publication No. 02-3659, Revised 2002.

2. Vermeire PA, Rabe KF, Soriano JB, Maier WC. Asthma control and differences in management practices across seven European countries. Respir Med 2002;96(3):142-9.

3. National Heart, Lung and Blood Institute. International consensus report on diagnosis and treatment of asthma. Eur Respir J 1992;5:601 41.

4. Asthma: a follow up statement from an international paediatric asthnua consensus group. Arch Dis Child 1992;67:240-8.

5. Dirksen WJ, Geijer RM, de Haan M, de Koning G, Flikweert S, Kolnaar BG. NHG-Standaard astma bij kinderen (eerste herziening). Huisarts Wet 1998;41(3):130-43.

6. Wettengel $\mathbb{R}$, Berdel D, Hofmann D, Krause J, Kroegel C, Kroidl RF at al. Empfehlungen zur Asthmatherapie bei Kindern und Erwachsenen. Pneumologie 1998;52(11):591-601.

7. Price J. The role of inhaled corticosteroids in children with asthma. Arch Dis Child 2000;82(suppl 2):II10-4.

8. Blais L, Suissa S, Boivin JF, Emst P. First treatment with inhaled corticosteroids and the prevention of admissions to hospital for asthma. Thorax 1998;53(12):1025-9.

9. Warman KL, Silver EJ, Stein RE. Asthma symptoms, morbidity, and antinflammatory use in inner-city children. Pediatrics $2001 ; 108(2): 277-82$.

10. Goodman DC, Lozano P, Stukel TA, Chang CH, Hecht J. Has asthma medication use in children become more frequent, more appropriate, or both? Pediatrics 1999;104(2P11):187-94.

11. Rabe KF, Vermeire PA, Soriano JB, Maier WC. Clinical management of asthnta in 1999: the Asthma Insights and Reality in Europe (AIRE) study. Eur Respir J 2000; ; 6(5):802-7.

12. van der Wal MF, Uitenbroek DG, Verhoeff AP. Toegenomen percentage basisschoolkinderen met astmatische klachten in Nederland, 1984/85-1994-95; een literatuuronderzoek. Ned Tijdschr Geneeskd 2000;144(37):1780-5.

13. Florey C du V, Leeder SR. Methods for Cohort Studies of Chronic Anglow Limitation. WHO Regional Publications European Series No. 12. London, United Kingdom, 1982.

14. Remes ST, Pekkanen J, Remes K, Salonen RO, Korppi M. In search of childhood asthma: questionnaire, tests of bronchial hyperresponsiveness, and clinical evaluation. Thorox $2002 ; 57(2) \ldots 120-6$.

15. Asher MI, Keil U, Anderson HR, Beasley R, Crane J, Martinez IF et al. International Sudy of Asthma and Allergies in Childhood (ISAAC): rationale and methods. Eur Respir $J$ $1995 ; 8(3): 483-91$. 


\section{$48 \mid$ Chapter 3}

16. Beinfohr $C$, Maziak W, von Mutius E, Hense HW, Leupold W, Martinez F et all. The use of antitasthmatic drugss in children: results of a community-based survey in Germany. Pharmacoepidemiot Drug Saf $2001 ; 10(4): 315-21$.

17. wan Schayck $C P$, van der Heijden FM, van den Boom $G$, Tirimanna $P R$, van Herwaarden $C L$. Underdiagnosis of asthma: is the doctor or the patient to blame? The DIMCA project. Thorax: $2000 ; 55(7), 562-5$.

18. Lagerlov P. Veninga CC, Muskowa M, Hummers-Pradier E, Stalsby Lundborg C. Andrew M et al. Asthma management in five European countries: doctors. knowledge, attitudes and prescribing behaviour. Drug Education Project (DEP) group. Eur Respir J 2000; 15(1):25-9.

19. Cerveri I, Locateli If, Zoia MC, Corsico A, Accordini S, de Marco R. Intemational variations. in asthma treatment compliance: the results of the European Community Respiratory Health. Stirvey (ECRHS), Eur Respir J 1999;14(2):288-94.

20. Bender $\mathrm{BG}$. Overcoming barriers to nonadherence in asthma treatment. J Allergy Clin Immunol 2002;109(6Suppl):S554-9. 


\section{CHADTER \\ Infant immunisation and the occurrence of atopic disease in Dutch and German children: a nested case-control study}

M MOMMERS

M WEISHOFF-HOUBEN'

GMH SWAEN $N^{2,3}$

H CREEMERS

H FREUND

W DOTा"

CP VAN SCHAYCK ${ }^{2}$

'INSTITUTE FOR HYGIENE AND ENVIRONMENTAL MEDICINE, RWTH AACHEN, GERMAMY

'DEPARTMENT OF GENERAL PRACTICE, CAPHRI, MAASTRICHT UNIVERSTTY, THE METHERLANOS "DEPARTMENT OF EPIDEMIOLOGY, CAPHRI, MAASTRICHT UNIVERSITY, THE NETHEFHANDS "YOUTH HEALTH CARE SECTION, MUNICIPAL MEALTH SERVICE WESTELLIKE MUPSTTEEFH, GELEEN, THE NETHERLANDS

"YOUTH HEALTH CARE SECTIOM, MUMHCIPAL HEALTH SEFVICE KREIS HEINSBEPG, HEHSEERG, GERMANY 


\section{ABSTRACT}

Our goal was to assess the role of early childhood vaccination in the occurrence of respiratory symptoms and allergic sensitisation in 7-8-year-old Dutch and German children.

A nested case-control study was conducted among children participating in a large longitudinal study on respiratory health, to study the relationship between vaccination (bacille Calmette Guérin (BCG), pertussis, measles/mumps, rubella, Haemophilus influenza type b (Hib)) and respiratory symptoms and allergic sensitisation. Parents of 510 7-8-year-old children with respiratory complaints and an equal number of randomly selected children without respiratory complaints were asked to complete a questionnaire. Blood samples were collected for specific serum IgE analysis. Vaccination status was assessed through the records of the participating Municipal Health Services.

No association between vaccination against pertussis, measles, rubella or Hib and respiratory symptoms or allergic sensitisation was found. For sensitisation against house dust mite, $\mathrm{BCG}$ vaccination resulted in increased risk $(\mathrm{OR}=2.28,95 \% \mathrm{Cl}$ : 1.05-4.96). Birth order was inversely associated with allergic sensitisation, but was not related to respiratory symptoms.

We found an association between $B C G$ vaccination and the subsequent risk for sensitisation against house dust mite. No evidence was found for an association between vaccination and respiratory symptoms. Earlier reports of an association of birth order with atopic disease were supported by the results of the present study. 


\section{INTRODUCTION}

In recent years the prevalence of atopic disease has increased substantially, but the causes of this increase remain unclear. As a possible explanation, Strachan [1] postulated the "hygiene hypothesis", in which he proposed a protective effect of early childhood infections on atopic disease. Several studies using number of older siblings or day-care attendance as marker for early childhood infections are supportive of a protective effect of infections early in life $[2,3]$. Vaccination, on the other hand, might promote atopic disease, either by preventing possible protective effects of natural infections or through direct immune effects, as is probably the case for bacille Calmette-Guérin (BCG), which has been thought to protect against atopy by inducing T-helper 1 (Th1)-immune responses [4]. However, the evidence for a role of vaccination in the development of atopic disease is inconclusive [4-8]. Vaccination programmes differ between Germany and the Netherlands, as does vaccination coverage. In Germany, poliomyelitis vaccine was administered orally until 1998, whereas in the Netherlands, poliomyelitis vaccine is coadministered with vaccination against tetanus and diphtheria, and normally also with pertussis. Combined measles, mumps and rubella (MMR) vaccination is standard in the Netherlands but in Germany, although MMR vaccination is recommended, some parents prefer to vaccinate their child against measles and mumps only. Furthermore, Haemophilus influenza type b (Hib) was introduced in the German guidelines in 1991, just after the children participating in the present study were born. In the Netherlands Hib vaccination has been recommended since 1993.

The present study is part of a large longitudinal study on respiratory symptoms and allergies conducted in the Dutch-German borderland. Because of differences in vaccination programme and vaccination coverage between Germany and the Netherlands, the data set provided the opportunity to assess the role of immunisation in the development of respiratory symptoms and allergic sensitisation in 7-8-year-old Dutch and German children.

\section{METHODS}

Study population and study design

A nested case-control study of participants in a longitudinal study on respiratory health in children was conducted in the Dutch-German borderland, involving the Municipal Health Services of Kreis Heinsberg, Germany (250,000 inhabitants) and of the Westelijke Mijnstreek, the Netherlands (170,000 inhabitants).

In 1995, parents of all 5052 children born between November $30^{\text {th }} 1989$ and December $1^{\text {st }} 1990$ and living in the study area, were invited to participate in the first survey. Parents of 3871 children $(76.6 \%)$ returned the completed questionnaire on respiratory symptoms and diagnosis. A second survey was conducted in 1997. By then, 218 children (5.6\%) were lost to follow-up because they had moved out of the study area or their forwarding address was unknown. Of the remaining 3653 children, $2884(78.9 \%)$ completed the 1997 questionnaire. Children with respiratory 
symptoms as well as controls were selected based on the answers given in the first and second survey. All 510 children with respiratory symptoms and an equal number of randomly selected control children were included in the case-control study.

\section{Data collection}

For both the first (in 1995) and second (in 1997) survey, data were collected in May. In autumn 1997, the case-control study was conducted. Together with an invitation for a physical examination, parental questionnaires were sent for selfcompletion. In the presence of one or both parents, completeness of the questionnaire was checked by an assistant of the Municipal Health Service, and blood samples were taken for immunological analysis.

Data on vaccination status and childhood infections were obtained from the Youth Health Care Department of the participating Municipal Health Services. In the Netherlands, vaccination status was registered during routine check-ups of children. In Germany, vaccination status was registered during the check-up of school beginners at age 5-6 years. Data were collected on vaccination against poliomyelitis, diphtheria, tetanus, pertussis, measles, mumps, rubella, Hib and $B C G$. For each individual vaccination, children were regarded as vaccinated if they had received at least one dose of the specific vaccine.

\section{Questionnaires}

The 1995 and 1997 surveys used identical questions about respiratory symptoms taken from the WHO questionnaire [9]. To obtain data for the case-control study, an extensive questionnaire was developed, including questions about respiratory symptoms based on the ISAAC-questionnaire [10] and questions on indoor environment.

\section{Definitions}

Respiratory symptoms were defined as reported wheezing in the last 12 months and reported attacks of shortness of breath with wheezing in the last 12 months, or reported coughing in the morning or during the day or evening in the autumn and winter, and coughing daily for about 3 months a year, in 1995 or 1997. Control children had negative answers to all questions about respiratory symptoms in 1995 as well as in 1997 .

In order to study the association between vaccination status and allergic sensitisation, we additionally determined specific immunoglobulin (Ig) $\mathrm{E}$ in the children participating in the case-control study. Children were regarded as sensitised if at least one specific $\lg E$ tested positive, irrespective of respiratory status. Children with specific $\operatorname{IgE}$ against grasses or specific $\operatorname{IgE}$ against house dust mite (HDM) were defined separately as sensitised against grasses or sensitised against HDM, respectively. For these analyses, controls were redefined as negative for all specific IgE tested. 


\section{Blood sampling and determination of Immunoglobulin E}

Blood samples were taken from the cubital vein of the child and, after $15 \mathrm{~min}$ at room temperature, were centrifuged for $10 \mathrm{~min}$ at $2000 \mathrm{~g}$. Sera were stored at $-20^{\circ} \mathrm{C}$ until further analysis.

Levels of specific IgE against Dermatophagoides pteronyssinus, Dermatophagoides farinae, Cladosporiwm herbarum, Aspergillus fumigatus, Altermaria temuis, chicken egg, cow's milk, cat and dog epithelium, and a mix of grasses were measured using the Pharmacia CAP System (Pharmacia \& Upjohn Diagnostics AB, Uppsala, Sweden) and were regarded as positive if $\geq 0.35 \mathrm{kU} / \mathrm{l}$.

\section{Statistical analysis}

Univariate analyses were performed by cross-tabulation of variables and Pearson's Chi-square test. Multivariate logistic regression anallysis was used to calculate adjusted risks for each individual vaccination. All regression models were additionally adjusted for gender, birth order, country of residence, socio-economic status, breastfeeding, exposure to environmental tobacco smoke, home dampness, pets, and childhood infections (measles, mumps, rubella, varicella and scarlet fever). Analyses stratified according to country of residence or respiratory status were additionally performed.

All analyses were performed using SPSS PC Version 10.0 (SPSS Inc. IL, USA).

\section{RESULTS}

The parents of $775(76.0 \%) 7-8$-year-old children returned the completed questionnaire. In 638 children specific $\mathrm{IgE}$ analyses for all test allergens were performed and for only one child was specific $\operatorname{lgE}$ analysis incomplete. Complete vaccination status could be retrieved for 572 of these children $(89.5 \%)$.

Ta ble 1. Vaccination rates for the participating German and Dutch children*

\begin{tabular}{|c|c|c|c|}
\hline \multirow[b]{2}{*}{ Vaccine } & \multicolumn{3}{|c|}{ 7.8-year-old children } \\
\hline & $\begin{array}{c}\text { All } \\
n(\%)\end{array}$ & $\begin{array}{c}\text { German } \\
n(\%)\end{array}$ & $\begin{array}{l}\text { Dutclit } \\
n(\%)\end{array}$ \\
\hline $\mathrm{BCG}$ & $75(13.1)$ & $74(25.9)$ & $1(0.3)$ \\
\hline Pertussisi & $364(63.6)$ & $81(28.3)$ & $283(99.0)$ \\
\hline Measles & $551(96.3)$ & $2655(92.7)$ & $286(100.0)$ \\
\hline Mumps & $551(96.3)$ & $265(92.7)$ & $286(100.0)$ \\
\hline Rubella & $438(76.6)$ & $152(53.1)$ & $286(100.0)$ \\
\hline Hilla & $247(43.2)$ & $247(86.4)$ & $0(0)$ \\
\hline
\end{tabular}

"All children were vaccinated against polionyellitis, diphtheria, and tetanus 
There were only marginal differences in response rates between cases and controls for the questionnaire $(75.1 \%, 76.9 \%)$ and specific IgE analyses $(62.5 \% v 62.7 \%)$. A somewhat larger difference was seen between cases and controls, with completed questionnaire and complete IgE data, for retrieval of vaccination status $(87.5 \% \mathrm{v}$ $91.6 \%$ ).

Because of differences in national vaccination programmes, vaccination status differed between German and Dutch children (Table 1). All participating German and Dutch children were vaccinated against poliomyelitis, tetanus, and diphtheria. Differing from the Netherlands, in Germany, poliomyelitis vaccination was orally administered until 1998. Because almost all children vaccinated against measles were also vaccinated against mumps, only measles vaccination will be considered in the further analyses.

No associations were seen between any of the vaccinations and respiratory symptoms or allergic sensitisation in univariate analyses (Tables 2 and 3). The adjusted odds ratios (OR) also did not show an association between vaccination and respiratory symptoms (Table 4). However, $\mathrm{BCG}$ vaccination increased the risk for sensitisation against HDM (OR=2.28, 95\% CI: 1.05-4.96). A tendency toward an increased risk with allergic sensitisation $(\mathrm{OR}=1.74,95 \% \mathrm{Cl}$ : $0.91-3.32)$ and sensitisation against grasses ( $\mathrm{OR}=1.95,95 \% \mathrm{CI}: 0.89-4.31)$ was also seen for $\mathrm{BCG}$ vaccination (Table 4 ). Because these analyses involved both children with and children without respiratory symptoms, the same analyses were repeated stratified according to respiratory status. The association between $\mathrm{BCG}$ vaccination and sensitisation against HDM was stronger and statistically significant only in children with respiratory symptoms ( $\mathrm{OR}=3.41,95 \% \mathrm{CI}: 1.03-11.29)$, but not statistically significant in children without respiratory symptoms (OR=1.87, 95\% CI: 0.45 7.82).

Table 2. Frequencies of $B C G$, pertussis, measles, rubella and Hib vaccination in children with respiratory symptoms and in sensitised children. Values are numbers (percentages)

\begin{tabular}{|c|c|c|c|c|c|c|}
\hline \multirow[b]{2}{*}{ Vaccine } & \multicolumn{3}{|c|}{ Respiratory symptoms } & \multicolumn{3}{|c|}{ Allergic sensitisation ${ }^{*}$} \\
\hline & $\begin{array}{c}\text { No symploms } \\
(n=293)\end{array}$ & $\begin{array}{c}\text { Symptoms } \\
(n=279)\end{array}$ & OR $(95 \% \mathrm{Cl})$ & $\begin{array}{l}\text { Not sensitised } \\
\quad(m=351)\end{array}$ & $\begin{array}{l}\text { Sensitised } \\
(n=220)\end{array}$ & OR $(95 \% \mathrm{Cl})$ \\
\hline $\mathrm{BCG}$ & $36(12: 3)$ & $39(14.0)$ & $1.16(0.71-1.89)$ & $44(12.5)$ & $31(14.1)$ & $1.14(0.70-1.88)$ \\
\hline Pertussis & $192(65.5)$ & $172(61.6)$ & $0.85(0.60-1.19)$ & $222(63.2)$ & $141(64.1)$ & $1.04(0.73-1.47)$ \\
\hline Measies & $283(96.6)$ & $268(96.1)$ & $0.86(0.36-2.06)$ & $336(95.7)$ & $214(97.3)$ & $1.59(0.61-4.97)$ \\
\hline Rubella & $226(77.1)$ & $212(76.0)$ & $0.94(0.64 \cdot 1.38)$ & $274(78.1)$ & $163(74.1)$ & $0.80(0.54-1.19)$ \\
\hline $\mathrm{Hib}$ & $122(41.6)$ & $125(44.8)$ & $1.14(0.82-1.58)$ & $154(43.9)$ & $93(42.3)$ & $0.94(0.67-1.32)$ \\
\hline
\end{tabular}

*At least one specific lgE $\geq 0.35 \mathrm{kUn}$ 
An inverse association between allergic sensitisation and number of older siblings was found (Table 4). The same inverse association was seen in children sensitised against grasses.

\section{DISCUSSION}

It has been hypothesized that vaccination may promote allergic disease by reducing clinical infections in children. In the present study, an association was found between $B C G$ vaccination and subsequent sensitisation in 7-8-year-old children. In addition, an inverse association with birth order was found for allergic sensitisation but not for respiratory symptoms.

The evidence for a role of vaccination in the development of atopic disease is confusing. Although measles vaccination was reported to reduce the risk of hay fever in children with multiple older sibling contacts [5], for pertussis vaccination, an increased risk of atopic disease was described [11]. Little evidence was found for an association between Hib-vaccination and atopic outcomes in East German children [12]. Other studies $[7,8,13]$ did not find an association between the vaccinations investigated and risk of asthma. The results of the present study are in accordance with these latter studies in showing no effect of childhood vaccination on respiratory symptoms and atopy.

Mycobacteria are potent Thl inducers, and infection and vaccination may consequently offer protection in relation to atopy, as was reported for early BCG vaccination [4]. Other, mostly European studies, failed to show such an inverse association of $\mathrm{BCG}$ vaccination with atopy, defined as presence of allergen-specific IgE $[6,14]$, or skin prick test positivity [6], or using questionnaire-based atopy definitions such as allergic disease [15] and diagnosis of atopic disease [16].

Table 3. Frequencies of $B C G$, pertussis, measles, rubelia and Hib vaccination in children sensitised against grasses and in children sensitised against HDM. Values are numbers (percentages)

\begin{tabular}{|c|c|c|c|c|c|c|}
\hline \multirow[b]{2}{*}{ Vaccine } & \multicolumn{3}{|c|}{ Sensitised against grasses } & \multicolumn{3}{|c|}{ Sernsitised against HDM } \\
\hline & $\begin{array}{c}\text { No } \\
(n=351)\end{array}$ & $\begin{array}{c}\text { Yes } \\
(n=144)\end{array}$ & OR $(95 \% \mathrm{Cl})$ & $\begin{array}{c}\text { No } \\
(n=351)\end{array}$ & $\begin{array}{c}\text { Yes } \\
(n=119)\end{array}$ & $\mathrm{OR}(95 \% \mathrm{Cl})$ \\
\hline $\mathrm{BCG}$ & $44(12.5)$ & $20(13.9)$ & $1.13(0.64-1.99)$ & $44(12.5)$ & $20(16.8)$ & $1.41(0.79 .2 .51)$ \\
\hline Pertussis & $222(63.2)$ & $92(63.9)$ & $1.03(0.69-1.54)$ & $222(63: 2)$ & $78(6.5 .5)$ & $1.1 \|(0.72 \cdot 1.71)$ \\
\hline Measles. & $336(95.7)$ & $142(98.6)$ & $3.17(0.72-14.04)$ & $336(95.7)$ & $115(96.6)$ & $1.28(0.42-3.95)$ \\
\hline Rubella & $274(78.1)$ & $105(72.9)$ & $0.76(0.48-1.18)$ & $274(78.1)$ & $87(7.3 .1)$ & $0.76(0.47-1.23)$ \\
\hline Hib & $154(43.9)$ & $58(40.3)$ & $0.86(0.58-1.28)$ & $154(43.9)$ & $56(47.1)$ & $1.14(0.75-1.73)$ \\
\hline
\end{tabular}


However, these latter studies found a protective effect in children from ethnic origin $[15,16]$. Also, a Finnish study conducted among adults, using an asthma definition based on drug reimbursement registry data, found a protective influence of Mycobacteriwm tuberculosis infection on asthma in women; in contrast this infection was a risk factor for asthma in men [17].

As in most previous studies, $B C G$ vaccination was not associated with presence of respiratory symptoms at 7-8 years of age. Also, in accordance with the results of the German and Swedish studies $[15,16]$, we observed a (statistically nonsignificant) tendency toward lower frequency of diagnosis of asthma, hay fever, or eczema, as well as a lower frequency of antiasthma medication use among BCG-vaccinated children with asthmatic symptoms compared to non-BCG-vaccinated asthmatic children (data not shown). Factors associated with BCG vaccination, such as healthcare access, may partly explain these differences, because indication for BCG vaccination in Western countries may selectively identify a subgroup of children with characteristics differing from the rest of the population.

In Germany, until 1998, BCG vaccination was recommended for children from regions with high tuberculosis prevalence or close contact with persons at risk. This risk group approach resulted in a higher proportion of children from ethnic backgrounds to be BCG-vaccinated. However, most children $(>95 \%)$ in our study sample were of German or Dutch origin. Our results differ from previous results in that they tended toward a positive association between $B C G$ vaccination and sensitisation, especially against HDM.

Table 4. Odds ratios $(\mathrm{OR})$ and $95 \%$ confidence intervals $(95 \% \mathrm{Cl})$ for the association between risk factors and alopic disease*

\begin{tabular}{|c|c|c|c|c|}
\hline & \multicolumn{2}{|c|}{ Respiratory symptoms } & \multicolumn{2}{|c|}{ Allergic sensitisadion ** } \\
\hline & OR & $95 \% \mathrm{Cl}$ & $\mathrm{OR}$ & $95 \% \mathrm{Cl}$ \\
\hline Gender (male $v$ female) & 1.68 & $1.13-2.49$ & 2.68 & $1.76-4.09$ \\
\hline \multicolumn{5}{|l|}{ Birth ordert } \\
\hline anly younger silblings & 1.06 & $0.54 \times 2.08$ & 0.57 & $0.29-1.13$ \\
\hline 1 older sibling & 0.91 & 0.47 .1 .76 & 0.47 & $0.24-0.92$ \\
\hline 2 older siblings & 1.63 & $0.74 \cdot 3.60$ & $0: 40$ & $0.18-0.91$ \\
\hline$>2$ alder siblings & 0.95 & $0.30-3.02$ & 0.33 & $0.09-1.15$ \\
\hline BCGt & 1.17 & $0.63-2.19$ & 1.74 & $0.91-3.32$ \\
\hline Pertussist & 0.83 & $0.45-1.52$ & 0.89 & $0.47-1.70$ \\
\hline Measlest & 0.93 & 0.30 .2 .90 & 1.51 & $0.43-5.35$ \\
\hline Rubellat & 1.17 & $0.65-2.10$ & 0.85 & $0.46-1.57$ \\
\hline Hibt & 1.39 & $0.60-3.19$ & 0.74 & $0.30-1.79$ \\
\hline
\end{tabular}

\footnotetext{
-Adjusted for all other variables listed and for breastfeeding, exposure to environmental tobacco smoke, home dampness, pets, country of residence, socio-economic status, and childhood infections (measles ${ }_{n}$ mumps, rubella, varicella, and scarlet fever:

* Al least one specific loE $\geq 0.35 \mathrm{kU} /$

$\uparrow$ Reference calegory: risk factor not present
} 
Excluding children from ethnic backgrounds from the analysis did not greatly change the results. Other factors such as low birth weight or smoking during pregnancy did not explain the results.

In a prospectively followed birth cohort of German children, transient protection against atopy was observed in BCG-vaccinated children early in life [18]. However, for the proportion of positive specific IgE tests, the tendency towards lower proportion of positive tests in the BCG-vaccinated group compared to the non$B C G$-vaccinated group during the first 3 years of life was reversed later in life and reached statistical significance at 5 and 7 years of age. The authors suggested that the lack of an inverse association between $B C G$ vaccination and atopy at later age might be attributable to other environmental influences overriding an initial $\mathrm{BCO}$ effect [18]. In our study, environmental influences associated with HDM allergen exposure and subsequent sensitisation may have been associated with BCG vaccination, and may consequently have resulted in the higher risk for sensitisation against HDM in BCG-vaccinated children. Ethnicity and socio-economic status (SES) are associated with BCG vaccination in our study sample and may explain part of the positive association with HDM sensitisation, through higher levels of HDM allergen exposure. For the Netherlands it was recently reported that mean Der pl levels from mattress dust were three times higher among Moroccan immigrant children compared to Dutch children or Turkish immigrant children, and consequently sensitisation was also most frequent in Moroccan children [19].

Table 4 continued

\begin{tabular}{|c|c|c|c|}
\hline \multicolumn{2}{|c|}{ Sensitised against grasses } & \multicolumn{2}{|c|}{ Sensitised against HDM } \\
\hline $\mathrm{OR}$ & $95 \% \mathrm{Cl}$ & OR & $95 \% \mathrm{Cl}$ \\
\hline 3.44 & $2.05-5.76$ & 2.90 & $1.69-4.96$ \\
\hline 0.52 & $0.24-1.12$ & 0.74 & $0.30 \cdot 1.83$ \\
\hline 0.44 & 0.200 .95 & 0.75 & $0.31 \cdot 1.82$ \\
\hline 0.40 & $0.16-1.02$ & 0.69 & $0.24-1.97$ \\
\hline 0.20 & $0.04 \times 1.13$ & 0.29 & $0.05-1.71$ \\
\hline 1.95 & $0.89-4.31$ & 2.28 & $1.05-4.96$ \\
\hline 0.84 & $0.38=1.84$ & 1.02 & 0.462 .25 \\
\hline 2.85 & $0.45-18.08$ & 1.93 & $0.38-9.95$ \\
\hline 0.75 & $0.36-1.56$ & 0.89 & $0.41 \times 1.92$ \\
\hline 0.55 & $0.19-1.58$ & 1.14 & $0.33 \cdot 3.89$ \\
\hline
\end{tabular}


Besides ethricity or SES, other factors not accounted for in the present study may likewise be associated with factors (such as way of heating or presence of insulation measures) contributing to higher indoor HDM allergen levels.

The argument that vaccination presents a risk because it reduces natural infection is not a likely explanation for our finding. Protective effects of Mycobacterium tuberculosis infection in childhood on asthma and atopy were reported [17], but tuberculosis incidence in Germany is low, and none of the German subjects in the present study were reported to have a tuberculosis infection.

The inverse association of birth order with atopic manifestations seen in the present study was repeatedly found in many but not all studies $[11,20-22]$. It is at present uncertain which factors cause this birth-order effect. Our findings are in accordance with the "hygiene hypothesis" [20], but alternative explanations focusing on in utero programming and endocrine effects [23] have also been proposed.

After adjustment for various childhood infections (measles, mumps, rubella, chickenpox, and scarlet fever) the association with birth order remained, indicating that other infections than those adjusted for were responsible for this birth-order effect. However, sibling order may represent differences in timing or dose of exposure, as was suggested for measles infection in children from a British national birth cohort, in whom contact with older siblings seemed to be a prerequisite for a protective effect of measles [5]. In addition, birth order may represent factors other than exposure to infection, such as changes in in utero environment and in some of the mother's lifestyle characteristics likely to change with parity [23]. In our study sample, children from atopic mothers (self-reported asthma, hay fever, or eczema ever), especially children from asthmatic mothers, more often had no siblings and less often older siblings than children from non-atopic or non-asthmatic mothers. Furthermore, paternal asthma was not associated with number of siblings. Previously it was also observed that atopic mothers had a lower number of offspring, and since maternal atopy is a strong risk factor for childhood atopy, this could partly explain the association between atopy in the child and birth order [24]. Vaccinated and unvaccinated children may differ in other respects than those accounted for in the regression models. For instance, atopic parents may be more reluctant to vaccinate their children than non-atopic parents. In our data, we found no evidence of selective avoidance of vaccination of their child by parents with selfreported asthma.

A limitation of the present study design is that children were selected based on answers to questions about respiratory symptoms in previous surveys and sensitisation was determined afterwards in the case-control study. Analyses stratified by respiratory status showed no evidence of an association between atopic disease and vaccination in children with respiratory complaints or in children without complaints, and the elevated risk for HDM-sensitisation with BCG vaccination was seen only in children with respiratory symptoms. Also, the casegroup consisted of children with wheezing or coughing symptoms. However, most children $(75.0 \%)$ had ever had wheezing, and $43.7 \%$ reported suffering from wheezing in the past 12 months. Narrowing our definition of respiratory symptoms 
down to children with only asthmatic symptoms, recent wheezing at age $7-8$ years, or asthmatic symptoms already present at age 5 did not change the results. Failure to find a consistent relationship between childhood asthima and respiratory infections may lie in the lack of a clear phenotypic description of asthma [25]. If the same applies to vaccination, our case definition may have diluted possible vaccination effects. However, because of the low number of BCG-vaccinated children, the power to detect an association between BCG vaccination and sensitisation was low. Consequently the association must be strong to reach statistical significance.

Although we acknowledge the potential problem of misclassification of disease outcome when relying on parental reports, we used reported respiratory symptoms instead of asthma diagnosis because of the large differences in prevalence rates of diagnosis between German and Dutch children [26].

A large advantage of the present study was that exposure (vaccination) and outcome (atopic disease) were independently assessed, so information bias is not likely to have greatly influenced our data. Also, considering only children born in 1 year excluded age as an important confounder.

In conclusion, the results provide no evidence for an association between vaccination and respiratory symptoms. However, positive associations were found between early childhood $B C G$ vaccination and sensitisation to house dust mite. Further studies to elucidate the mechanisms underlying the effect of $\mathrm{BCG}$ vaccination on atopic disease are needed, as the possible role of mycobacteria in the prevention and treatment of atopic disease is currently being discussed. Earlier reports of an association of birth order with atopic disease were supported by the results of the present study.

\section{ACKNOWLEDGEMENTS}

The authors wish to thank R. Derkx, A.W. Jongmans-Liedekerken, P. Mertens, B. Ziemer and S. Riess for their cooperation in the study, and H.F. Merk and his team for specific $\operatorname{IgE}$ measurements.

\section{REFERENCES}

1. Strachan DP. Hay fever, hygiene, and household size. BMJ 1989;299(6710):1259-60.

2. Kramer U, Heinrich J, Wjst M, Wichmann HE. Age of entry to day nursery and allergy in later childhood. Lancet 1999;353(9151):450-4.

3. Ball TM, Castro-Rodriguez JA, Griffith KA, Holberg CJ, Martinez FD, Wright AL. Siblings, day-care attendance, and the risk of asthma and wheezing during childhood. $N$ Engl $J$ Med $2000 ; 343(8): 538-43$.

4. Aaby P, Shaheen SO, Heyes CB, Goudiaby A. Hall AJ, Shiell AW et al. Early BCG vaccination and reduction in atopy in Gumea-Bissau. Clin Exp Allergy 2000;30(5):644-50.

5. Lewis SA, Britton JR. Measles infection, measles vacination and the effect of birtly order in the aetiology of hay fever. Clin Exp Allergy 1998;28(12); 1493-500. 
6. Alm JS, Lilja $G$, Pershagen G, Scheynius A. Early $B C G$ vaccination and development of atopy. Lancet $1907,350(9075): 40003$.

7. Wickens $K$, Crane J, Kemp T, Lewis S, D'Souza W, Sawyer G et al. A case-control study of risk factors for asthma in New Zealand children. Austr N ZJ Public Heallh 2001;25(1):44-9.

8. DeStefano $\mathrm{F}$, Gu $\mathrm{D}$, Kramarz $\mathrm{P}$, Truman $\mathrm{BI}$, lademarco MF, Mullooly JP et al. Childhood vaceinations and risk of asthma. Pediatr Infect Dis $J 2002 ; 21(6): 498-504$.

9. Florey $\mathrm{C}$ du V, Leeder SR. Methods for cohort studies of chronic ainflow limitation. WHO Regional Publications Buropean Series. London, United Kingdom, 1982.

10. Asher MI, Keil U, Anderson HR, Beasley R, Crane J, Martinez F et al. Internationall Study of Asthma and Allergies in Childhood (ISAAC): rationale and meihods. Eur Respir $J$ $1995 ; 8(3): 483-91$.

11. Faroogi 1S, Hopkin JM. Early childhood infection and atopic disorder. Thorax $1998 ; 53(11): 927-32$.

12. Laubereau B, Grote $\mathrm{V}$, Holscher $\mathrm{G}$, Holscher $\mathrm{B}$, Frye $\mathrm{C}$, Wichmann HE et al. Vaccination against Haemophilus influenzae type b and atopy in East German schoolchildren. Eur I Med Res 2002;7(9):387-92.

13. Henderson $J$, North $K K_{\text {, Griffiths } M}$, Ularvey I, Golding J. Pertussis vaccination and wheezing Illnesses in young children: prospective cohort study. The Longitudinal Study of Pregnancy and Childhood Team. BMJ 1999;318(7192):1173-6.

14. Krause TG, Hviid A, Koch A, Friborg J, Hjuler T, Wohlfahrt $J$ et al. BCG vaccination and risk of atopy. JAMA 2003;289(8):1012-5.

15. Strannegard J.L, Larsson LO, Wennergren G, Strannegard O. Prevalence of allergy in children in relation to prior BCG vaccination and infection with atypical mycobacteria. Allergy $1998 ; 53(3): 249-54$.

16. Gruber $C$, Meinlschmidt $G$, Bergmann $R$, Wahn $U$, Stark $K$. Is early $B C G$ vaccination associated with less atopic disease? An epidemiological study in German preschool children with different ethnic backgrounds. Pedicar Allergy Immwol 2002;13(3):177-81.

17. won Hertzen L, Klaukka T, Mattila H, Haahtela T. Mycobacterium tuberculosis infection and the subsequent development of asthma and allergic conditions. I Allergy Clin Immunol $1999 ; 104(6): 1211-4$.

18. Gruber C, Kulig M, Bergmann R, Guggenmoos-Holzmann I, Wahn U. Delayed hypersensitivity to uberculin, total immunoglobulin E, specific sensitisation, and atopic manifestation in llongitudinally followed early bacille Calmette-Guerin-vaccinated and nonvaccinated children. Pediatrics 2001;107(3):E36.

19. Van Amsterdam JG, Bischoff EW, Hady M, Opperhuizen A, Steerenberg PA. The prevalence of allergic sensitisation in immigrant children in the Netherlands. Int Arch Allergy Immunol 2004;133(3):248-54.

20. Strachan DP. Family size, infection and atopy: the first decade of the "hygiene hypothesis". Thorat 2000;55 Suppl 1:S2-S10.

21. Pekkanen I, Remes $\mathrm{S}$, Kajosaari M, Husman T, Soininen L. Infections in early childhood and risk of atopic disease. Acta Paediat 1999;88(7):710-4.

22. Rasanen M, Laitinen T, Kaprio J, Koskenvuo M, Laitinen LA. Hay fever, asthma and number of older siblings - a twin study. Clin Exp Allergy 1997;27(5):515-8.

23. Karmaus $W$, Botezan $C$. Does a higher number of siblings protect against the development of allergy and asthma? A review. J Epidemiol Community Healih 2002;56(3):209-17.

24. Sunyer J, Anto JM, Harris J, Torrent M, Vall O, Cullinan P et al. Maternal atopy and parity, Clin Exp Allergy 2001;31(9):1352-5.

25. Holt $\mathrm{PG}_{\mathrm{G}}$ Sly $\mathrm{PD}$. Interactions between respiratory tract infections and atopy in the aetiology of asthma. Ent Respir $J$ 2002;19(3):538-45.

26. Weishoff-Houben $M$, Mommers $M$, Derkx $R$, longmans-liedekerken AW, Mertens P, Steup A et al. Prevalences of respiratory and allergic symptoms in children in the Dutch-German borderland. In J Hyg Environ Health 2001;204:278. 


\section{Childhood infections and risk of wheezing and allergic sensitisation at age 7-8 years}

M MOMMERS ${ }^{1,2}$

GMH SWAEN $N^{2,3}$

M WEISHOFF-HOUBEN'

HCREEMERS ${ }^{4}$

H FREUND

W DOTT'

CP VAN SCHAYCK ${ }^{2}$

"INSTITUTE FOR HYGIENE AND ENVIROMMENTAL MEDININ, RWTH AACHEN, GERMAGY

"DEPARTMENT OF GENERAL PRACTICE, CAPHRI, MAASTRICHT UNIVEFSTT, THE NETHERLANDS

"DEPARTMENT OF EPIDEMIOLOGY, CAPHRI, MAASTFICHT UINUEERITY, THE NETHERLANDS

"YOUTH HEALTH CARE SECTION, MUNICHPAL HEALTH SERWCE WESTELIUKE MIJNGTREEK, GELEEN,THE NETHERLAMDS

5Y YOUTH HEALTH CARE SECTION, MUNICHFAL HEALTH SEFWICE KrEISHEUHSBERG,

HEINSGERG;, GERMANY

EUR \& EPIDEMIOL 2004;19(10):945-5 I 


\section{ABSTRACT}

BACKGROUND: Childhood atopic disease has been associated with exposure to infections early in life. There is however considerable controversy on this issue, since evidence exists for both protective and adverse effects of infections. Aim of this study was to investigate the association between childhood infections and the occurrence of wheeze and allergic sensitisation in 7-8-year-old Dutch and German children.

METHODS: A nested case-control study was conducted among German and Dutch children participating in a large longitudinal study on respiratory health. Parents of 510 7-8-year-old children with respiratory complaints and an equal number of children without respiratory complaints were asked to complete a questionnaire. Blood samples were collected for specific serum Immunoglobulin (Ig) E analysis. Data on childhood infections were collected through records of the participating Municipal Health Services.

RESULTS: No association was found between recent wheeze and any of the childhood infections investigated. For scarlet fever infection an increased risk of allergic sensitisation $(\mathrm{OR}=2.82,95 \% \mathrm{CI}: 1.40-5.72)$ and sensitisation against grasses ( $O R=3.00,95 \% \mathrm{CI}: 1.35-6.69$ ) at the age of $7-8$ years was found. Varicella infection tended towards increased risk of sensitisation against grasses (OR $=1.88$, 95\% Cl: 0.99-3.58). For allergic sensitisation and sensitisation against grasses the odds ratios increased with increasing number of infections.

CONCLUSIONS: The results do not lend support to the suggestion that childhood infection protects against wheezing or allergic sensitisation at age 7-8 years. Scarlet fever or varicella infection presented an increased risk of allergic sensitisation. 


\section{INTRODUCTION}

The prevalence of atopic disease in children has increased in recent years and research has focused on identifying possible environmental causes. In about the same time period this increase among children occurred, a reduction in childhood infections has taken place in Western countries, as a result of increasing levels of vaccination. The possibility that childhood infections may protect against atopic disease [1] is supported by findings that relate birth order or day-care attendance, as indirect markers of increased infectious burden, to reduced risk of asthma and atopy $[2,3]$. Moreover the Th1/Th2 paradigm seems to provide a plausible immunological mechanism for the effect of early childhood infections on atopic manifestations, although it might be an oversimplification $[4,5]$.

The role of infections in the development of asthma and atopy is at present still unclear. Besides protective effects, infections have also been found to have adverse effects on atopic disease. The most frequent cause of asthma exacerbations in school-aged children is common colds [6]. Respiratory syncytial virus (RSV) infection in infancy has been linked with the subsequent development of asthma in 7-year-old children [7], as have lower respiratory tract infections, such as pneumonia and croup [8]. Besides the nature of the infection, the timing may also be of importance. Especially, the timing between infection and allergen exposure might be of great relevance [9] and could provide an explanation for the conflicting evidence concerning the effect of common childhood infections on the development of atopic disease. For Mycobacterium tuberculosis an inverse association with asthma was reported $[10,11]$ and for measles infection a reduced risk has been found for hay fever [12], skin prick test positivity to house dust mite [13] and adult onset doctor diagnosed asthma [14]. In contrast, a large Finnish study recently showed a significant increase in the prevalence of atopic disease after measles infection [15], whereas others found a weak or no association [16,17]. The results of the few studies investigating the possible association between varicella, rubella, mumps, or scarlet fever and atopic disease are likewise conflicting [8,16-19].

The present study was part of a large study on respiratory symptoms and allergies in children conducted in the Dutch-German borderland which offered the opportunity to investigate the association between childhood infections and the development of wheezing and allergic sensitisation. Differences in vaccination programme and vaccination coverage resulted in variation in infection rates for some infectious diseases between Germany and the Netherlands. We examined whether childhood infections are protective against the development of wheezing and allergic sensitisation at the age of $7-8$ years. 


\section{METHODS}

\section{Study population and study design}

A nested case-control study of participants in a longitudinal study on risk factors of respiratory symptoms in children was conducted in the Dutch-German borderland. In the part of the study presented here, the Municipal Health Services of the regions Kreis Heinsberg (Germany) and the Westelijke Mijnstreek (the Netherlands) participated. The Dutch region has approximately 170,000 inhabitants, while Heinsberg has approximately 250,000 inhabitants.

Children included in the case-control study, were recruited from the group of children that had previously participated in both the first (in 1995) and second survey (in 1997) of the study. In 1995, the parents of all 5052 children, born between November $30^{\text {th }} 1989$ and December $1^{\text {st }} 1990$ and living in the study area (Kreis Heinsberg, Germany or the Westelijke Mijnstreek, the Netherlands), were invited to participate in the first survey. Parents of 3871 children $(76.6 \%)$ returned the completed questionnaire on respiratory symptoms and diagnosis in 1995. In 1997, only 218 children (5.6\%) were lost to follow-up. Some of them had moved out of the study area or their forwarding address was unknown. Of the 3653 available children 2884 participated in 1997, resulting in a response rate of $78.9 \%$. Because of the elaborate and demanding data collection protocol, we preferred a case-control design for studying risk factors associated with respiratory symptoms in these children.

Children with respiratory symptoms as well as controls were selected based on the answers given in the first and second survey: 510 children with respiratory symptoms and an equal number of randomly chosen control children were eligible for participation in the case-control study.

\section{Data collection}

For both the first (in 1995) and second survey (in 1997), data were collected in May. In the autumn of 1997 the case-control study was conducted. Together with an invitation to a physical examination, questionnaires were sent to the parents of the children for self-completion. The physical examination was carried out by a team of four persons. At these physical examinations blood samples were taken for immunological analysis.

Data on childhood infections and vaccination status were obtained from the Youth Health Care Department of the participating Municipal Health Services. In the Netherlands, these childhood infections were registered during routine check-ups of the children. In Germany this was registered during the check-up of school beginners at the age of 5-6 years. Data were collected on measles, mumps, rubella, varicella and scarlet fever.

\section{Questionnaires}

The 1995 and 1997 surveys used identical questionnaires, with questions about respiratory symptoms taken from the WHO questionnaire [20]. To obtain data for the case-control study, an elaborate questionnaire was developed, including 
questions about respiratory symptoms and indoor environment. Questions about respiratory symptons were adopted from the International Study of Asthma and Allergies in Childhood ("ISAAC") questionnaire [21].

\section{Definitions}

Children meeting the following criteria were identified as cases: reported wheezing in the last 12 months and reported attacks of shortness of breath with wheezing in the last 12 months, or reported coughing in the moning or during the day or evening in the autumn and winter, and coughing daily for about 3 months a year, in 1995 or 1997. Control children had negative answers to all questions about respiratory symptoms in 1995 as well as in 1997 . This case definition was only used to select participants for the case-control study, to study the association between recent wheeze at 7-8 years of age and childhood infections, we used the question 'Has your child had wheezing or whistling in the chest in the last 12 months' from the third more detailed questionnaire in order to identify (case-)children with recent wheeze.

To study the association between childhood infection and allergic sensitisation, we additionally determined specific Immunoglobulin (Ig) $\mathrm{E}$ in the children included in the case-control study. Children were defined as sensitised if at least one specific $\operatorname{IgE}$ tested positive, irrespective of respiratory status. Children with specific $\operatorname{lgE}$ against grasses or specific IgE against house dust mite (HDM) were defined separately as sensitised against grasses or sensitised against HDM, respectively. For these analyses, controls were redefined as negative for all specific $\operatorname{IgE}$ tested.

Confounders were defined using corresponding questions from the questionnaire. Socio-economic status (SES) was defined according to highest level of education of the father or the mother. Environmental tobacco smoke (ETS), home dampness and pet keeping (cat, dog, bird or rodent), all consisted of three categories i.e., never, in the past or currently exposed. Breastfeeding was defined as never breastfed, breastfed for shorter than 3 months, or breastfed for at least 3 months.

\section{Blood sampling and determination of Immunoglobulin E}

Blood was taken from the cubital vein of the child. After $15 \mathrm{~min}$ at room temperature, blood samples were centrifuged for $10 \mathrm{~min}$ at $2000 \mathrm{~g}$. Sera were stored at $-20^{\circ} \mathrm{C}$ until further analysis.

Levels of specific IgE were measured using the Pharmacia CAP System (Pharmacia \& Upjohn Diagnostics AB, Uppsala, Sweden). Specific IgE against Dermatophagoides pteronyssinus, Dermatophagoides farinae, Cladosporium herbarum, Aspergillus fumigatus, Alternaria tenuis, chicken egg, cow's milk, cat and dog epithelium and a mix of grasses were measured and were regarded as positive if $\geq 0.35 \mathrm{kU} / \mathrm{l}$.

\section{Statistical analysis}

Univariate analyses were performed by cross-tabulation of variables and Chi-square tests were used to analyse differences. Multivariate logistic regression analysis was 
used to calculate the adjusted effect of each variable. In addition to infections, all regression models were adjusted for gender, maternal asthma, birth order, county of residence, socio-economic status, breastfeeding, exposure to environmental tobacco smoke, home dampness, pets and vaccination status (BCG, pertussis, measles, rubella and Haemophilus influenza type b (Hib))

All analyses were performed using SPSS PC Version 10.0 (SPSS Inc. IL, USA).

Table 1. Infection rates for the participating German and Dutch children

\begin{tabular}{lccc}
\hline Infection & $\begin{array}{c}\text { All } \\
n(\%)\end{array}$ & $\begin{array}{c}\text { German } \\
n(\%)\end{array}$ & $\begin{array}{c}\text { Dutch } \\
n(\%)\end{array}$ \\
\hline Measiles & $17(2.8)$ & $17(5.5)$ & - \\
Murnps & $6(1.0)$ & $6(1.9)$ & - \\
Rubella & $14(2.3)$ & $14(4.5)$ & - \\
Varicella & $459(76.4)$ & $223(71.9)$ & $236(81.1)$ \\
Scarlet fever & $57(9.5)$ & $48(15.5)$ & $9(3.1)$ \\
& & & \\
\hline
\end{tabular}

\section{RESULTS}

The parents of $775(76.0 \%) 7-8$-year-old children returned the completed questionnaire. In a total of 638 blood samples, specific IgE concentrations to all test allergens were determined: for one child specific IgE analysis was incomplete. For 38 of these children $(5.9 \%)$ we had no information on childhood infections. There were no large differences in response rates between cases and controls for the questionnaire $(75.1 \%, 76.9 \%)$ and for specific IgE analyses $(62.5 \% \vee 62.7 \%)$.

The frequencies of past measles, mumps and rubella infections were low in German children and none of these infections were reported for Dutch children (Table 1), due to high vaccination rates, especially in Dutch children of whom all had been waccinated against measles and mumps and $99.7 \%$ also had been vaccinated against rubella. Varicella infection was more prevalent in Dutch children $(81.1 \%)$ than in German children $(71.9 \%)$ whereas more of the German children $(15.5 \%)$ had had scarlet fever as compared with only $3.1 \%$ of the Dutch children (Table 1). Tables 2 and 3 show the crude odds ratios of the association between measles, mumps, rubella, varicella, and scarlet fever with recent wheeze, allergic sensitisation, sensitisation against grasses, or sensitisation against HDM in 7-8year-old children. For varicella a positive association with allergic sensitisation $(\mathrm{OR}=1.54,95 \% \mathrm{CI}: 1.03-2.30)$ and sensitisation against grasses $(\mathrm{OR}=1.90,95 \%$ Cl: 1.16-3.11) was seen. Also, a tendency towards increased risk with scarlet fever infection was observed for allergic sensitisation $(\mathrm{OR}=1.62,95 \% \mathrm{CI}: 0.94-2.80)$ and sensitisation against grasses $(\mathrm{OR}=1.70,95 \% \mathrm{CI}: 0.92-3.14)$. 
Table 2. Frequencies of measles, mumps, rubella, varicella and scantet fever in children with recent wheeze and in sensitised children and risk of atopic manifestations according to infection. Values are numbers (percentages)

\begin{tabular}{|c|c|c|c|c|c|c|}
\hline \multirow[b]{2}{*}{ Infection } & \multicolumn{3}{|c|}{ Recent wheeze } & \multicolumn{3}{|c|}{ Allergic sensitisation" } \\
\hline & $\begin{array}{l}\text { No wheeze } \\
\qquad(n=305)\end{array}$ & $\begin{array}{l}\text { Wheeze } \\
(n=112)\end{array}$ & OR $(95 \% \mathrm{Cl})$ & $\begin{array}{c}\text { No } \\
(n=369)\end{array}$ & $\begin{array}{c}\text { Yes } \\
(n=231)\end{array}$ & OR $(95 \% \mathrm{Cl})$ \\
\hline Measles & $8(2.6)$ & $6(5.4)$ & $2.10(0.71-6.20)$ & $8(2.2)$ & $9(3.9)$ & $1.83(0.70 .4 .81)$ \\
\hline Mumps & $4(1,3)$ & $1(0.9)$ & $0.68(0.08-6.13)$ & $3(0.8)$ & $3(1.3)$ & $1.61(0.32-8.02)$ \\
\hline Rubella & $6(2.0)$ & $5(4.5)$ & $2.33(0.70-7.79)$ & $9(2.4)$ & $5(2.2)$ & $0.89(0.29 \cdot 2.67)$ \\
\hline Varicella & $242(79.3)$ & $85(75.9)$ & $0.82(0.49-1.37)$ & $271(73.4)$ & $187(8.0)$ & $1.54(1.03-2.30)$ \\
\hline Scarlet fever & $25(8.2)$ & $15(13.4)$ & $1.73(0.88-3.42)$ & $29(7.9)$ & $28(12.1)$ & $1.62(0.94-2.80)$ \\
\hline
\end{tabular}

"Alleast one specific $\lg E \geq 0.35 \mathrm{kUM}$

The adjusted odds ratios (Table 4) showed a strong association between scarlet fever and allergic sensitisation. This association with scarlet fever was also found for children sensitised against grasses. Varicella also tended towards increased risk for sensitisation against grasses. As a consequence of the higher infection rates in German children, we additionally restricted the analyses to German children only, but this resulted in similar associations as presented in Table 4 .

Because children were selected for participation in the nested case-control study based on answers to questions about respiratory symptoms in previous surveys and sensitisation was determined afterwards in the case-control study, additional analyses stratified according to respiratory status were conducted. Scarlet fever remained a risk factor for allergic sensitisation in children with respiratory symptoms $(\mathrm{OR}=2.84,95 \% \mathrm{CI}: 0.92-8.74)$ and in children without respiratory symptoms $(\mathrm{OR}=3.25,95 \% \mathrm{Cl}: 1.11-9.56)$.

Table 3. Frequencies of measles, mumps, rubella, varicella and scarlet fever in children sensiltised against grasses and in children sensitised against HDM and risk of sensitisation against grasses or HDM according to infection. Values are numbers (percentages)

\begin{tabular}{|c|c|c|c|c|c|c|}
\hline \multirow[b]{2}{*}{ Infection } & \multicolumn{3}{|c|}{ Sensitisation against grasses } & \multicolumn{3}{|c|}{ Sensilisation against HDM } \\
\hline & $\begin{array}{c}\mathbb{N a} \\
(n=369)\end{array}$ & $\begin{array}{c}\text { Yes } \\
(n=150)\end{array}$ & OR $(95 \% \mathrm{Cl})$ & $\begin{array}{c}\text { No } \\
(n=369)\end{array}$ & $\begin{array}{c}Y \in S \\
(n=123)\end{array}$ & OR $(95 \% \mathrm{Cl})$ \\
\hline Measles & $8(2.2)$ & $4(2.7)$ & $1.24(0.37-4.17)$ & $8(2,2)$ & $5(4.1)$ & $1.91(0.61-5.96)$ \\
\hline Mumps & $3(0.8)$ & $3(2.0)$ & $2.49(0.50-12.48)$ & $3(0.8)$ & $1(0.8)$ & $1.00(0.10 .9 .70)$ \\
\hline Rubellai & $9(2.4)$ & $5(3.3)$ & $1.38(0.46-4.19)$ & $9(24)$ & $3(24)$ & $1.00(0.27-3.75)$ \\
\hline Varicella & $271(73.4)$ & $126(84.0)$ & $1.90(1.16-3.11)$ & $271(73.4)$ & $95(77.2)$ & $1.23(0.76-1.98)$ \\
\hline Scarlet fever & $29(7.9)$ & $19(127)$ & $1.70(0.92-3.14)$ & $29(7.9)$ & $13(10.6)$ & $1.39(0.70 .2 .76)$ \\
\hline
\end{tabular}


An elevated risk with sensitisation against grasses was seen for scarlet fever in children with respiratory symptoms $(\mathrm{OR}=4.09,95 \% \mathrm{Cl}: 1.15-14.62)$ but in children without respiratory symptoms this association was not statistically significant $(O R=1.90,95 \% \mathrm{Cl}: 0.46-7.85)$. Varicella tended towards increased risk for allergic sensitisation $(\mathrm{OR}=2.38,95 \% \mathrm{Cl}: 0.93-6.06)$ and sensitisation against grasses $(\mathrm{OR}=3.33,95 \% \mathrm{CI}: 0.90-12.32)$ in children without respiratory symptoms but not in children with respiratory symptoms.

Some confounders, such as maternal asthma, ETS, presence of pets or damp spots in the home were positively associated to recent wheeze, but when any one of these confounders was omitted from the analyses, the results remained as presented in Table 4. For allergic sensitisation, sensitisation against grasses, and sensitisation against HDM, leaving presence of damp spots in the home as confounder out of the analyses had the largest influence on the results; point estimates increased substantially for allergic sensitisation $(\mathrm{OR}=3.06,95 \% \mathrm{CI}: 0.83-11.26)$ and for sensitisation against $\mathrm{HDM}(\mathrm{OR}=4.99,95 \% \mathrm{Cl}: 1.07-23.24)$ with measles infection, and, for scarlet fever, odds ratios decreased for allergic sensitisation $(\mathrm{OR}=2.09$, $95 \% \mathrm{CI}: 1.07-4.05)$ and for sensitisation against grasses (OR=2.18, 95\% CI: $1.02-$ 4.65 ) but remained statistically significant.

Table 4. Odds ratios (OR) and $95 \%$ confidence intervals $(95 \% \mathrm{Cl})$ for the association between childhood infections and atopic manifestations

\begin{tabular}{|c|c|c|c|c|}
\hline \multirow[t]{2}{*}{ Infection } & \multicolumn{2}{|c|}{ Recent wheeze } & \multicolumn{2}{|c|}{ Allergic sensitisation ** } \\
\hline & OR & $95 \% \mathrm{Cl}$ & OR & $95 \% \mathrm{Cl}$ \\
\hline Measles & 0.81 & $0.13-5.13$ & 2.00 & $0.44-9.04$ \\
\hline Mumps & 0.75 & $0.07-8.40$ & 2.17 & $0.37-12.77$ \\
\hline Rubella & 1.82 & $0.30-12.39$ & 0.74 & $0.16-3.44$ \\
\hline Varicellia & 0.97 & $0.49-1.89$ & 1.47 & $0.88-2.47$ \\
\hline Scarlet fiever & 1.44 & $0.57-3.65$ & 2.82 & $1.40-5.72$ \\
\hline \multicolumn{5}{|c|}{ 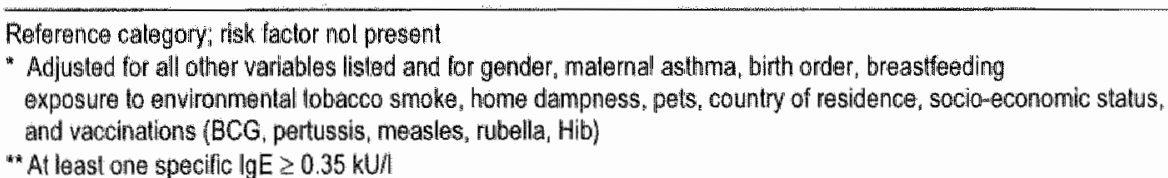 } \\
\hline
\end{tabular}

For allergic sensitisation and sensitisation against grasses the odds ratios increased with increasing number of infections (Table 5). In contrast, for recent wheeze this trend was not observed. Number of viral infections, was positively associated with sensitisation against grasses. 


\section{DISCUSSION}

The results of the present study show an increased risk of allergic sensitisation and sensitisation against grasses at the age of 7-8 years with scarlet fever infection in childhood. In contrast, no association between allergic sensitisation and mumps, measles or rubella infection was found. Recent wheeze was not associated with any of the childhood infections investigated.

Few studies have looked at scarlet fever or varicella in relation to atopic manifestations. A German study found no significant effect of bacterial infections (as a group, including scarlet fever), but reported a protective effect of viral infections of the herpes type (including varicella) on asthma at age 7 [8]. Additionally, no association with atopy or a slightly increased risk of asthma following varicella infection have also been reported [16-19]. The results of the present study show a positive association of scarlet fever infection with sensitisation against grasses, likewise varicella infection tended towards increased risk with sensitisation against grasses. In contrast, no association between these infections and wheezing at 7-8 years of age was observed.

Table 4 continued

\begin{tabular}{|c|c|c|c|}
\hline \multicolumn{2}{|c|}{ Sensitised against grasses } & \multicolumn{2}{|c|}{ Sensitised against $\mathrm{HDM}$} \\
\hline OR & $95 \% \mathrm{Cl}$ & OR & $95 \% \mathrm{Cl}$ \\
\hline 1.45 & $0.21-10.13$ & 3.45 & $0.61-19.73$ \\
\hline 4.41 & $0.59-28.84$ & 1.59 & $0.14-18.44$ \\
\hline 1.16 & $0.24-5.62$ & 1.38 & $0.29-6.64$ \\
\hline 1.88 & $0.99-3.58$ & 1.12 & $0.61-2.08$ \\
\hline 3.00 & $1.35-6.69$ & 2.19 & $0.91-5.29$ \\
\hline
\end{tabular}

For measles infection a decreased risk thas been reported for hay fever [12], skin prick test positivity to house dust mite [13], and adult onset doctor diagnosed asthma [14]. 
A large Finnish study however, showed a significant increase in the prevalence of atopic disease with measles infection [15]. Corresponding with the results of the present study, others also found no association between measles infection and atopic manifestations $[16,17]$.

Because of high vaccination rates for measles $(>95 \%)$, measles infection was scarce in our study, which may consequently have lacked the power to detect an effect of measles infection on wheeze or allergic sensitisation. The same applies to rubella and mumps. Most children vaceinated against measles had also been vaccinated against mumps and rubella, using combined measles, mumps and rubella (MMR) vaccine.

For the Dutch children MMR coverage was almost $100 \%$, in contrast although over $90 \%$ of the German children had been vaccinated against mumps and measles, only about half of the German children had been vaccinated against rubella.

Microbial burden in general rather than single infections has been suggested to be of greater importance for the regulation of immune responses in early life [22]. This is supported by findings that relate birth order or day-care attendance to reduced risk of atopic disease [2,3], as well as by the observation that in German children total number of infections in the first three years of life was inversely related to asthma diagnosis, current wheezing and bronchial hyperreactivity [8]. In contrast, different studies have reported significantly increased risk of atopic disease with increasing number of infections in the first 2 or 3 years of life $[18,19]$. Our results also show an increased risk of allergic sensitisation, especially sensitisation against grasses, but not of wheeze with increasing number of infections.

Table 5. Risk of atopic manifestations according to sum of infections*

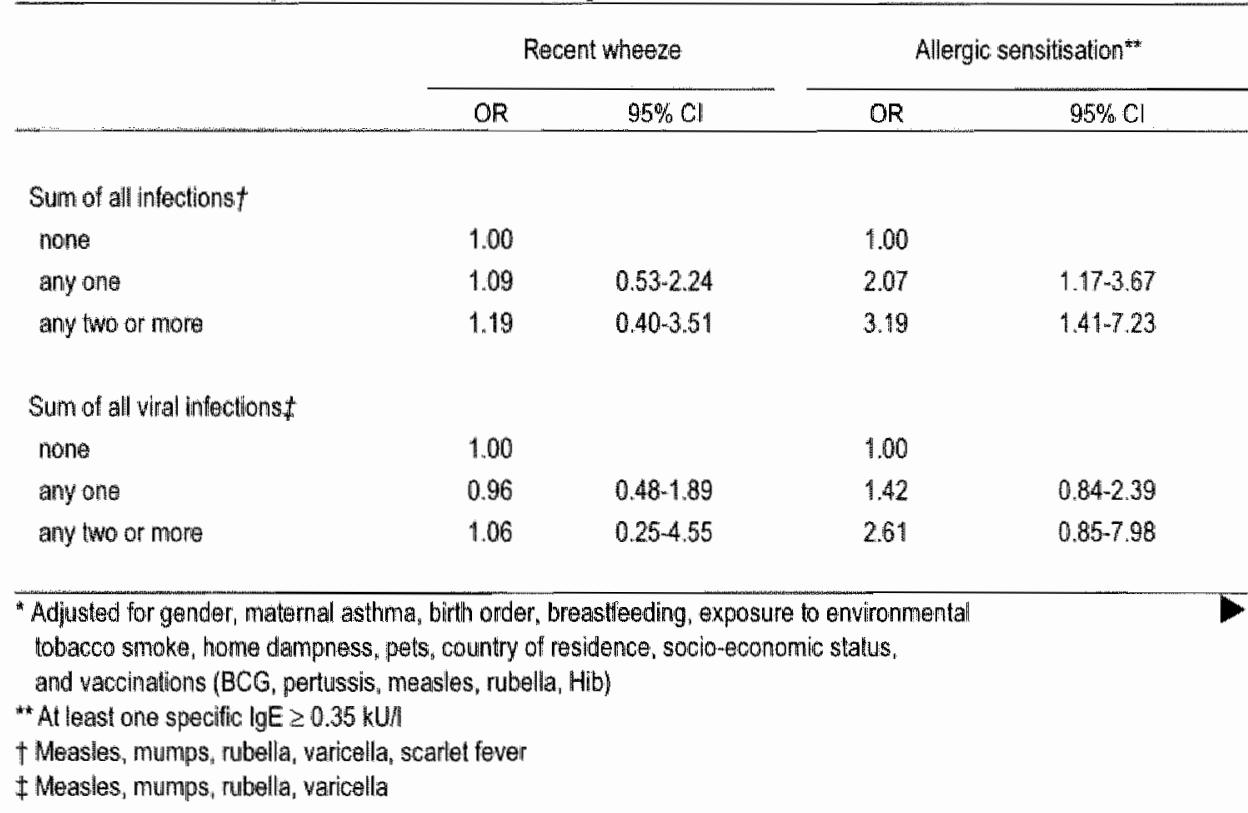


The same trend was observed when only viral infections were included in the analysis. Given the heterogeneous nature of wheeze (wheeze may not necessarily be atopy-related), our study may have had insufficient statistical power to detect an association between wheeze and infection.

As birth order and day-care attendance have been thought of as indirect markers of increased infectious burden, we investigated whether birth order or day-care attendance could explain increased exposure as studied in our sample. Total number of infections was not associated with birth order, but there was an association with day-care attendance. Children attending day-care more often had one or more infections $(82.2 \%)$ than children not attending day-care $(69.2 \%)$. This finding is in accordance with earlier reports that children attending day-care have more infections than children in home care [23]. Both decreased [2,3,24] and increased $[23,25]$ risk of atopic disease related to day-care attendance has been reported, and the effect is thought to be mediated through higher levels of exposure to infection at already an earlier age. We have no information on the age at childhood infection in our study sample, but scarlet fever infection is relatively uncommon before the age of three. Varicella may be acquired at any age, and it has been reported that varicella at least in Belgium [26], affects very young children since almost $50 \%$ of the 2-year-old children are immune. Also, a shift toward a decreased age at infection has recently been reported for Scotland [27]. Kindergarten and pre-schoolage-mixing patterns are believed to play a crucial role in the spread of these infections [26].

Table 5 continued

\begin{tabular}{|c|c|c|c|}
\hline \multicolumn{2}{|c|}{ Sensitised against grasses } & \multicolumn{2}{|c|}{ Sensitised against HDM } \\
\hline OR & $95 \% \mathrm{Cl}$ & OR & $95 \% \mathrm{Cl}$ \\
\hline 1.00 & & 1.00 & \\
\hline 2.46 & $1.20-5.03$ & 1.41 & 0.722 .74 \\
\hline 4.86 & $1.83-12.92$ & 2.36 & $0.89-6.27$ \\
\hline 1.00 & & 1.00 & \\
\hline 1.69 & $0.89-3.21$ & 1.11 & $0.59-2.09$ \\
\hline 4.41 & $1.28-15.23$ & 3.05 & $0.82-11.29$ \\
\hline
\end{tabular}


It has been proposed that for the protective effect of infections on the development of atopy, the first months of life may be essential, whereas infections later in life may trigger symptoms [28]. In most children in our study sample exposure to infection may have simply occurred too late in childhood to have a protective influence.

A major strength of the present study is that exposure and outcome were independently assessed. Moreover, allergic sensitisation was assessed objectively by measuring specific IgE. Therefore, information bilas is not likely to have influenced our data largely. Also, by considering only children born in the same year, age was excluded as an important confounder. Furthermore, all children born in the same year and living in the study area were enclosed in the study, and all children with respiratory symptoms according to the definition used in the present study were invited to participate in the nested case-control study. This approach ensured a high number of study participants and high response rates were attained for all parts of the study. Also, as a result of the longitudinal follow-up, respiratory symptons were addressed at three occasions ensuring a more certain case definition as well as control definition.

Several limitations to our findings should be taken into account. First, we relied on parental reporting of symptoms. Only recent symptoms were used to prevent recall bias as much as possible. Although we are aware of the potential problem of random misclassification of disease outcome, we used reported symptoms instead of asthma diagnosis because of large differences in diagnosis rates between the German and Dutch children in our study sample.

Second, we have no serological ascertainment of parent's reports on clinical infection in their child. However, chickenpox, for example, is quite easy to recognise and mother's reports of chickenpox correspond well with serological results [29]. Also, infections with a subclinical course may have been missed, potentially leading to misclassification of exposure. Especially, in the case of rubella infection this may present a problem because about half of the infections are believed to be asymptomatic, particularly in very young children. However, this misclassification most likely is non-differential and resulted in bias towards null.

A third potential problem concerns the heterogeneity of the label 'scarlet fever'. For Germany scarlet fever has been defined as streptococcus infection (mostly pharyngitis) accompanied by a characteristic exanthema caused by streptococcal exoloxine [30]. However, in clinical practice more atypical disease patterns are also labelled as scarlet fever, and this may explain the higher prevalence rates in Germany compared to the Netherlands. When Dutch children were excluded from the analyses, scarlet fever remained a risk factor in German children.

If children with atopic predisposition are more susceptive for acquiring infections or have more pronounced clinical symptoms, a spurious association between atopic manifestations and infection could have occurred in our analysis. However, in our data, parents with self-reported asthma tended to report fewer infections for their child than parents without asthma, except for scarlet fever which was reported significantly more for children of parents with self-reported asthma. Also, when 
adjusted for maternal asthma, odds ratios for individual infeotions differed little from odds ratios not adjusted for maternal asthma.

In conclusion, the results do not lend support to the suggestion that childhood infection protects against wheezing or allergic sensitisation. Scarlet fever or varicella infection presented an increased rather than decreased risk of allergic sensitisation.

\section{ACKNOWLEDGEMENTS}

The authors wish to thank R Derkx, AW Jongmans-Liedekerken, P Mertens, B Ziemer and $S$ Riess for their cooperation in the study, and HF Merk and his team for specific $\operatorname{IgE}$ measurements. The study was financially supported by the European Union, the Euregio Maas-Rhine (Interreg II project EMR.INT2.96.09.V.039), the Land Northrhine-Westphalia, the Province of Limburg and the counties of Heinsberg, Midden-Limburg and Westelijke Mijnstreek.

\section{REFERENCES}

1. Strachan DP. Hay fever, hygiene, and household size. BMJ 1989;299(6710):1259-60.

2. Ball TM, Castro-Rodriguez JA, Griffith KA, Holberg C., Martinez FD, Wright AL. Siblings, day-care attendance, and the risk of asthma and wheezing during childhood. $N$ Engl $J$ Med $2000 ; 343(8): 538-43$.

3. Kramer U, Heinrich $\mathrm{J}$, Wjst $\mathrm{M}$, Wichmann HE. Age of entry to day nursery and allergy in later childhood. Lancet 1999;353(9151):450-4

4. Renz H, won Mutius E, Illi S, Wolkers F, Hirsch T, Weiland SK. T(H) $1 / T(H) 2$ immune response profiles differ between atopic children in eastem and western Germany. J Allergy Chin Immunol 2002;109(2):338-42.

5. Sheikh A, Smeeth L, Hubbard R. There is no evidence of an inverse relationship between TH2. mediated atopy and THI-mediated autoimmone disorders: Lack of support for the hygiene Inypothesis. J Allergy Clin Immunol 2003: 111(1):131-5.

6. Openshaw $\mathrm{PJ}_{\mathrm{s}}$ Hewit $\mathrm{C}$. Protective and harmfull effects of viral infections in childhood on wheezing disorders and asthma. Am , Respir Crit Care Med 2000;162(2Pt2):40-3.

7. Sigurs $N$, Bjarnason $R$, Sigurbergsson $F$, Kjellman B. Respiratory syncytiall virus bronchiolitis in infancy is an important risk factor for asthma and allergy at age 7. Am J Respir Crit Care Med 2000;161(5):1501-7.

8. Illi S, von Mutius E, Lau S, Bergmann R, Niggemann B, Sommerfeld C et al. Early childhood infectious diseases and the development of asthma up to school age: a birth cohort study. BMJ $2001 ; 322(7283): 390-5$.

9. Renz H, Herz U. The bidirectional capacity of bacterial antigens to modulate allergy and asthma. Eur Respir $J 2002 ; 19(1): 158-71$.

10. won Hertzen L, Klaukka T, Mattila H, Haahtela T. Mycobacterium tuberculosis infection and the subsequent development of asthma and allergic conditions. I A Mergy Clin Immowol $1999 ; 104(6): 12111-4$.

11. von Mutius $\mathbb{E}$, Pearce $N$, Beasley $R$, Cheng $S$, von Ehrenstein $O$, Bjorksten $B$ et all, Internathonal patterns of tuberculosis and the prevalence of symptoms of asthma, rhinitis, and eczema. Thorax 2000;55(6):449-53. 


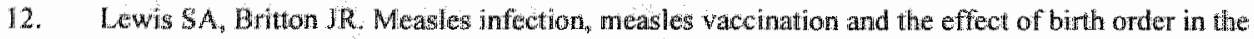
aetiology of hay fever. Chin Exp Allergy 1998;28(12):1493-500.

13. Shaheen $\mathrm{SO}$, Aaby P, Hall AJ, Barker DI, Heyes CB, Shiell AW et al. Meas.les and atopy in Guinea-Bissau. Lancer 1996;347(9018):1792-6.

14. Bodner C, Anderson WJ, Reid TS, Godden DJ. Childhood exposture to infection and risk of adult onset whete and atopy. Thorax 2000;55(5):383-7.

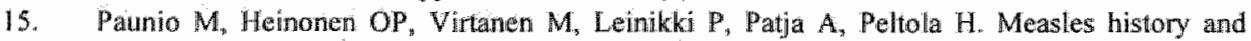
atopic diseases: a population-based cross-sectional study. JAMA 2000;283(3):343-6.

16. Matricardi PM, Rosmini F, Riondino S, Fortini M, Ferrigno L, Rapicetta M et al. Exposure to foodborne and orofecal microbes versus airborne viruses in relation to atopy and allergic asthma: epidemiological study. BMI 2000;320(7232):412-7.

17. Faroogi IS, Hopkin IM. Early childnood infection and atopic disorder. Thorax 1998;53(11):927-32.

18. Bager $\mathrm{P}$, Westergaard $\mathrm{T}$, Rostgaard $\mathrm{K}$, Hjalgrim $\mathrm{H}$, Melbye $\mathrm{M}$. Age at childhood infections and risk of atopy. Thorax $2002 ; 57(5): 379-82$.

19. Bodner C Godden D, Seaton A. Family size, childhood infections and atopic diseases. The Aberdeen WHEASE Group. Thorex 1998;53(1):28-32.

20. Florey C du V, Leeder SR. Methods for Cohort Studies of Chronic Aimflow Limitation. WHO Regional Publications European Series No.12. London, United Kingdom, 1982.

21. Asher ML, Keil U, Anderson HR, Beasley R, Crane M, Martinez F et al. Intemational Study of Asthma and Allergies in Childhood (ISAAC): rationale and methods. Eur Respir $y$ $1995 ; 8(3): 483-91$.

22. Martinez FD. The coming-of-age of the hygiene hypothesis. Respir Res $2001 ; 2(3): 129-32$.

23. Nystad W, Skrondal A, Magnus P. Day care attendance, recurrent respiratory tract infiections and asthma. Int If Eidemiol 1999;28(5):882-7.

24. Infante-Rivard $C_{4}$ Amre D, Gautrin D, Malo IL. Family size, day-care attendance, and breastfeeding in relation to the incidence of childhood asthma. Am $J$ Epidemiol $2001 ; 153(7): 653-8$

25. Pekkanen J, Remes $S$, Kajosaari M, Husman T, Soininen L. Tnfections in early childhood and risk of atopic disease. Acta Paediatr 1999;88(7):710-4.

26. Thiry $N$, Beutels $P$, Shkedy $Z$, Vranckx $R$, VarnderMeulen $C$, Wielen MV et al. The seroepidemiology of primary varicella-zoster virus infection in Flanders (Belgium). Eur $J$ Pediatr 2002;161(1 1):588-93.

27. Bramley JC, Jones IG. Epidemiology of chickenpox in Scotland: 1981 to 1998. Commum Dis Public Healh $2000 ; 3(4): 282-7$.

28. von Mutius E. Infection: friend or foe in the development of atopy and asthmat? The epidemiological evidence. Eur Rexpir J 2001;18(5):872-81.

29. Poulsen A, Qureshi K, Lisse I, Kofoed PE, Nielsen J, Vestergaard BF et al. A household study of chickenpox in Guinea-Bissau: Intensity of exposure is a determinant of severity. $I$ Infect $2002 ; 45(4): 237-42$.

30. Robert Koch Institut. Ratgeber Infektionskrankheiten: Scharlach und andere Infektionen durch Streptococcus pyogenes. Epid Bull 2000;43;343-5. 


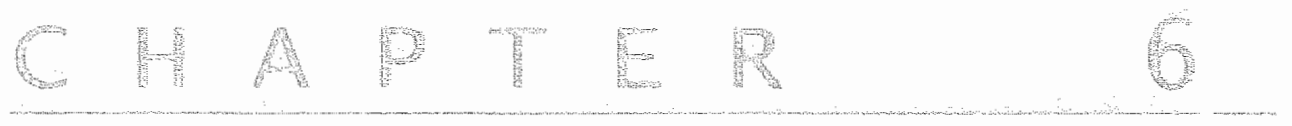

\title{
Indoor environment and respiratory symptoms in children living in the Dutch-German borderland
}

\author{
M MOMMERS $S^{1.2}$ \\ A JONGMANS-LIEDEKERKEN ${ }^{3}$ \\ R DERKX \\ W DOTT' \\ P MERTENS \\ CP VAN SCHAYYKK \\ A STEUP' \\ $G M \mathbb{H}$ SWAEN $^{2,6}$ \\ B ZIEMER \\ M WEISHOFF-HOUBEN'
}

\footnotetext{
'INSTITUTE FOR HYGIENE AND ENVIRONMENTAL MEDICINE. RWTH AACHEIN, GEMAMANY "DEPAFTMENT OF GENERAL PRACTICE, CAPHRI, MAASTRICHT UNIVERSITY" THIE NETHERLANDS "MUNICIPAL HEALTH SERVICES LIMBURG" THE NETHEFLANDS MMUNICIPAL HEALTH SERWICE. WESTELIJKE MIINSTIREEK, GELEEN, THE NETHERLANDS "MUMICIPAL HEALTH SERWICE MIDDEN-LIMQUFG, ROEFMOND, THE NETHERHARDS "DEPARTMENT OF EPIDEMIOLOGT, CAPHRI, MAASTRICHT UNIVERSITY, THE METHERLANOS "MUNICIPAL. HEALTH SERWICE KREIS HEINSBERG, HERASEERG, GERMANY
} 


\section{ABSTRACT}

OBJECTVE: To investigate the relation between indoor environmental risk factors and respiratory symptoms in 7-8-year-old children living in the Dutch-German borderland.

METHODS: A nested case-control study was conducted among children participating in a large longitudinal study on respiratory health. Parents of all 78\7-8-year-old children with respiratory complaints and an equal number of randomly selected controls were asked to complete a questionnaire, including questions on indoor environment.

RESULTS: The parents of 1191 children $(76.2 \%)$ participated. Past exposure to environmental $(\mathrm{OR}=2.73,95 \% \mathrm{Cl}: 1.14-6.67)$ as well as in utero exposure $(O R=2.28,95 \% \mathrm{Cl}: 1.15-4.53)$ to tobacco smoke, the use of an unvented geyser for water heating ( $\mathrm{OR}=3.01,95 \% \mathrm{Cl}: 1.21-7.56)$, long-term exposure to dampness $(\mathrm{OR}=2.98,95 \% \mathrm{Cl}: 1.10-8.28)$ or pets $(\mathrm{OR}=2.18,95 \% \mathrm{Cl}: 1.39-3.42)$ increased the risk of asthmatic symptoms in 7-8-year-old children. A middle or low socioeconomic status also increased the risk of asthmatic symptoms. An inverse association with asthmatic symptoms was seen for wall-to-wall carpeting $(\mathrm{OR}=0.57,95 \% \mathrm{Cl}: 0.33-0.95)$ and insulation measures $(\mathrm{OR}=0.46,95 \% \mathrm{CI}: 0.25-$ 0.83 ). Except for the presence of an unvented geyser these factors also presented a risk for coughing symptoms in children.

CONCLUSION: This study showed an increased risk of respiratory symptoms in children exposed to several indoor environmental risk factors. 


\section{INTRODUCTION}

Differences in asthma symptom prevalence have been observed between and within countries $[1,2]$, and it has been reported that the prevalence of asthma and other atopic diseases has increased in past decades $[3,4]$. The causes of these differences are at present still unclear and many factors thave been suggested to be involved, including childhood infections [5], dietary [6], and indoor as well as outdoor environmental factors. The pattern of asthma prevalence however indicates that outdoor air pollution is not a major risk factor for asthma in populations [2]. The quality of the indoor environment is likely to have a greater impact on the development of asthma. The relation between respiratory symptoms and indoor environmental pollutants, such as allergens, environmental tobacco smoke (ETS) and nitrogen dioxide $\left(\mathrm{NO}_{2}\right)$, has been subject of research for several years. In Western Europe, house dust mite exposure is considered to be an important risk factor for the development of respiratory symptoms. Sensitisation to dust mite allergen, and probably to mould, plays an important role in the relation between living in a damp home and respiratory symptoms [7]. Pets are another indoor source of allergens [8]. In addition, environmental tobacco smoke has also been recognised as a risk factor, especially in the case of maternal smoking [9]. Gas cooking and unvented gas appliances used for water heating are sources of $\mathrm{NO}_{2}$ in the home, and it has been suggested that gas cooking may affect respiratory health in atopic subjects [10].

The present case-control study was part of a large longitudinal study on respiratory symptoms conducted in the Dutch-German borderland, with municipal health services and universities from both countries cooperating in identifying risk factors associated with respiratory complaints, ultimately aiming to establish uniform prevention strategies for the Dutch-German region. Among others, healthcare setting differs between the German and Dutch region and may have resulted in a different approach to treatment and prevention of respiratory complaints. Preliminary analysis of the data already showed regional variation in distribution of indoor exposures [11]. As various studies have investigated the relationship between single indoor environmental factors and respiratory symptoms, the present study was designed to study a variety of indoor environmental exposures, such as damp housing but also housing characteristics (such as insulation and carpeting) and organic waste disposal (as a possible source of moulds) in households, with a special interest in identifying preventable risk factors for respiratory symptoms of importance for this region. The present case-control study was designed to investigate the role of indoor environmental risk factors on respiratory symptoms in 7-8-year-old children living in the Dutch-German borderland. 


\section{METHODS}

\section{Study population and study design}

As part of a large longitudinal study on respiratory health and indoor environment, among children living in the Dutch-German borderland, a nested case-control study was conducted. The borderland region covers the geographic area consisting of the municipal health regions Kreis Heinsberg (Germany), Midden-Limburg and the Westelijke Mijnstreek (the Netherlands). Together, the two Dutch regions have approximately 380,000 inhabitants, and Heinsberg has approximately 250,000 inhabitants.

Cases as well as controls were recruited from children who had previously participated in both the first (in 1995) and second (in 1997) survey of the study. In 1995 the parents of all 7201 childiren, born between November $30^{\text {th }} 1989$ and December $1^{\text {st }} 1990$ and living in the study area, were invited to participate in the first survey. Parents of 5692 children $(79.0 \%$ ) returned the completed questionnaire on respiratory symptoms and diagnosis in 1995. In 1997, 233 children (4.1\%) were lost to follow-up because they had moved out of the study area or their forwarding address was unknown. Of the remaining 5459 children, 4462 agreed to participate in 1997.

Because of the elaborate study protocol we preferred a case-control design for studying risk factors associated with respiratory symptoms. Cases as well as controls were selected based on the answers given in the first and second survey. Cases were defined as children with asthmatic symptoms (reported wheezing and attacks of shortness of breath with wheezing in the past 12 months) or coughing (reported coughing in the morning or during the day or evening, in the autumn and winter and coughing daily for about 3 months a year), in 1995 or 1997. Control children had negative answers to all the questions about respiratory symptoms in 1995 as well as in 1997. All 781 children fitting the case definition and an equal number control children were invited to participate in the case-control study. Simple random sampling, stratified by region, was used for selecting the control children.

\section{Data collection}

In the autumn of 1997 the case-control study was conducted. The questionnaires, together with an invitation to a physical examination, were sent to the parents of the children for self-completion. The physical examination was carried out by a team of four, native speaking persons, consequently leading to the formation of separate teams for Germany and the Netherlands. Prior to the data collection phase, these teams received detailed instructions about how to carry out the physical examination. Completeness of the questionnaire was checked by an assistant of the Municipal Health Service in the presence of one or both parents. When answers to questions were missing, the parents were asked to fill out the missing question at the physical examination. The assistants were not allowed to give additional information or give an explanation if asked, but only pointed out that answers to questions were missing. 
Information about the study was provided by the local authorities through a brochure. The study was approved by the medical ethics committee of the "Ärztekammer Nordrhein" in Germany.

\section{Questionnaire}

The 1995 and 1997 surveys used identical questionnaires, which included the WHO questions about respiratory symptoms [12]. To obtain data for the case-control study, a detailed questionnaire was developed, including questions about respiratory symptoms and indoor environment. Questions about respiratory symptoms were adopted from the International Study of Asthma and Allergies in Childhood ("ISAAC") questionnaire [13].

\section{Risk factors}

Categories of indoor environmental risk factors were defined using the corresponding questions from the questionnaire. For ETS, pet keeping (cat, dog, rodent, or bird) and mould or damp spots categories including duration of exposure were formed (i.e., never exposed, exposed for a short period, exposed for a long period, always exposed). Wall-to-wall carpeting consisted of three categories; wallto-wall carpeting not present in living room and child's bedroom, wall-to-wall carpeting present in living room or child's bedroom, wall-to-wall carpeting present in living room and child's bedroom. Insulation included double-glazing and door and window seals in the living room, child's bedroom, bathroom or kitchen. Hearth or open fireplace consisted of three categories (i.e., hearth or open fire place not present, used 1 or 2 times a month and used daily or weekly) and gas cooking of four categories (no gas cooking, gas cooking with cooker hood used daily, cooker hood used irregularly or cooker hood was not used). Way of water heating comprised the categories; no gasgeyser, vented gasgeyser and unverted gasgeyser. Organic waste removal from the home consisted of four categories, i.e., immediately, or once or twice daily removed, every two days removed, once a week removed and once every two weeks removed. Heating was defined as favourable when central heating or electricity was used and as unfavourable when coal, wood, gas or oil was used. Socio-economic status (SES) was defined as low, middle or high according to the highest level of education of the father or mother.

\section{Dara analysis}

As wheezing and coughing may have diverse pathophysiology with different risk factor patterns [14], we additionally studied asthmatic symptoms and coughing separately.

Crude associations between indoor environmental risk factors and respiratory symptoms were assessed and analysed using Chi-squared tests. Adjusted odds ratios (OR) were calculated using multivariate logistic regression. The logistic regression models included following variables; gender, smoking during pregnancy, ETS, presence of pets, mould or damp spots in the home, wall-to-wall carpeting, presence of insulation measures, hearth or open fire place, gas cooking, water heating, 
organic waste removal, way of heating, SES, and country of residence. In children with only one missing value for one of the variables in the logistic regression models, the missing value was replaced by the overall median value for the variable.

Analyses were performed using the Statistical Analysis System SAS version 6.12 for Windows (SAS Institute Ine., Cary, NC, USA).

\section{RESULTS}

The parents of $1191(76.2 \%) 7-8$-year-old children completed and returned the questionnaire of the case-control study. There were only marginal differences in overall response rates between cases $(75.5 \%)$ and controls $(77.0 \%)$. The percentage of males was higher in the case group (58.5\%) than in the control group (49.4\%). About $95 \%$ of the children were of German or Dutch nationality and did not differ largely between cases $(94.4 \%)$ and controls $(95.0 \%)$.

Table 1 describes the distribution of housing characteristics and indoor risk factors in the German and Dutch children.

Table 1. Housing characteristics and indoor risk factors currently present in the homes of $7-8$-year-old Dutch and German participants by case-control status

\begin{tabular}{|c|c|c|c|c|}
\hline & \multicolumn{2}{|c|}{ German children } & \multicolumn{2}{|c|}{ Dutch children } \\
\hline & $\begin{array}{c}\text { Cases } \\
(n=192)\end{array}$ & $\begin{array}{l}\text { Controls } \\
(n=203)\end{array}$ & $\begin{array}{c}\text { Cases } \\
(n=398)\end{array}$ & $\begin{array}{l}\text { Controls } \\
(n=398)\end{array}$ \\
\hline ETS & $106(56.4)$ & $P 8(39.0)$ & $204(51.5)$ & $176(44.4)$ \\
\hline Pets & $106(56.1)$ & $93(46.5)$ & $197(50.6)$ & $182(46.0)$ \\
\hline Mould or damp spots* & $44(23.8)$ & $21(10.6)$ & $83(21.2)$ & $54(13.7)$ \\
\hline Wall-to-wall carpoting** & $125(70.2)$ & $153(80.1)$ & $145(37.6)$ & $201(50.9)$ \\
\hline Insulation measurest & $131(70.4)$ & $151(74.4)$ & $356(90.4)$ & $372(93.5)$ \\
\hline Unfavourable way of heatingt & $13(7.9)$ & $8(4,4)$ & $12(3,4)$ & $10(2.7)$ \\
\hline Hearth or open fire place & $28(15.3)$ & $33(16.3)$ & $79(20.1)$ & $103(26.2)$ \\
\hline Gás cooulking & $7(3.8)$ & $4(2.0)$ & $268 \cdot(71.1)$ & $254(67.9)$ \\
\hline Gasgeyser used for water heafing & $34(20.0)$ & $39(20.4)$ & $360(93.0)$ & $352(90.0)$ \\
\hline Organic waste removalf & $39(22.5)$ & $49(25.8)$ & $163(42.4)$ & $188(49.0)$ \\
\hline
\end{tabular}

Data are presented as number of posilive responses with percentages between parentheses

Due to missimg observations numbers do not always add up to tota:

* Presence of mould or damp spots in the home in the past 12 months

* Present in living room and/or child's bedroom

+ Double glazing or door and windiow seals in living room, whilds bedroom, balhroom or kitchen

* Coal, wood, gas or oll

If Slored in the home for two days or longer 
For some indoor factors large differences were found between German and Dutel households; gas cooking, a gasgeyser used for water heating, and organic waste storage in the home for 2 days or longer were more prevalent among Dutch households whereas in more of the homes of German children wall-to-wall carpeting was present compared to homes of Dutch children, especially for children with respiratory symptoms.

We observed positive associations between the presence of respiratory symptoms and smoking during pregnancy, ETS, pets, dampness or mould growth, and a negative association with wall-to-wall carpeting in unadjusted analyses. For hearth or open fire place and organic-waste removal a weak negative association was observed (Table 2).

The adjusted odds ratios and $95 \%$ confidence intervals for risk factors associated with respiratory symptoms are shown in Table 3. Male gender was positively associated with the presence of respiratory symptoms, especially with asthmatic symptoms. Smoking during the first trimester of pregnancy presented a risk for the later development of respiratory symptoms in the child. ETS was related to respiratory symptoms, especially to asthmatic symptoms.

Pets in the home as well as presence of dampness or mould growth increased the risk of asthmatic symptoms and coughing. The use of an unvented geyser for water heating increased the risk of asthmatic symptoms. Also, a middle or low SES increased the risk of asthmatic symptoms as well as of coughing.

An inverse association was seen between respiratory symptoms and wall-to-wall carpeting in all regression models. Insulation, i.e., double-glazing and door and window seals, reduced the risk of asthmatic symptoms when they were concurrently present in the living room, children's bedrooms, kitchen and bathroom. No statistically significant association was found between way of heating, organicwaste removal from the home or gas cooking and respiratory symptoms.

\section{DISCUSSION}

The present study investigated the association between indoor environmental risk factors and respiratory symptoms in children. Environmental as well as in urero exposure to tobacco smoke, the presence of an unvented geyser for water heating, presence of mould or damp spots and presence of pets in the home, increased the risk of respiratory symptoms in 7-8-year-old children, while insulation and wall-towall carpeting reduced this risk.

Past ETS exposure was related to asthmatic symptoms, and tended toward a positive association with coughing. In several other studies, an association has been observed between ETS exposure and the development of wheeze [15], especially in (younger) children [16-18] and with maternal smoking [18]. In a systematic quantitative review of the evidence relating parental smoking to the prevalence of respiratory symptoms in school-aged children, Cook and Strachan reported pooled odds ratios of 1.24 for wheezing and 1.40 for coughing [19]. 
Table 2. Crude odds ratios (OR) and $95 \%$ confidence intervals $(95 \%$ Cl) for the association between risk factors and respiratory symptoms

\begin{tabular}{lcc}
\hline & OR* & $95 \% \mathrm{Cl}$ \\
\hline Smoking during pregnancy & 1.82 & \\
ETS & 1.92 & $1.40-2.36$ \\
Pet kesping & 1.56 & $1.51-2.44$ \\
Mould or damp spots & 2.33 & $1.22-1.99$ \\
Heating & 1.50 & $1.68-3.23$ \\
Wall-to-will carpeting & 0.60 & $0.81-2.78$ \\
Insulation & 0.78 & $0.48-0.76$ \\
Hearth or open fire place & 0.77 & $0.56-1.08$ \\
Gas cuoking & 1.17 & $0.58-1.02$ \\
Gasgeyser used for water heating & 1.18 & $0.93-1.48$ \\
Organic waste removal & 0.81 & $0.92-1.52$ \\
& & $0.64-1.03$ \\
\hline
\end{tabular}

"Present vabsent

In the present study, past exposure to ETS for a longer period of time increased the risk of respiratory symptoms more markedly than always being exposed. This may have been caused by the fact that the parents of children with (more severe) respiratory symptoms stopped smoking because of their child's complaints, or that they underreported their current smoking behaviour. However, from studies that used cotinine as a biological marker for exposure to ETS it has been concluded that questionnaire reports of parental smoking were accurate in terms of the dichotomy exposed-unexposed [20] and that the association between ETS and wheezing bronchitis was similar when either questionnaire data or urinary cotinine levels were used [17].

Adjustment for maternal smoking during pregnancy removed little of the effect of ETS exposure on respiratory symptoms. As smoking is often continued after delivery of the child, it is difficult to study in utero exposure to tobacco smoke independently of postnatal ETS exposure. The present study was not designed to investigate the independent effect of in utero exposure, but the results indicate an additional risk of smoking during pregnancy. Smoking during the first trimester of pregnancy was a risk factor for the later development of respiratory symptoms, especially for asthmatic symptoms, in the child. In other studies, in urero exposure to tobacco smoke was found to increase the occurrence of physician-diagnosed asthma [21], and was associated with reduced respiratory function after birth [22] and at school-age [23].

Gas cooking and unvented gas appliances used for (water)heating are sources of $\mathrm{NO}_{2}$ in the home. In the present study, a statistically significant association was found between heating water with an unvented geyser and asthmatic symptoms. Although we did not measure indoor $\mathrm{NO}_{2}$ levels directly but used the presence of 
gas appliances as a proxy, we expect exposure to $\mathrm{NO}_{2}$ in our study sample to be low. It is possible that $\mathrm{NO}_{2}$ only induces respiratory symptoms in children who are more sensitive to this exposure. In line with this, Kerkhof et al. suggested that gas cooking might only affect the respiratory health of atopic subjects [10]. In an Australian study, although not statistically significant, atopic children tended to be at greater risk of developing respiratory symptoms when exposed to gas stoves or $\mathrm{NO}_{2}$ than were non-atopic children [24].

Dampness and mould growth are known risk factors for respiratory symptoms. It has been speculated that dampness affects respiratory health through different mechanisms than ETS or $\mathrm{NO}_{2}$ [15]. Sensitisation to dust mites and possibly to mould, plays an important role in the relation between living in a damp home and childhood respiratory symptoms [7]. Strong associations have been found with coughing symptoms $[15,16,25]$ and with wheezing [26]. In the present study, dampness and mould growth was associated with asthmatic symptoms and with coughing; the association was somewhat stronger with coughing than with asthmatic symptoms.

Another source of indoor allergens is pets. The greatest risk of developing respiratory symptoms was associated with keeping pets indoors during the entire life of the child. A British study [27] also found an association with furry pets and wheezing in children. However, other studies did not find an association [28]. Rönmark and co-workers reported a decreased risk of asthma as well as of atopic sensitisation associated with pets, probably due to the avoidance of pets in families with a history of atopic diseases [29]. Results from a recent study suggest that exposure to dogs or cats in the first year of life may reduce a child's risk of allergic sensitisation [30]. It has been suggested that exposure to higher levels of house-hold pets associated bacterial endotoxin, may shift the developing immune system towards a $\mathrm{T}$ hellper cell $\mathbb{1}(\mathrm{Th} 1)$-type response, thus preventing allergic sensitisation [31]. As for pets, removal of wall-to-wall carpeting is often recommended as a preventive measure against asthmatic symptoms, because upholstered furniture and other soft surfaces, such as carpets, beds, etc, contain thigh concentrations of allergens [8]. This probably explains the inverse association with wall-to-wall carpeting found in the present study. Alternatively, simultaneously with removal of wall-to-wall carpeting, other decorating activities may have been carried out, such as painting, which have been reported to promote airways disease in small children at high risk for atopy [32]. We have no information about other decorating activities, or to the timing of these changes. However a substantial number of parents reported that the change in bedroom floor covering was a consequence of the child's respiratory complaints (for $51.3 \%$ of the Dutch children with respiratory complaints and for $42.9 \%$ of the German children with respiratory complaints), making the first explanation the more likely one.

Middle or low SES significantly increased the risk of respiratory symptoms. This may have been due to differing housing conditions, diagnosis rates, compliance to medication use, or the undertaking of preventive measures between the socioeconomic groups. 
Table 3. Odds ratos (OR) and $95 \%$ confidence intervals $(95 \% \mathrm{Cl}$ ) for the association between risk factors and respiratory symptoms:

\begin{tabular}{|c|c|c|c|c|c|c|}
\hline & \multicolumn{2}{|c|}{ All cases } & \multicolumn{2}{|c|}{ Asthmatic symptoms" } & \multicolumn{2}{|c|}{ Coughing } \\
\hline & OR & $95 \% \mathrm{Cl}$ & OR & $95 \% \mathrm{Cl}$ & $\mathrm{OR}$ & $95 \% \mathrm{Cl}$ \\
\hline \multicolumn{6}{|l|}{ Smoking during pregnancy } & $0.98-1.72$ \\
\hline 1 si timester & 1.79 & $1.00-3.27$ & 2.28 & 1.154 .53 & 1.74 & $0.94-3.26$ \\
\hline 2的 trimestien & 0.85 & $0.31-2.33$ & 0.99 & $0.29-3.19$ & 0.80 & $0.27 \times 2.32$ \\
\hline 3 an trimester & 1.21 & $0.83-1.78$ & 1.30 & $0.82-2.08$ & 1.20 & $0.80-1.80$ \\
\hline \multicolumn{7}{|l|}{ ETS } \\
\hline short period in the past & 1.28 & $0.88-1.89$ & 1.05 & $0.84-1.68$ & 1.44 & $0.96-2.16$ \\
\hline long period in the past & 2.36 & 1.12 .5 .18 & 2.73 & $1.14-6.07$ & 2.13 & 0.944 .93 \\
\hline always & 1.34 & $0.93-1.93$ & 1.18 & $0.75-1.84$ & 1.36 & $0.92 \cdot 2.01$ \\
\hline \multicolumn{7}{|l|}{ Pets } \\
\hline short period & 1.34 & $0.97-1.85$ & 1.21 & $0.81 \cdot 1.82$ & 1.56 & $1.10-2.20$ \\
\hline long period & 1.05 & $0.71-1.55$ & 1.32 & $0.83-2.10$ & 1.10 & $0.72-1.68$ \\
\hline always & 1.82 & $1.11-2.36$ & 2.18 & $1.39 \times 3.42$ & 1.64 & $1.09-2.46$ \\
\hline \multicolumn{7}{|l|}{ Mould or damp spots } \\
\hline short period & 1.99 & $1.32 \cdot 3.03$ & 1.97 & $1.21-3.22$ & 2,03 & $1.32-3.14$ \\
\hline Iong periad & 2.73 & $1.47-6.83$ & 2.98 & $1.10-8.28$ & 3.25 & $1.35-8.28$ \\
\hline always & 1.10 & $0.38-3.26$ & 0.76 & $0.21-2.57$ & 1.24 & $0.40-3,88$ \\
\hline \multicolumn{7}{|l|}{ Wall-to-wall carpeting } \\
\hline bedroom or liwing room & 0.53 & $0.40-0.70$ & 0.42 & $0.30-0.60$ & 0.51 & $0.38-0.69$ \\
\hline beadroam and liwing room & 0.68 & $0.44-1.05$ & 0.57 & $0.33-0.95$ & 0.63 & $0.39-1.00$ \\
\hline \multicolumn{7}{|l|}{ Insulation measurest } \\
\hline in 1 or 2 rooms & 0.90 & $0.57-1.42$ & 0.62 & $0.35-1.07$ & 1.01 & $0.62-1.66$ \\
\hline in 3 or 4 rooms & 0.85 & $0.57-11.28$ & 0.69 & $0.43-1.11$ & 1.00 & $0.64-1.57$ \\
\hline in 4 roons all measures. & 0.64 & $0.39-4.06$ & 0.46 & $0.25-0.83$ & 0.73 & $0.42-1.27$ \\
\hline \multicolumn{7}{|l|}{ Hearth or open fire place } \\
\hline used 1 or 2 times a month & 0.99 & $0.55-1.78$ & 0.74 & $0.31-1.62$ & 1.02 & $0.54-1.89$ \\
\hline used daily or weekly & 0.97 & $0.67-1.39$ & 1.22 & $0.79-1.88$ & 0.87 & $0.58-1.29$ \\
\hline \multicolumn{7}{|l|}{ Gas cooking with cooker hood } \\
\hline used dally & 0.93 & $0.65 \mathrm{~m} 1.33$ & 0.94 & $0.60-1.46$ & 0.93 & $0.64-1.36$ \\
\hline used irregularly & 1.48 & $0.82-2.67$ & 1.27 & $0.61-2.64$ & 1.49 & $0.80-2.78$ \\
\hline not used & 1.15 & $0.70-1.89$ & 1.25 & $0.69-2.26$ & 1.25 & $0.74-2.11$ \\
\hline \multicolumn{7}{|l|}{ Water heating } \\
\hline vênled gásgeyser & 1.23 & $0.83-1.81$ & 1.33 & $0.83-2.14$ & 1.28 & $0.85-1.94$ \\
\hline urvented gasgeyser & 1.93 & $0.88-4.34$ & 3.01 & $1.21-7.56$ & 1.74 & $0.74-4.12$ \\
\hline \multicolumn{7}{|l|}{ Orgenice waste removal } \\
\hline $\begin{array}{l}\text { oncly < deys } \\
\text { once a wetek }\end{array}$ & $\begin{array}{l}0.00 \\
0.78\end{array}$ & $\begin{array}{l}.04-1.15 \\
0.46-1.30\end{array}$ & 0.81 & $\begin{array}{l}0.7-1.43 \\
0.41-1.54\end{array}$ & 0.73 & $0.59-1.11$ \\
\hline once every 2 weeks & 0.63 & $0.11-3.60$ & 0.35 & $0.02-3.01$ & 0.54 & $0.07-3.42$ \\
\hline \\
\hline (unfavourable v favourable) & 1.41 & $0.69-2.92$ & 0.93 & $0.34 \times 2.37$ & 1.52 & $0.72 \times 3.23$ \\
\hline \multicolumn{7}{|l|}{ SES } \\
\hline middle $v$ high & 1.56 & 1.17 .2 .09 & 1.43 & $1.00-2.04$ & 1.53 & $1.12-2.10$ \\
\hline low $v$ high & 3.18 & $1.94-5.29$ & 3.32 & 1.88 .5 .93 & 3.37 & $2.01-5.71$ \\
\hline
\end{tabular}

Reference category: risk factor not present. For organic waste removal, reference category is 'immediate removal'

* Adjusted for all other wariables isted and country of residence

** Recent wheezing and recent attacks of wheezing with shortness of breath

† Double glazing or door and window seals in living room, child's bedroom, bathroom or kitchen 
Socio-economic differences in asthma diagnosis [33] and hospital admissions [34] have been reported, although others did not find a relation between diagnostic labelling and medication use and SES [35,36]. Mielck and co-workers concluded that no consensus exists in the literature concerning the association between childhood asthma and SES, probably because this association is strongly modified by the degree of asthma severity [37].

In the present study, parents with a low SES tended to report ever asthma, speechlimiting wheeze and sleep disturbance due to wheezing (at least one night a week) more often than parents with a middle or high SES. This might indicate socioeconomic differences in severity or alternatively, differences in parental perception or reporting of asthmatic symptoms between different socio-economic groups [36].

Response rates in this case-control study were high. No large differences were seen in response rates between the cases and controls. Knowledge of health outcome may have influenced parents" reporting of risk factors, and might have biased our results. We used reported respiratory symptoms for defining the cases instead of asthma diagnosis because there were large differences in diagnosis rates between the German and Dutch children in the present study [38]. In Dutch children, asthma diagnosis was more prevalent than in German children, whereas most of the German children were diagnosed with bronchitis.

In conclusion, this study showed an increased risk of respiratory symptoms in children with environmental or in utero exposure to tobacco smoke, exposure to dampness and mould growth, an unvented geyser used for water heating or pets.

\section{ACKNOWLEDGEMENTS}

The study was financially supported by the European Union, the Euregio MaasRhine (Interreg II project EMR.INT.2.96.09.V.039), the Land NorthrhineWestphalia, the Province of Limburg and the counties of Heinsberg, MiddenLimburg and Westelijke Mijnstreek.

\section{REFERENCES}

1. European Community Respiratory Health Survey. Variations in the prevalence of respirtory symptoms, self-reported asthma attacks, and use of asthma medication in the European Community Respiratory Health Survey (ECRHS). Eur Respir w/ 1996;9(4);687-95.

2. ISAAC Steering Committee. Worldwide variation in prevalence of symptoms of asthma, allergic rhinoconjunctivitis, and atopic eczena: ISAAC. The Intermational Study of Asthma and Allergies in Childhood (ISAAC) Steering Committee. Lancel 1998:351(9111):1225-32.

3. Omran $\mathrm{M}$, Russell $\mathrm{G}$. Continuing increase in respiratory symptoms and atopy in Aberdeen schoolchildren. BMJ 1996;312(7022):34.

4. Weiss KB, Gergen PJ, Wagener DK. Breathing better or wheezing worse? The changing epidemiology of asthma morbidity and mortality. Ammu Rev Public Health 1993;14:491-513.

5. Strachan DP. Family size, infection and atopy: the first decade of the "hygiene hypothesis". Thorax 2000;55 Suppl 1:2-10.

6. Ellwood P, Asher MI, Bjorksten B, Burt M, Pearce N, Robertson CF. Diet and asthma, allergic thinoconjunctivitis and atopic eczema symptom prevalence: an ecological analysis of the 
International Study of Asthna and Allergies in Childhood (SSAC) data. ISAAC Phase One Sidy Group. Eu Respir I 2001;17(9):43,6-43.

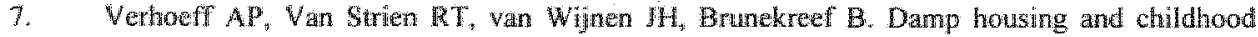
respiratory symptoms: the role of sernsitization to dust mates and molds. Awt $J$ Epidemiol $1995 ; 1412): 103-10$.

8. Woodcock $A_{r}$ Custovic A. ABC of allergies. Avoiding exposure to indoor allergens. BMJ $1998 ; 516(7137): 1075-8$

9. Murray $A B$, Morrison BS. Passive smoking and the seasional difference of severity of asthma in children. Chest 1988,94(4):701-8.

10. Kerkhof M, De Monchy IO, Rijken B, Schouten JP. The effect of gas cooking on bronchial hyperresponsiveness and the tole of immunoglobulin $\mathbb{E}$. Eur Respir $/ 1999 ; 14(4): 839-44$

11. Monmers M, Derkx R, Hahn A, Jongmans-Liedekerken AW, Mertens P, Steup A et al. Similar respiratory symptoms in Dutch and German children with different indoor exposure. Proceedings of Indoor Air "99. The $8^{\text {th }}$ International Conference on Indoor Air Quality and Climate. Construction Research Communications Lud, 1999, pp 489-94.

12. Florey $\mathrm{C}$ du V, Leeder SR, Methods for cohor studies of chronic arflow limilation. WHO Regional Publications European Series. London, United Kingdom, 1982.

13. Asher ML, Keil U, Anderson HR, Beasley $\mathrm{R}$, Crane J, Martinez F et al. Intermational Study of Asthma and Allergies in Childhood (ISAAC): rationale and methods. Eur Respir I 1995;8(3):483-91.

14. Wright AL, Holberg CJ, Morgan WJ, "laussig LM, Halonen M, Martinez FD. Recurrent cough in clildliood and its relation to asthma. Am J Respir Crir Care Med 1996;153(4 Pt 1):1259-65.

15. Dijkstra L, Houthuijs D, Brunekreef B, Akkerman I, Boleil IS. Respiratory health effects of the indoor environment in a population of Dutch children. Am Rev Respir Dis 1990;142(5):1172-8.

16. Cuipers CE, Swaen GM, Wesseling $G$, Sturnans $F$, Wouters EF. Adverse effects of the indoor environment on respiratory health in primary school children. Environ Res 1995;68(1):1 1-23.

17. Rylander E, Pershagen $G$, Eriksson $M$, Bermann G. Parental smoking, urinary cotinine, and wheezing bronchitis in children. Epidemiology 1995;6(3):289-93.

18. Stoddard $J$, Miller $T$. Impact of parental smoking on the prevalence of wheezing respiratory illness in chilldren. Am J Epidemiol 1995;141(2):96-102.

19. Cook DG, Strachan DP. Health effects of passive smoking. 3. Parental smoking and prevalence of respiratory symptoms and asthma in school age children. Thorax 1997;52(12):1081-94.

20. Tager IB. Health effects of "passive smoking" in children. Chest 1989,96(5):1 1.61-4.

21. Gilliland ED, Li YF, Peters JM. Effects of maternal smoking during pregnancy and environmental tobacco smoke on asthma and wheezing in children. Am J Respir Crit Care Med $2001 ; 163(2): 429-36$.

22. Stick SM, Burton PR, Gurrin 1 , Sly PD, LeSouef PN. Effects of maternal smoking during pregnancy and a family tistory of asthma on respiratory function in newborn infanis. Lamcet 1996:348(9034): $1060-4$.

23. Gilliland FD, Berhane $\mathrm{K}$, McConnell $\mathrm{R}$, Gauderman WJ, vora $\mathrm{H}$, Rappaport EB et al. Maternal smoking during pregnency, environmental tobacco smoke exposure and childhood lung function. Thor ax 2000;55(4):271-6.

24. Garrett MH, Hooper MA, Hooper BM, Abramson MI. Respiratory symptoms in children and indoor exposure to nitrogen dioxide and gas stoves. Am $J$ Respir Crit Care Med $1998 ; 158(3): 891-5$.

25. Dales RE, Zwanenburg $H$, Bumett $R$, Franklin $C A$. Respiratory health effects of home dampness and molds among Canadian children. Am J Epidemiol 1991;134(2):196-203.

26. Strachan DP. Damp housing and childhood asthma: validation of reporting of symptoms. BMI 1988:297(6658):1223-6.

27. Burr ML, Anderson HR, Austin JB, Harkins LS, Kaur B, Strachan DP et al. Respiratory symptoms and home environment in children: a national survey. Thorax 1999;54(1):27-32.

28. Hosein HR, Corey P, Robertson JM. The effect of domestic factors on respiratory symptoms and FEVI. Im J Epidemiol 1989;18(2):390-6. 
29. Ronmark E, Lundback B, Jonsson E, Platts-Mills T. Asthma, type-1 allergy and related conditions in 7- and 8-year-old children in northern Sweden: prevalence rates and risk factor pattern. Respir Med 1998:92(2):316-24.

30. Ownby DR, Johnson $\mathrm{CC}_{\mathrm{s}}$ Peterson EL. Exposure to dogs and cats in the first year of lite and risk of allergic sensitization at 6 to 7 years of age JAMA 2002;288(8),963-72.

31. Gereda JE, Leung DY, Thatayatikom A, Streib JE, Price MR, Klinnert MD of al Relation between house-dust endotoxin exposure, type \& T-cell development, and allergen sensitisation in infants at high risk of asthma. Lancet $2000 ; 355(9216): 1680-3$.

32. Diez U, Rehwagen M, Rolle-Kampczyk U, Wetzig H, Schulz R, Richter M et al. Redecowtion of apartments promotes obstructive bronchitis in atopy risk infants-mresults of the LARS Study. Int J Hyg Ewiron Health 2003;206(3):173-9.

33. Gergen P. Social class and asthma-distinguishing between the disease and the diagnosis. Am $J$ Public Health 1996;86(10):1361-2.

34. Asthma and respiratory symptoms in 6-7 yr old ltalian children: gender, latitude, urbanization and socioeconomic factors. SIDRIA (ltalian Studies on Respiratory Disorders in Childhood and the Environment), Eur Respir. $J 1997 ; 10(8): 1780-6$.

35. Janson $C$, Chinn $S$, Jarvis D, Bumey $\mathbb{P}$. Individual use of antiasthmatic drugs in the European Community Respiratory Health Survey. Eur Respir $J 1998 ; 12(3): 557-63$.

36. Strachan DP, Anderson HR, Limb ES, O'Neill A, Wells N. A national survey of asthma prevalence, severity, and treatment in Great Britain. Arch Dis Child 1994;70(3):174-8.

37. Mielck A, Reitmeir $P_{3}$ Wjst M. Severity of childhood asthma by socioeconomic starus. Ini $J$ Epidemiol 1996:25(2):388-93.

38. Mommers M, Swaen GM, Weishoff-Houben $M$, Dott $W$, van Schayck CP. Differences in asthma diagnosis and nedication use in children living in Germany and the Netherlands. Prim Care Resp J 2005;14:31-7. 


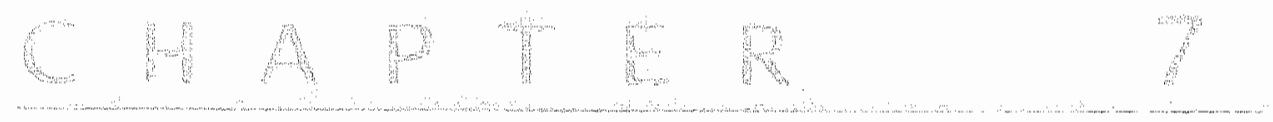

\title{
Different risk factor patterns for asthmatic symptoms in atopic and non-atopic Dutch and German children
}

\author{
M MOMIMERS \\ $P$ MERTENS \\ R DERKX ${ }^{4}$ \\ W DOTT" \\ A JONGMANS-LIEDEKERKEN ${ }^{5}$ \\ GMH SWAEN ${ }^{2.65}$ \\ CP VAN SCHAYCK ${ }^{2}$ \\ B ZIEMER \\ M WEISHOFF-HOUBEN
}

\footnotetext{
'INSTITUTE FOR HYGIENE AND ENYIRONMENTAL MEDHCINE, RWTH AACHEN, GEHMANY DEPARTMENT OF GENERAL PRACTICE, CAPHRI, MAASTRICHT UNIVERSITY, THE NETHERLANDS "MUNICIPAL HEALTH SEFWICE MIDDEN-LIMBURG, ROERMOND, THE METHERLANDS "MUNICIPAL HEALTH SEFWICE WESTELIWE MIJNSTREEK, GELEEN, THE NETHERLANOS "MUNICIPA HEALTH SEFWICES LIMBURG. THE NETHERLANDS "DEPARTMENT OF EPIDEMIOLOGY, CAPHRI, MAASTRICHT UNIVERSITY, THE NETHERLANDS MUNICIPAL MEALTH SERWICE KREIS HEINSBERO, HEINSEERG, GERMANT
} 


\section{ABSTRACT}

BACKGROUND: Although little is known about the pathogenesis of asthma, it has become clear that childhood asthma is a phenotypically heterogeneous disease and different atopic and non-atopic wheezing syndromes have been described, which may not share the same aetiology and prognosis.

OBJECTIVE: The aim of this study was to investigate whether risk factor patterns for asthmatic symptoms differed between atopic and non-atopic children aged 7-8 years old.

METHODS: A nested case-control study was conducted among German and Dutch children participating in a large longitudinal study on respiratory health. Parents of 465 7-8-year-old children with asthmatic symptoms and 781 7-8-year-old children without symptoms were asked to complete a questionnaire. Blood samples were collected to determine total and specific serum IgE.

RESULTS: Atopic children appeared to have more severe symptoms and had more often used medication in the year preceding the survey than non-atopic subjects. Male gender and maternal asthma were significant risk factors for asthmatic symptoms in atopic children but not in non-atopic children. Breastfeeding increased the risk of persistent asthmatic symptoms (OR=2.75, 95\% Cl: $1.14-6.65)$ and of recent wheeze $(\mathrm{OR}=2.73,95 \% \mathrm{Cl}: 1.20-6.21)$ only in atopic children. Presence of mould or damp spots in the home at $2-5$ years of age was positively associated with asthmatic symptoms $(\mathrm{OR}=3.81,95 \% \mathrm{Cl}: 1.23-11.84)$ and with recent wheeze $(\mathrm{OR}=4.82,95 \% \mathrm{Cl}: 1.07-21.74)$ in non-atopic children. Recent wheeze was positively associated with exposure to environmental tobacco smoke in the first two years of life $(\mathrm{OR}=2.63,95 \% \mathrm{Cl}: 1.11-6.27)$ in non-atopic children. Presence of a cat or a dog was not associated with asthmatic symptoms or wheeze in 7-8-year-old children.

CONCLUSION: The results of the present study suggest that risk factor patterns for asthmatic symptoms and severity of disease differ between atopic children and nonatopic children. Future research should take into account this heterogeneity, especially when planning prevention strategies as risk factors may act differently in the various asthma subgroups. 


\section{INTRODUCTION}

Childhood asthma is a heterogeneous disease with wheezing as its most conmon clinical expression. It has been reported that at least two different wheezing syndromes coexist in young children [1] and a classification of distinct subphenotypes based on atopy has also been described [2]. It has become routine to describe asthma as an atopic disease although epidemiological evidence suggests that the population-based proportion of asthma cases that are attributable to atopy is less than half [3]. Various studies have reported an increased prevalence of asthma symptoms in recent years $[4,5]$ and it has been suggested that this increase is mainly in children from families without a strong history of atopic disease [6]. A Norwegian study found a disproportionate increase in prevalence of asthma in children without other atopic diseases compared to children with other atopic diseases [7]. A dissociation between mechanisms involved in the pathogenesis of asthma and factors operating in the development of allergy was pointed out in a German study [8].

Outdoor air pollution, particularly from diesel exhaust particles as well as indoor environmental factors, diet, and childhood infections have been implicated as risk factors for atopic diseases [9-12]. Especially early life events have been suggested to have an important influence on the later development of atopic disease. Atopic and non-atopic forms of wheeze may be associated with different risk factors and prognosis. Few studies on aetiology of respiratory disease have taken this heterogeneity into account. The studies that have, indicated differences in risk factor patterns between the asthma subgroups although no clear picture emerged due to differing atopy definition, outcome measures, and risk factors investigated $[2,13,14]$. However, if risk factors affect atopic and non-atopic children differently, this also implicates that by taking these differences into account treatment and prevention for these children could be improved.

The present case-control study is nested in a large longitudinal study on respiratory symptoms and allergies conducted in the Dutch-German borderland. The aim of this study was to investigate whether risk factor patterns for asthmatic symptoms differed between atopic and non-atopic children aged $7-8$ years old.

\section{METHODS}

\section{Study area and population}

A nested case-control study of participants in a longitudinal study on respiratory health and indoor environment, was conducted among children living in the DutchGerman borderland. This borderland region covers the geographic area consisting of the municipal health regions Kreis Heinsberg (Germany), Midden-Limburg and the Westelijke Mijnstreek (the Netherlands). Together, the two Dutch regions have approximately 380,000 inhabitants while Heinsberg has approximately 250,000 inhabitants. 
Children included in the case-control study, were recruited from children who had previously participated in both the first (in 1995) and second (in 1997) survey of the study. In 1995, the parents of all 7201 children, born between November $30^{\text {th }} 1989$ and December $1^{58} 1990$ and living in the study area were invited to participate in the first survey. Parents of 5692 children $(79.0 \%)$ returned the completed questionnaire on respiratory symptoms and diagnosis in 1995 . The second survey was conducted in 1997. By then, 233 children were lost to follow up because they had moved out of the study area or their forwarding address was unknown. Of the remaining 5459 children, 4462 completed the questionnaire in 1997, resulting in a response rate of $81.7 \%$. Children with asthmatic symptoms (cases) as well as controls were selected based on the answers given in the first and second survey. All 465 children fitting the case definition and 781 control children were invited to participate in the casecontrol study. Simple random sampling, stratified by region, was used for selecting the control children. The study was approved by the medical ethics committee of the "Ärztekammer Nordrhein" in Germany.

\section{Data collection}

For both the first (in 1995) and the second (in 1997) survey, data were collected in May. In the autumn of 1997 the data collection phase for the case-control study was conducted. Together with an invitation to the physical examination, questionnaires for self-completion were sent to the parents of the children. The physical examination was carried out by a team of four persons (physicians and nurses). In the presence of one or both parents, completeness of the questionnaire was checked by an assistant of the Municipal Health Service and blood samples were taken for immunological analysis.

\section{Questionnaire}

The 1995 and 1997 surveys used identical questionnaires, with questions about respiratory symptoms taken from the WHO questionnaire [15]. To obtain data for the case-control study, an elaborate questionnaire was developed including questions about respiratory symptoms and the indoor environment. Questions about respiratory symptoms were adopted from the International Study of Asthma and Allergies in Childhood ("ISAAC")-questionnaire [16].

\section{Definitions}

Children were regarded asthmatic if they had reported wheezing and attacks of shortness of breath with wheeze in the last 12 months, in one or both surveys. Children with asthmatic symptoms in one survey, who also reported recent wheeze and/or recent shortness of breath with wheeze in the other survey, were regarded as children with persistent asthmatic symptoms. We used the question 'Has your child had wheezing or whistling in the chest in the last 12 months?" from the third more detailed questionnaire, to identify asthmatic children with recent wheeze at the time of the case-control study. Control children had negative answers to all questions about respiratory symptoms in 1995 as well as in 1997. 
Children were defined as atopic if at least one specific Immunoglobulin (Ig) $\mathrm{E}$ tested positive and as non-atopic if negative for all specific IgE tested.

\section{Blood sampling and determination of Immunoglobulin $E$}

Blood was extracted from the cubital vein of the child. After 15 min at room temperature, blood samples were centrifuged for $10 \mathrm{~min}$ at $2000 \mathrm{~g}$. Sera were stored at $-20^{\circ} \mathrm{C}$ until further analysis.

Levels of specific and total $\operatorname{lgE}$ were measured in the laboratory of the Dermatology department of the RWTH-Aachen in Germany, using the Pharmacia CAP System (Pharmacia \& Upjohn Diagnostics AB, Uppsala, Sweden). Specific IgE against Dermatophagoides pteronyssinus (Der p1), Dermatophagoides farinae (Der Il), Cladosporium herbarum, Aspergillus fumigatus, Alternaria tenuis, chicken egg, cow's milk, cat and dog epithelium and a mix of grasses were measured and were regarded as positive if $\geq 0.35 \mathrm{kU} / \mathrm{l}$.

\section{Data analysis}

After log-transformation total serum IgE levels were reported as geometric means and analysed using ANOVA. Crude associations between risk factors and asthmatic symptoms were assessed and their statistical significance tested using Chi-squared tests. Adjusted odds ratios were calculated using multivariate logistic regression. The regression models included following variables; gender, maternal asthma, birth order, breastfeeding, smoking during pregnancy, environmental tobacco smoke (ETS), presence of a cat, mould or damp spots in the home, gas cooking, socioeconomic status and country of residence. All analyses were performed using SPSS PC Version 11.0 (SPSS Inc. IL, USA).

Table 1. Characteristics of children with asthmatic symptoms, according to atopic status

\begin{tabular}{lccc}
\hline & $\begin{array}{c}\text { Atopictic } \\
(n=149)\end{array}$ & $\begin{array}{c}\text { Non-atopic } \\
(n=118)\end{array}$ & pevalue \\
\cline { 2 - 4 } & $103(76.3)$ & $48(45.7)$ & $<0.01$ \\
Wheeze in the last year & $41(30.1)$ & $5(4.8)$ & $<0.01$ \\
Wheeze attacks > 3/year in the last year & $19(14.2)$ & $13(12.9)$ & 0.77 \\
Noctumal wheeze at least once a week in the last year & $30(22.1)$ & $8(7.8)$ & $<0.01$ \\
Speech-limiting wheeze in the last year & $67(46.9)$ & $26(23.2)$ & $<0.01$ \\
Asthma ever & $100(67.6)$ & $41(35.3)$ & $<0.01$ \\
Asthma medication last year & & & \\
& $75(52.1)$ & $33(29.7)$ & $<0.01$ \\
Eczerna ever & $46(32.6)$ & $7(6.3)$ & $<0.01$ \\
Hay fewer ever & & &
\end{tabular}

Values are numbers (percentages)

Due to missings numbers do not always add up to total

* Defined as at least one specific lg $\mathrm{E} \geq 0.35 \mathrm{kLM}$ 


\section{RESULTS}

For $267(57.4 \%)$ children with asthmatic symptoms and for $485(62.1 \%)$ control children, data on specific IgE against all allergens tested was complete, and questionnaires were available.

Specific IgE against any of the allergens tested was present in $55.8 \%$ of the $7-8-$ year-old children with asthmatic symptoms and in $28.0 \%$ of the control children. Raised specific IgE levels against two or more allergens were present in $82.6 \%$ of the atopic children with asthmatic symptoms and in $52.9 \%$ of the atopic children without symptoms $(\mathrm{p}<0.01$ ). Also, total IgE levels were higher in atopic children with asthmatic symptoms than in atopic children without symptoms $(253.8 \mathrm{kU} / 1 \mathrm{v}$ $143.3 \mathrm{kU} / \mathrm{l} ; \mathrm{p}<0.01)$, this difference was not seen between non-atopic cases ( 38.1

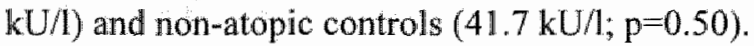

Table 2. Risk factors for as thmatic symptoms and recent wheeze according to atopic status

Asthmatic symptoms ${ }^{*}$

\begin{tabular}{|c|c|c|c|c|}
\hline & \\
\hline & \multicolumn{2}{|c|}{ Atopic childrent } & \multicolumn{2}{|c|}{ Non-atopic children } \\
\hline & OR $¥$ & $95 \% \mathrm{Cl}$ & OR $¥$ & $95 \% \mathrm{Cl}$ \\
\hline Gender (male v female) & 3.22 & $1.53-6.76$ & 1.57 & $0.92-2.65$ \\
\hline Maternal asthmai & 21.79 & $2.55-185.99$ & 2.22 & $0.77-6.42$ \\
\hline \multicolumn{5}{|l|}{ Birth order } \\
\hline only younger siblings & 1.70 & $0.56-5.15$ & 0.95 & $0.35 \times 2.62$ \\
\hline 1 older sibling & 2.84 & $0.95-8.44$ & 0.78 & $0.29-2.13$ \\
\hline 2 older siblings & 1.72 & $0.38 m 7.70$ & 0.68 & $0.21 \cdot 2.17$ \\
\hline$>2$ older siblings & 0.76 & $0.05-10.49$ & 0.72 & $0.11-4.89$ \\
\hline Breastfeeding & $1.7 \mathrm{~s}$ & $0.85-3.50$ & 1.12 & $0.64-1.93$ \\
\hline Smoking during pregnancy & 1.27 & $0.50-3.25$ & 1.56 & $0.77 \cdot 3.14$ \\
\hline \multicolumn{5}{|l|}{ Enwironmental lobacco smoke } \\
\hline lirst 2 yre of life & 2.34 & $0.99-5.50$ & 1.72 & $0.85-3.48$ \\
\hline $\operatorname{age} \times 2$ yrs & 2.04 & $0.49-8.55$ & 0.97 & 0.37 .2 .55 \\
\hline \multicolumn{5}{|l|}{ Cat } \\
\hline first 2 yrs of life & 0.89 & 0.31 .2 .57 & 0.79 & $0.32-1.99$ \\
\hline $\operatorname{age}>2 \mathrm{yrs}$ & 1.47 & $0.36-6.08$ & 195 & 0.794 .80 \\
\hline \multicolumn{5}{|l|}{ Mould / Darnp spots } \\
\hline first 2 yrs of life & 2.63 & $0.42-16.49$ & 0.88 & $0.16-4.71$ \\
\hline $2-5$ yrs of age & 0.89 & $0.28-2.86$ & 3.81 & $1.23-11.84$ \\
\hline recent (past 12 months) & 2.34 & $0.96-5.67$ & 1.57 & $0.78-3.15$ \\
\hline \multicolumn{5}{|l|}{ Gas cooking with cookar hood } \\
\hline used daily & 0.49 & $0.19-1.27$ & 0.52 & $0.23-11.46$ \\
\hline used irregularly & 0.83 & $0.20-3.42$ & 2.97 & $0.93-9.51$ \\
\hline not used & 1.58 & $0.39-6.35$ & 0.77 & $0.30-1.95$ \\
\hline \multicolumn{5}{|l|}{ Socio-economic status } \\
\hline middle $v$ high & 1.58 & $0.77-3.27$ & 0.75 & $0.41-1.38$ \\
\hline low whigh & 1.31 & $0.37-4.65$ & 2.13 & $0.83-5.48$ \\
\hline
\end{tabular}


Table 1 describes atopic and non-atopic cases in respect to recent asthmatic symptoms. In general, atopic children had more severe asthmatic complaints, had more often used medication in the last year and, had more often suffered from eczema or hay fever.

The adjusted odds ratios (OR) and $95 \%$ confidence intervals $(95 \% \mathrm{Cl})$ for risk factors associated with asthmatic symptoms and recent wheeze are shown in Table 2. Male gender and maternal asthma show a strong positive association with asthmatic symptoms and recent wheeze in atopic children. For non-atopic children this association was absent. The data suggested an association between breastfeeding and recent wheeze at age 7-8 years in atopic children $(\mathrm{OR}=2.73,95 \%$ $\mathrm{Cl}: 1.20-6.21)$ but not in non-atopic children $(\mathrm{OR}=0.88,95 \% \mathrm{CI}: 0.44-1.77)$.

Table 2 continued

Wheezente

\begin{tabular}{|c|c|c|c|}
\hline \multicolumn{2}{|c|}{ Atopic childrent } & \multicolumn{2}{|c|}{ Non-alopic children } \\
\hline ORt & $95 \% \mathrm{Cl}$ & OR: & $95 \% \mathrm{Cl}$ \\
\hline 3.17 & $1.38-7.30$ & 0.70 & $0.35-1.43$ \\
\hline 33.98 & $3.75-308.35$ & 1.87 & $0.52=6.79$ \\
\hline 1.15 & $0.31-4.21$ & 1.18 & $0.31-4.46$ \\
\hline 2.98 & $0.87-10.15$ & 0.91 & $0.24-3.40$ \\
\hline 1.52 & $0.28-8.32$ & 0.98 & $0.22-4.30$ \\
\hline 0.05 & $0.00-12.50$ & 1.70 & $0.19-15.09$ \\
\hline 2.73 & $1.20-6.21$ & 0.88 & $0.44-4.77$ \\
\hline 1.75 & $0.61-5.05$ & 0.98 & $0.42-2.31$ \\
\hline 1.50 & $0.58-3.89$ & 2.63 & $1.11-6.27$ \\
\hline 1.54 & 0.32 .7 .50 & 1.09 & $0.30-3.96$ \\
\hline 1.28 & $0.40-4.07$ & 0.39 & $0,08 \cdot 4.98$ \\
\hline 1.02 & $0.19-5.42$ & 1.94 & $0.59 \cdot 6.44$ \\
\hline 4.04 & $0.62-26.60$ & 0.79 & $0,08.7 .78$ \\
\hline 1.32 & 0.414 .24 & 4.82 & $1.07-21.74$ \\
\hline 2.61 & $1.00-6.77$ & 1.67 & $0.72-3.90$ \\
\hline 0.48 & $0.17-1.40$ & 1.60 & $0.53-4.80$ \\
\hline 0.82 & $0.14 \times 4.72$ & 7.42 & $1.55-35.58$ \\
\hline 1.09 & $0.22-5.48$ & 1.45 & $0.41-5.07$ \\
\hline 239 & $1.02-5.56$ & 1.53 & $0.67-3.50$ \\
\hline 294 & $0.74-11.59$ & 4.44 & $1.42-13.91$ \\
\hline
\end{tabular}


Mould or damp spots in the home at 2 to 5 years of age, presented a risk for asthmatic symptoms and for recent wheeze in non-atopic children. In contrast, recent exposure to mould or damp spots was positively associated with recent wheeze in atopic children. Environmental tobacco smoke exposure during the first two years of life, gas cooking with irregular use of cooker hood and lower socioeconomic status were positively associated with recent wheeze at age 7-8 years in non-atopic children. A cat present during the first two years of the child's life, was not related to astlumatic symptoms (or recent wheeze) in atopic and non-atopic children, the same was true for the presence of a dog (atopic children $O R=1.01$, $95 \% \mathrm{Cl}: 0.37-2.73$ and non-atopic children $\mathrm{OR}=1.83,95 \% \mathrm{Cl}: 0.94-3.59)$ (data not shown in the tables).

To exclude the possibility that our definition of asthmatic symptoms also included children who only transiently presented respiratory symptoms for instance in response to a viral infection, we narrowed our definition of asthmatic symptoms down to children with reported recent asthmatic symptoms on two separate occasions i.e., at the age of 5-6 years and at the age of 7-8 years. Although we observed similar associations as seen for asthmatic symptoms, for breastfeeding a risk for persistent symptoms was observed for atopic children ( $\mathrm{OR}=2.75,95 \% \mathrm{CI}$ : 1.14-6.65) but not for: non-atopic children ( $\mathrm{OR}=0.95,95 \% \mathrm{Cl}: 0.40-2.25$ ). Also, lower socio-economic status was associated with persistent asthmatic symptoms in non-atopic children $(\mathrm{OR}=4.81,95 \% \mathrm{Cl}: 1.27-18.16)$ but was not associated with persistent symptoms in atopic children $(\mathrm{OR}=2.15,95 \% \mathrm{CI}: 0.45-10.25)$.

\section{DISCUSSION}

In this study, risk factor patterns for asthmatic symptoms differed between atopic and non-atopic children, with male gender, maternal asthma and breastfeeding presenting as significant risk factors for asthmatic symptoms and recent wheeze in atopic children but not in non-atopic children.

From the Tucson Children's Respiratory Study it became clear that childhood astlhma is a phenotypically heterogeneous disease and three main syndromes, i.e., transient infant wheeze, non-atopic wheeze and atopic wheeze, have been described [17]. Studies using atopy definitions based on skin prick test reactivity to a panel of common allergens [13], Alternaria skin prick test reactivity [2] or definitions based on specific IgE against house dust mite [14] have indicated differences in risk factor pattern for asthma or wheezing between subgroups. Next to different definitions of atopic status, these studies also differed in outcome measures and risk factors investigated.

Two of the studies investigated the relation between family history of asthma and asthma outcome in the child. Although an association with a family history of asthma was observed for asthma outcome in atopic children [2,13], one study [2] found a significant influence of maternal asthma especially in non-atopic children. In contrast, our data showed maternal asthma to present an increased risk for asthmatic symptoms only in atopic children. 
Factors acting early in life have recently attracted considerable attention, but their role is still elusive. In the present study, exposure to environmental tobacco smoke in the first two years of life showed a tendency towards increased risk of asthmatic symptoms in both atopic and non-atopic children. Smoking during pregnancy presented no risk for asthmatic symptoms. It is however difficult to separate the effects of in utero smoke and postnatal tobacco smoke exposure, because mothers usually continue smoking after birth of the child. Removing ETS from the analyses increased the odds ratios for asthmatic symptoms with in utero tobacco smoke exposure in atopic children ( $O R=2.05,95 \% \mathrm{Cl}: 0.92-4.61)$, and especially in nonatopic children $(\mathrm{OR}=2.35,95 \% \mathrm{Cl}: 1.31-4.21)$, indeed indicating a correlation between prenatal and postnatal smoke exposure.

The presence of a cat (or dog) in the first two years of life was not associated with asthmatic symptoms in atopic and non-atopic children. Although sensitisation to common indoor allergens is strongly associated with asthma, recent reports have suggested that the presence of pets in the home early in life could protect against later atopic disease [18-21]. Several explanations for this possible protective effect of pet exposure early in infancy have been proposed such as increased exposure to pet related endotoxin [22] or immune tolerance brought about by high levels of allergen in the absence of sensitisation [23]. Avoidance of pets in families with a history of asthma has also been suggested [19]. A large Dutch birth cohort study found that parental allergy was related to presence of cats in the infant's home, but was unrelated to the presence of dogs at home [24]. In our data pet keeping in the first two years of life was not related to parental asthma (data not shown).

The increased risk of persistent asthmatic symptoms and recent wheeze with breastfeeding seen for atopic children might be viewed in the light of the hygiene hypothesis. Breastfeeding has been shown to protect against lower respiratory tract infections during the first months of life [17], lower respiratory tract infections in turn have been thought to stimulate the immune system in much the same way as has been proposed for endotoxines. By reducing this stimulus, the Th1/Th2 balance may remain skewed towards a neonatal Th2-profile, associated with atopic disease. The stronger association of breastfeeding with asthmatic symptoms in atopic children than in non-atopic children has previously also been reported for children enrolled in the Tucson Children's Respiratory Study, and has been interpreted as increased susceptibility of atopics to reduced exposure to microbes [17]. Alternatively, breastfeeding has been advocated to reduce the risk of atopy, and this might have selectively induced atopic mothers to breastfeed their child. However, in the present study the proportion of mothers breastfeeding their child was comparably similar between mothers with a positive history of asthma or hay fever $(53.6 \%)$ and mothers with a negative history (56.5\%).

There are several methodological characteristics of the study that need to be taken into account in the interpretation of the study results. Although overall response rates for the questionnaire part of the case-control study were high, considerably less children also consented to the taking of blood samples, which could have introduced selection bias. Considering only children born in one year excluded age 
as an important confounder. We based our definition of asthmatic symptoms on answers to questions in two consecutive surveys instead of on asthma diagnosis, because of large differences in asthma diagnosis rates between Germany and the Netherlands. The presence of risk factors was later, retrospectively assessed by questionnaire as part of a nested case-control study. Knowledge of health outcome may have influenced parent's reporting of risk factors, possibly biasing our results. For ETS, questionnaire data were compared with nicotine measurement in dust samples from 190 randomly selected homes, and nicotine measurements were found to agree well with reported smoking behaviour in the home, for cases as well as for controls (data not shown). We therefore considered our questionnaire data on ETS exposure to be reasonably accurate, although recall bias may still have played a role for past exposures. For exposure to cats, misclassification could have occurred to a certain extent, because cat allergens are ubiquitous allergens, which can also be found in homes without cats [25].

In conclusion, atopic children with asthmatic symptoms differed from non-atopic asthmatic children in respect to risk factor pattern and severity of disease, possibly indicating that in atopic children different pathological pathways lead to asthmatic symptoms than in non-atopic children. Future research should take into account the heterogeneity of asthma, especially when planning prevention strategies as risk factors may act differently in the various asthma subgroups.

\section{ACKNOWLEDGEMENTS}

The authors wish to thank HF Merk and his team for total and specific IgE analyses. The study was financially supported by the European Union, the Euregio MaasRhine (Interreg II project EMR.INT.2.96.09.V.039), the Land NorthrhineWestphalia, the Province of Limburg and the counties of Heinsberg, MiddenLimburg and Westelijke Mijnstreek.

\section{REFERENCES}

1. Murtinez FD, Wright AL, Taussig LM, Holberg CJ. Hatonen M, Morgan WJ. Asthma and wheezing in the first six years of life. The Group Health Medical Associates. $N$ Engl $J$ Med $1995 ; 332(3): 133-8$

2. Hatonen M, Stern DA, Lohman C, Wright AL, Brown MA, Martinez FD. Two subphenotypes of childhood asthma that differ in maternal and paternal influences on asthma risk. Am $J$ Respir Crit Care Med 1999;160(2):564-70.

3. Pearce $\mathrm{N}$, Pekkanen $J$, Beasley $\mathrm{R}$. How much asthma is really attributable to atopy? Thorca $1999 ; 54(3): 268-72$

4. Omran $\mathrm{M}$, Russell $\mathrm{G}$. Continuing increase in respiratory symptoms and atopy in Aberdeen schoolchildren. BMA 1996;312(7022):34.

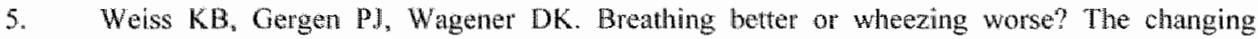
epideniology of asthma morbidity and mortality. Anm Rev Public Health 1993;14:491-513.

6. Christie $\mathrm{GL}, \mathrm{McD}$ ougall $\mathrm{CM}$, Helms PJ. Is the incresse in asthma prevaltence occurring in children without a family history of atopy? Scott Med J 1998;43(6):180-2. 
7. Nystad W. Magnus P, Gulswik A. Increasing risk of asthma whout other atopic diseases in school children: a repeated cross-sectional study after 13 years. Ew I bidemiol $1998 ; 14(3): 247-52$

8. von Mutius E, Weiland SK, Fritzsch C, Dulme H, Keil U. Increasing prevalence of hay fever and atopy among children in Leipzig, East Germany. Lancet 1998;351(9106):862-6.

9. Brunekreef B, Janssen NA, de Hartog J, Harssema H, Knape M, van Vliet $P$. Air pollution fron truck traffic and lung function in children living near motorways. Epidemiology 1997;8(3):298303.

10. Hodge L, Saliome CM, Peat JK, Haby MM, Xuan W, Woolcock A.J. Consumption of oily fish and childhood asthma risk. Med J A ust 1996; 164(3):137.40.

11. Strachan DP. Family size, infection and atopy: the first decade of the "liygiene hypothesis". Thora: 2000;55 Suppl 1:2-10.

12. Peat JK. Li J. Reversing the trend: reducing the prevalence of asthma. $J$ Allerg Chin Immonol 1999;103(1 Pt 1):1-10.

13. Ronmark E, Jonsson E, Platis-Mills T, Lundback B. Different partern of risk factors for atopic and nonatopic asthma anong childrenmreport from the Obstructive Lung Disease in Northem Sweden Sudy. Allergy 1999:54(9):926-35.

14. Court CS, Cook DG, Strachan DP. Comparative epidemiology of atopic and non-atopic wheeze and diagnosed asthma in a national sample of English adults. Thor:ax 2002;57(11):951-7.

15. Florey $\mathrm{C}$ du $\mathrm{V}$, Leeder SR. Methods for colnort studies of chronic ainflow limifotion. WHO Regional Publications European Series. London, United Kingdom, 1982.

16. Asher MI, Keil U, Anderson HR, Beasley R, Crane J, Martinez F et al. International Sudy of Asthma and Allergies in Childhood (ISAAC): rationale and methods. Eur Respir $r$ $1995 ; 8(3): 483-91$.

17. Taussig LM, Wright AL, Holberg CJ, Halonen M, Morgan WJ, Martinez FD. Tucson Children's Respiratory Study: 1980 to present. J Allergy Clin Imwmol 2003;1 114(4):661-75.

18. Ownby DR, Johnson CC, Peterson EL. Exposure to dogs and cats in the first year of life and risk of allergic sensitization at 6 to 7 years of age. JAMA 2002;288(8):963-72.

19. Nafstad P, Magnus P, Gaarder PI, Jaakkola JJ. Exposure to pets and atopy-related diseases in the first 4 years of life. Allergy $2001 ; 56(4): 307-12$.

20. Remes ST, Castro-Rodriguez JA, Holberg CI, Martinez FD, Wright AL. Dog exposure in infancy decreases the subsequent risk of frequent wheeze but not of atopy. I Allergy Clin Immunol 2001;108(4);509-15.

21. Hesselmar B, Aberg N, Aberg B, Eriksson B, Bjorksten B. Does early exposure to cal or dog protect against later allergy development? Clin Exp Allergy 1999;29(5):611-7.

22. Martinez FD. Holt PG. Role of microbial burden in aetiology of allergy and asthma. Lancet 1999:354 Suppl 2:12 $\times 5$.

23. Platts-Mills T, Vaughan J, Squillace S, Woodfolk J, Sporik R. Sensitisation, asthma, and a modified Th2 response in children exposed to cat allergen: al population-based cross-sectional study. Lancet 2001;357(9258):752-6.

24. Wijga A, Smit HA, Brunekreef B, Gerritsen J, Kerkhof M, Koopman LP et al. Are children at high familial risk of developing allergy born into a low risk environment? "The PIAMA Birth Cohort Study. Pirevention and Incidence of Asthma and Mite Allergy. Clin Exp Allergy $2001 ; 31(4): 576-81$.

25. Lau S, Wahn U. Pets-good or bad for individuals with atopic predisposition? a Allergy Clin Immunol $2003 ; 112(2): 263-4$. 
$C H A P T E R$

8

General Discussion 
$102 \mid$ Chapter 8 


\section{MAIN FINDINGS}

This thesis describes prevalence of respiratory symptoms, diagnosis and treatment for asthmatic symptoms, as well as risk factors for respiratory symptoms and allergic sensitisation in German and Dutch children.

The prevalence of recent wheeze in Dutch children steadily declined between 1989 and 2001, paralleled by an increasing proportion of wheezy children using medication. Diagnosis and treatment of asthmatic symptoms were found to differ between German and Dutch children. In Dutch children asthmatic symptoms were more often labelled as asthma whereas German physicians preferred to label them as bronchitis. This differential labelling of symptoms may have led to the observed differences in treatment practice. Inhaled $\beta_{2}$-agonists and inhaled corticosteroids were used by more of the Dutch children than of the German children, whereas more German children used inhaled sodium cromoglycate or nedocromil as antiinflammatory medication as compared to Dutch children.

Vaccination and infection rates differed between Dutch and German children. However, no evidence was found to support the suggestion that childhood infections protect against sensitisation or asthmatic symptoms. No association was found between respiratory symptoms and any of the childhood infections or vaccinations investigated. Scarlet fever or varicella infection presented an increased rather than a decreased risk of allergic sensitisation, as did BCG vaccination. Also, birth order was inversely associated with allergic sensitisation but was unrelated to respiratory symptoms. However, several indoor environmental exposures were found to increase the risk of respiratory symptoms, and some housing conditions appeared to protect against respiratory symptoms. Risk factor patterns for asthmatic symptoms differed between atopic and non-atopic children. Male gender, maternal asthma and breastfeeding were significant risk factors for (persistent) asthmatic symptoms or recent wheeze in atopic children, but not in non-atopic children. Presence of mould or damp spots in the home when the child was 2-5 years old was positively associated with asthmatic symptoms and recent wheeze in non-atopic children. Recent wheeze was positively associated with exposure to environmental tobacco smoke in the first two years of life, with gas cooking with irregular use of" cooker hood, and with lower socio-economic status in non-atopic children. Atopic children appeared to have more severe symptoms and had more often used medication in the year preceding the study than non-atopic children.

\section{METHODOLOGICAL CONSIDERATIONS}

\section{Study design and data collection}

\section{CHOICE OF STUDY DESIGN}

The Dutch-German study on childhood respiratory health and environment has two components. In the first part of the study information on respiratory symptom prevalence was collected in two consecutive questionnaire surveys. The first survey 
was conducted when the children were aged 5-6 years and the second at 7-8-years of age. In the second part of the study risk factors for respiratory symptoms and allergic sensitisation were studied in a case-control setting.

Although the most suitable design for studying potential risk factors in the development of childhood asthmatic symptoms is a cohort study in which children are followed longitudinally from birth on we preferred a different approach for the following reasons. The main goals of the participating Municipal Health Services were first, to study the extent of the respiratory health problem for their region (prevalence), second, to identify preventable risk factors for respiratory symptoms which are modifiable at an age the Municipal Health Services have access to the children and, third, to use the resources of the Health Services to study prevalence of and risk factors for respiratory symptoms and to implement or improve prevention measures. For these reasons we identified a birth cohort of children at the age of 5-6 years. Children of this age are contacted for the first time by the Youth Health Care Department of the Municipal Health Service for a routine medical check-up. Subsequently, they are seen by youth healthcare personnel on a regular basis until they have reached the age of 19 years.

\section{QUESTIONNAIRE SURVEYS}

The surveys included all children who were born between November $30^{\text {th }} 1989$ and December $1^{\text {st }} 1990$ and were living in the study area i.e., Kreis Heinsberg (Germany), Midden-Limburg or Westelijke Mijnstreek (the Netherlands) at the time of the survey. Names and addresses of the children were provided through the Municipal Health Services: in the Netherlands these data were obtained from the 'Provinciale Entadministratie' and in Germany through the 'Einwohnermeldeamt' (municipal registration office). In view of privacy considerations, Municipal Health Service personnel was responsible for mailing the (coded) questionnaires to the parents as well as for updating the 1995 address information for the second survey in 1997. In 1997 the Municipal Health Services managed to trace $95.9 \%$ of the children who had previously participated in the 1995 survey. Children were lost to follow-up because they had moved out of the study area or because their forwarding address was unknown. High response rates were attained in both the $1995(79.0 \%)$ and the 1.997 survey $(81.7 \%$ ), although response rates tended to be higher for the Dutch children $(86.0 \%$ in 1995 and $85.4 \%$ in 1997) than for the German children $(69.4 \%$ in 1995 and $74.8 \%$ in 1997). These differences probably originated from the different position of the Health Service in the respective countries. Dutch parents are more familiar with the Health Service than German parents, mostly through the regular check-ups of their children by the Youth Health Care Department. Also, Dutch Municipal Health Services are legally committed to study health issues in the field of collective prevention, and they perform surveys among their population on a regular basis. In Germany the Health Service performs the check-up of school beginners at the age of 5-6 years, on which results the decision for the child at that time to start school or not is made. 
The first survey (in 1995), conducted when the children were aged 5-6 years, was a postal survey and was unlinked to the check-ups routinely performed on children of this age in both Germany and the Netherlands. Although linking the survey to the check-up would probably have resulted in even higher response rates (see also Chapters $2 a$ and $2 b$ ), differences in approach between the Health Services could have led to biased results.

\section{CASE-CONTROL STUDY}

A case-control study has certain advantages when studying risk factors related to respiratory health. First, childhood asthma is a multifactorial disease, and a casecontrol setting is well-suited for studying a number of potential risk factors concurrently, such as indoor environmental risk factors, infections, and vaccinations. Second, because of the elaborate and demanding data collection protocol, including blood- and urine sampling and home visits, a case-control design enabled us to use a well-defined case and control group, leading to a clear contrast between the two groups thereby reducing the necessary size of the study sample and saving time and costs.

The case-control study was conducted in the fall of 1997 and the data collection period was kept as short as possible (about 6 weeks), mostly to avoid seasonal influences as much as possible but also for practical reasons (organisation of personnel and study location). Many people were involved, including personnel from the Municipal Health Services (physical examination), the University of Aachen (lung function testing and home visits) and the Dutch "Bloedbank" (blood sampling in Dutch children). In the Netherlands, physical examination of the children took place on a location in the vicinity of their homes "Green Cross" building, hospital, or general practitioners' practice). Physical examination of the German children was performed at the schools. In this way, children living in the same neighbourhood or going to the same school were examined on the same day. This approach however made it difficult to reschedule appointments of children who wanted to participate but were unable to attend at the arranged day or time. We asked these parents if they could not attend, to at least sent the filled out questionnaire back to the Municipal Health Service. This explains some of the difference between questionnaire response $(76.2 \%)$ and response to blood sampling for IgE analysis $(62.7 \%)$. Another reason is that not all parents or children attending the physical examination also consented to the taking of blood samples.

Response rates did not differ substantially between cases and controls (questionnaire $75.5 \% \vee 77.0 \%$; blood sampling for $\operatorname{IgE}$ analysis $62.7 \% v 62.6 \%$ ) but were somewhat higher in German than in Dutch children (questionnaire $78.7 \% v$ $75.1 \%$; blood sampling for $\operatorname{IgE}$ analysis $66.3 \% v 60.9 \%$ ).

Parents of children with symptoms are thought to be more willing to participate in asthma studies than parents of children without symptoms. Although not reflected in the response rates for the case-control study, this might also have been the case in the present study (Chapter 3). Children invited for participation in the case-control study had to have participated in both previously conducted surveys and thus this 
form of selection most likely had already taken place before the start of the casecontrol study. Although this might have influenced prevallence rates for respiratory symptons in the questionnaire surveys (discussed below), for studying risk factors in the case-control study selection bias in this form most likely had no major consequences, thereby keeping in mind that our definition of case-children has probably selected children with more persistent symptoms, most children had these symptoms at 5-6 and $7-8$ years of age.

\section{Defining respiratory symptoms}

Various "asthma" definitions have been used in epidemiological studies for example based on bronchial hyperresponsiveness, peak flow variability, doctor"s diagnosis of asthma, or symptom reporting. In the present study case-children were defined using reported recent wheeze and shortness of breath, or cough. To support the case-definition on group level, lung function tests without provocation were performed in a subsample consisting of German children. According to a lung specialists' evaluation of the lung function test results, $12.4 \%$ of the cases and $2.2 \%$ of the controls deviated from normal spirometry result. Agreement between symptom history and spirometry result for defining cases and controls was low, although this classification represented a statistically significant difference between the case and control groups ( $\mathrm{OR}=6.2,95 \% \mathrm{CI}: 2.4-16.2)$. This finding is in line with the findings from Remes et al [1], who concluded that bronchial hyperresponsiveness tests were clearly inferior to symptom history for identifying asthmatic children in a community setting due to their low sensitivity despite their high specificity.

Current asthma, defined by response to questions about wheezing in the past 12 months has been reported to be in close agreement with a physicians diagnosis of astlima [2] which at the moment is considered the most appropriate "gold standard" for epidemiological studies in the field of asthma research [3]. Although we had information about asthma diagnosis, we used reported respiratory symptoms (asthmatic symptoms and/or cough) for defining the cases because of the large differences in the prevalence rates of asthma diagnosis between the German and Dutch children in our study sample, which had probably originated from differential labelling habits between Dutch and German physicians (Chapter 3). An additional advantage of using a symptom based definition is that it does not select people with better access to healthcare as has been suggested for definitions based on physicians diagnosis [3].

The previously described definition was primarily used to select children for participation in the case-control study, whereas this definition was refined for further analyses of potential risk factors. The definition of respiratory symptoms was narrowed down to children with asthmatic symptoms, recent wheeze at age $7-8$, asthmatic symptoms already present at age 5, and asthmatic symptoms present at 56 years as well as at $7-8$ years of age. 


\section{Potential sources of bias}

In the 1995 and 1997 survey identical questionnaires were used, with questions about respiratory symptoms derived from the WHO questionnaire [4] that was reported to have good reproducibility for questions about asthmatic symptoms [5]. We assumed that the questionnaire similarly classified children with respiratory symptoms in the two countries, which may not necessarily have been the case, due to cultural and linguistic influences. This applies especially to the German language because there is no colloquial term for "wheeze" [6]. Evidence however suggests that this played no major role in the present study. It is unlikely that the effect of linguistic influences differs between parents from 5-6-year-olds and (the same) parents from 7-8-year-olds. Prevalence rates for recent wheeze were similar in 5-6year-old German $(18.2 \%)$ and Dutch $(17.7 \%)$ children, but differed between German $(13.6 \%)$ and Dutch $(10.6 \%)$ children at the age of $7-8$ years $(p<0.01)$. Because of the previously described differences in response rates between German and Dutch children in the surveys, we checked if response bias had contributed to the differences in prevalence rates between German and Dutch children. This did not seem to be the case, as for both countries, we found the same trends as reported for children participating in both the 1995 and 1997 survey, also in children that participated only once. However, 1997 prevalence rates tended to be lower for (German as well as for Dutch) children participating in the 1997 survey only, compared to prevalence rates in 7-8-year-old children who had previously also participated in 1995. From this we expect response bias to have influenced the 1997 prevalence rates to some extent, but this influence was not larger in German children than in Dutch children, as could be expected from the lower response rates in German children. The exact same question for recent wheeze was used in the Westelijke Mijnstreek study (Chapters $2 \mathrm{a}$ and $2 b$ ), which yielded response rates of over $95 \%$ and prevalence rates for wheeze in this study were similar to the prevalence for wheeze found in the Dutch-German study.

The potential problem of subjective recognition or recall of symptoms is inherent to the use of questionnaires. Only questions about recent respiratory symptoms were used to prevent recall bias as much as possible, however the possibility of random misclassification of disease status as well as of exposure status remains. We made an effort to validate the questionnaire exposure data, and investigated 219 out of 240 randomly selected homes (112 homes of case children and 107 homes of control children) in more detail. Besides a visual inspection of the home, conducted by trained personnel from the Institute of Hygiene and Environmental Medicine (RWTH-Aachen), dust and air samples were collected for VOC, PAH and mould analysis; the results have been described elsewhere [7,8]. In brief, they indicated that parental reports of smoking (compared with results from nicotine measurements in the home) and dampness or mould growth (compared with results from the visual inspection of the home) were reasonably accurate and did not differ between cases and controls. Double-glazing was found to be underreported by the German (Heinsberg) parents. 


\section{STUDY RESULTS FROM A PUBLIC HEALTH PERSPECTIVE}

Childhood asthma constitutes a large social and economic burden in many industrialised countries. Prevalence rates of asthmatic symptoms in school-aged children in the Netherlands were found to be the highest in the south-eastern part of the Netherlands (in particular in the Westelijke Mijnstreek), at least in the late eighties and early nineties [9]. Also, Midden-Limburg and Westelijke Mijnstreek have the highest rates of asthma hospital discharge diagnoses in the Netherlands [10]. From previous surveys conducted by the Municipal Health Service Westelijke Mijnstreek (in 1989 and 1993, see Chapter 2a) it had become clear that childhood respiratory symptoms were an important health issue for this region.

However, nothing was known about the problem on larger scale, and for the neighbouring German regions little information about respiratory symptom prevalence was available at that time.

Table 1. Definitions of wheeze and increase in prevalence of recent wheeze and shortness of breath in surveys using identical parental questionnaires and study design to study time trends in asthma symptom prevalence*

\begin{tabular}{|c|c|c|c|}
\hline Country & Study years & Age & Number of parlicipants \\
\hline United Kingdom [18] & $\begin{array}{l}1978 \\
1991\end{array}$ & $71 / 2-81 / 2$ & $\begin{array}{l}4147 \\
3070\end{array}$ \\
\hline Greece [19] & $\begin{array}{l}1978 \\
1991 \\
1998\end{array}$ & $8-10$ & $\begin{array}{l}3003 \\
2417 \\
3076\end{array}$ \\
\hline Norway $[20]$ & $\begin{array}{l}1981 \\
1994\end{array}$ & $6 * 16$ & $\begin{array}{l}1674 \\
2188\end{array}$ \\
\hline Australia [21] & $\begin{array}{l}1982 \\
1992\end{array}$ & $8-10$ & $\begin{array}{c}\text { Belmond: } \\
718 \\
873\end{array}$ \\
\hline & $\begin{array}{l}1082 \\
1992\end{array}$ & $8-10$ & $\begin{array}{c}\text { Wagga Wagga: } \\
769 \\
795\end{array}$ \\
\hline Swedten [22] & $\begin{array}{l}1985 \\
1995\end{array}$ & $7-16$ & $\begin{array}{l}9603 \\
8568\end{array}$ \\
\hline United Kingdom [23] & $\begin{array}{l}1990 \\
1998\end{array}$ & $1-5$ & $\begin{array}{l}1422 \\
2127\end{array}$ \\
\hline Unilled Kingdom [24] & $\begin{array}{l}1991 \\
1999\end{array}$ & $8-9$ & $\begin{array}{l}4580 \\
5011\end{array}$ \\
\hline Australia $\mid 25$ & $\begin{array}{l}1992 \\
1997\end{array}$ & $8-11$ & $\begin{array}{c}850 \\
1016\end{array}$ \\
\hline
\end{tabular}

\footnotetext{
"Nol intended as a comprehensive listing of studies showing increasing wheeze prevalence: only studies with a last one survey in the 1990 s included

** $\mathrm{SOB}=$ Shortness of breath $/$ breathlessness

† Following positive answer to first phase screening question "Has your child had asthnatic symptoms in the past year andior taken medicine for asthma at least once"
} 
With the exception of a small Dutch-German study foeussing on the role of outdoor air pollution in the aetiology of childhood respiratory symptoms [11], other environmental risk factors, most notably indoor risk factors had not been studied in these regions.

The results from the Dutch-German study revealed that the high asthma synptom prevalence was not specific for the Westelijke Mijnstreek nor was it a temporally confined problem. At present, no conclusive information about the causes of these, also internationally observed trends is available. From a public health point of view it therefore seems worthwhile to use information on known risk factors for planning prevention strategies. This is reflected in the aim of the Municipal Health Services to identify potential risk factors for respiratory symptoms important for the region which are modifiable, and which are effective at an age the Health Services have access to the children (school-age). A number of risk factors that fulfilled these requirements were identified. The following sections describe the findings in more detail and consider public health consequences.

Table 1 continued

\begin{tabular}{|c|c|c|}
\hline Recent wheeze & Recent SOB & Definition of wheseze \\
\hline $\begin{array}{l}8.8 \% \\
11.6 \%\end{array}$ & & Any attack of asthma or wheezing lalness over the past 12 months \\
\hline $\begin{array}{l}1.5 \% \\
4.6 \% \\
6.0 \%\end{array}$ & & $\begin{array}{l}\text { Physician stating that the child had asthma in the last } 2 \text { years or on } 2 \text { or } \\
\text { more occasions stating that the child had wheezing in the last } 2 \text { years }\end{array}$ \\
\hline $\begin{array}{l}3.7 \% \\
6.8 \%\end{array}$ & & $\begin{array}{l}\text { During the last } 3 \text { years, has the child had an attack of wheezing at rest } \\
\text { without having a coid }\end{array}$ \\
\hline $\begin{array}{c}\text { Belmond: } \\
10.4 \% \\
27.6 \% \\
\text { Wagga Wagga: } \\
15.5 \% \\
23.1 \%\end{array}$ & & Attacks of wheeze occuring in the previous 12 months \\
\hline $\begin{array}{l}5.2 \% \\
5.3 \%\end{array}$ & $\begin{array}{l}4.6 \% \\
6.7 \%\end{array}$ & $\begin{array}{l}\text { Has your child thad any of the following symptoms during the last } 12 \\
\text { months (1) wheezing }(2) \text { chest tightiness and breathlessness }\end{array}$ \\
\hline $\begin{array}{l}2 \% \\
25 \%\end{array}$ & & Any attacks of wheeze in the past year \\
\hline $\begin{array}{l}17.0 \% \\
19.4 \%\end{array}$ & & ISAAC-question on wheeze \\
\hline $\begin{array}{l}22.1 \% \\
27.2 \%\end{array}$ & & Has your child ever wheezed? If yes, was this in the past 12 months? \\
\hline
\end{tabular}


Symptoms, diagnosis and treatment

Compared to other regions in the Netherlands, asthmatic symptoms seem to occur more frequently in children living in the south-east of the Netherlands (Limburg), with prevalence rates for recent wheeze being the highest for children living in the Westelijke Mijnstreek, at least in the late eighties and early nineties [9]. Results from the Dutch-German study show that in 1995, prevalence rates for wheeze were comparably high in the Westelijke Mijnstreek, Midden-Limburg and Kreis Heinsberg (Germany) [7]. Two years later, at the age of 7-8 years, the prevalence of wheeze was significantly higher in children living in Kreis Heinsberg than in children living in the Dutch regions.

Unlike most previous reports, from the Netherlands [9] and other countries (Table 1) using a variety of study designs and definitions for wheeze, the prevalence of wheeze, the most common clinical expression of asthma, has steadily decreased since 1989 among children living in the Westelijke Mijnstreek (Chapters 2a and $2 b)$. These results are in line with studies that were published very recently, which reported no further increase or even a decrease in asthma symptom prevalence among British [12] and Swiss adolescents [13], and among Australian schoolchildren $[14,15]$.

It is unclear what has caused this relatively high prevalence of wheeze in the DutchGerman region or which factor is responsible for the steady decrease in wheeze prevalence since 1.989 in the Westelijke Mijnstreek. Various factors complicate a straightforward interpretation of the results. First, wheeze is a symptom shared by a variety of "wheezing syndromes" (Fig. 1) that occur in childhood and that show a certain degree of overlap [16] although prognosis and risk factor patterns vary. Wheezing at school-age appears to be mostly atopy-related (Chapter 7, Table 1) (Fig. 1) with sensitisation identified as the most important risk factor [17].

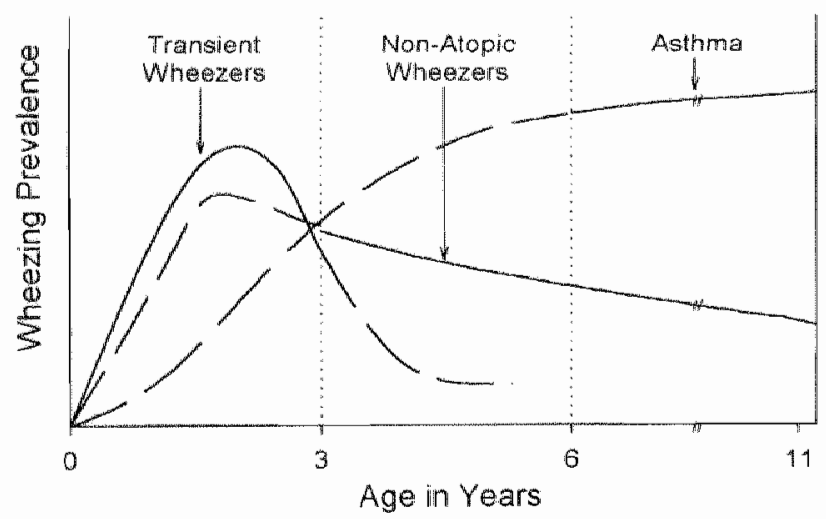

Fig 1 .

Hypothetical peak prevalence by age for the 3 different wheezing phenotypes (groups are not exclusive) Fram Taussig LM, Wright AL, Holberg CU, Halonen M, Morgan WJ, Martinez FD. Tucson children's respiratory study: 1980 to present. J Allergy Clin Immunol 2003; 111(4):661-75 
Second, the prevalence of shortness of breath increases during the same time period the prevalence of wheeze decreases (Chapter 2a). Literature on time trends of prevalence of shortness of breath is scarce, and although most studies studying time trends of asthma symptom prevalence include wheezing and physician-diagnosed asthma, very few also reported data on shortness of breath (Table 1).

The lack of association between changes in asthma symptom prevalence and other atopic conditions such as eczema and allergic rhinitis is a third factor that complicates a straightforward explanation of the observed time trend [14].

Changes in awareness of asthma symptoms as well as changes in asthma management may, at least partly, explain our results. In 1992-93, national guidelines on asthma diagnosis and treatment were introduced in the Netherlands. A 1998 revision stressed the importance of steroids in asthma management [26]. About $80 \%$ of the children with recent asthmatic symptoms were using some form of anti-asthma medication, and almost $40 \%$ of the Dutch children were using inhaled corticosteroids for their asthma in 1997 (Chapter 3).

The proportion of medication use is higher in children participating in the DutchGerman study than the observed medication use in the Westelijke Mijnstreek (Chapters $2 \mathrm{a}$ and $2 \mathrm{~b}$ ) because study design and definition of asthmatic symptoms differed between the two studies.

Guidelines further include recommendations on avoidance of exposure to relevant allergens and to tobacco smoke. For instance, the proportion of children exposed to environmental tobacco smoke, decreased remarkably during the period 1989 to 1997 (Chapter 2a). This decreased tobacco smoke exposure has most likely not resulted from a decreased prevalence of smoking among parents, as reports from the Netherlands [27] and from Germany [28] indicate that prevalence of smoking among adults has changed little over the last decade. The results probably indicate a change in smoking behaviour in the homes of families with small children, since the survey question specifically asked about daily smoking in the home of the child.

Other environmental factors of likely influence include emissions from industry and from heavy traffic, none of which were covered in our study, but which may have played a role in determining prevalence rates for the study area.

\section{Environmental factors associated with respiratory symptoms and sensitisation}

Aitered exposure to environmental factors has been suggested as a cause for the observed changes in asthma symptom prevalence. However, many factors appear to be involved in the development of childhood asthma and in the precipitation of asthma exacerbations. Especially early life events have been thought to be particularly important in the development of atopic manifestations.

When considering the role of risk factors in asthma prevention, two issues should be kept in mind. First, risk factors may act differently at the various stages of the disease process and second, there is considerable controversy surrounding the role of allergen avoidance as primary preventive measure in reducing atopic disease prevalence. 
Besides the different wheezing syndromes that have been described, childhood asthma and sensitisation to local aeroallergens, although closely associated, represent different steps of the disease process and risk factor patterns may differ between the subgroups and stages of the disease. Two views about the role of allergen sensitisation in childhood asthma prevail in contemporary scientific literature. One states that allergen sensitisation is the principal cause of childhood asthma, the other that the development of childhood asthma and allergen sensitisation run parallel [29]. The latter view might imply that allergic sensitisation confounds the relationship between environmental risk factors and respiratory symptoms, and we therefore studied these relationships separately over the different strata of allergie sensitisation (Chapter 7). For infections and vaccination the relationship was studied for allergic sensitisation and respiratory symptoms separately as well (Chapters 4 and 5).

Prevention may involve both primary and secondary intervention measures, although in the long run, only primary intervention measures are expected to reduce the incidence of asthmatic symptoms. As the first results from intervention trials are now becoming available it seems that no large clinical benefits have resulted from implementation of the available allergen reduction measures in primary prevention, even though reductions in allergen load could be achieved, possibly owing to the fact that allergen levels were already low at baseline or that asthma is a multicausal disease that can only be effectively prevented by using a multifaceted intervention programme [30].

From the results of the present study some modifiable risk factors emerged, that were of importance for respiratory symptoms in children in this Dutch-German region. Environmental factors significant to risk of respiratory symptoms in children living in the Dutch-German study area had not previously been defined. This information, however, is essential to the intent of the Municipal Health Services to initiate or optimise prevention for their region on a communal level. As the Municipal Health Services are in regular contact with children of school-age, secondary prevention would be a more suitable tool for these institutions to directly implement in their organisation. Because the present study was designed with this in mind, from its results inferences can be made for improving secondary prevention. Information as to what factors are responsible for the onset of asthmatic symptoms or of sensitisation is mostly of retrospective nature and should therefore be interpreted with some caution. Even though focusing on risk factors suitable for secondary prevention, such as allergen avoidance or reduction of environmental tobacco smoke exposure, does not directly decrease incidence of disease it can reduce morbidity [31-33]. Besides timing of prevention (primary or secondary), prevention on a population level should also concern risk factors that can be changed (easily) in the individual households. The present study identified various factors that influenced the risk of respiratory symptoms, in particular of asthmatic symptoms (Chapters 6 and 7), although the nature of some of the risk factors (such as male sex, positive matemal history of asthma, low birth order) makes them unsuitable for intervention. Interestingly, the distribution of indoor environmental 
risk factors was found to differ substantially between German and Dutch households [34] (Chapter 6).

Some housing conditions (i.e., wall-to-wall carpeting and presence of insulation measures) were found to protect against respiratory symptoms. The protective effect of wall-to-wall carpeting most likely resulted from compliance with avoidance measures recommended to persons with atopic complaints. Allergen avoidance measures have been found to reduce mite-allergen levels in the home substantially, and although beneficial as secondary preventive measure, their role in primary prevention is at the time still subject of study $[29,30,35]$.

In this respect, we initially regarded better insulated homes (i.e., double glazing and door- and window seals) as a risk factor for respiratory symptoms because it reduces natural ventilation, causing adverse substances to accumulate in the home as well as increasing humidity levels, and by doing so generating a favourable environment for mite (and mould) growth. House dust mite concentrations in carpets and mattresses have been found to increase after installation of insulated windows and central heating [36]. The results of the present study however showed a decreased risk of asthmatic symptoms (but not coughing) in chilldren living in highly insulated homes. In the present study, presence of insulated windows might have been a surrogate for other factors associated with respiratory disease risk such as socio-economic differences. Presence of insulated windows was positively associated with higher socio-economic status but was not related to presence of damp spots (data not presented), which are both independent risk factors for respiratory symptoms (Chapters 6 and 7). Differences in disease risk have been reported for various socio-economic groups and may represent, among others, differences in housing conditions, healthcare access, and dietary habits.

In the present study keeping pets during the entire life of the child was found to increase the risk of asthmatic symptoms (Chapter 6), but when stratified according to atopic status, no statistically significant association was seen between presence of a cat or a dog during the first two years of life and asthmatic symptoms in these children (Chapter 7). Recently, some studies showed protective effects of exposure to pets early in life [37-40], although not pet allergen exposure itself, but pet associated endotoxin exposure may be responsible for the protective influence [41]. Van Schayck and Knottnerus [42] have suggested "confounding by behaviour" as an alternative explanation, based on their observation that all indications in favour of the hygiene hypothesis stem from observational studies. Although having pets in the home very early in life may have beneficial effects, exposure to pet allergens worsens the disease in children with asthmatic symptoms, sensitised to pet allergens. Therefore, reduction of exposure to pet allergens remains important in these children and the best way to reduce exposure to these allergens is to remove the pet from the home. Pets, however, were found to be present in about $50 \%$ of the homes of symptomatic children (Chapters $2 \mathrm{a}$ and 6 ), and the proportion of homes where pets were kept indoors, did not differ between children sensitised to pet allergens and children not sensitised to pet allergens (data not shown). 
Exposure to dampness or mould growth as well as the presence of an unvented geyser used for water heating (source of $\mathrm{NO}_{2}$ ) presented an important risk for respiratory symptoms in the present study. However, the number of households involved was small. The situation is different for exposure to environmental tobacco smoke, the proportion of children exposed to environmental tobacco smoke is large. Although the proportion of children exposed to tobacco smoke in the home was found to have decreased over the last decade (Chapter 2a), more than $50 \%$ of the parents of children with respiratory complaints in this study reported current smoking in the home. From these data it was estimated that reducing exposure to tobacco smoke in this population could achieve a substantial reduction in respiratory symptom prevalence (population attributable risk for exposure to environmental tobacco smoke: $23 \%$ [7]). Reduction of environmenta] tobacco smoke exposure in the homes of symptomatic children is especially worthwhile because the effects of passive smoke exposure are reversible [32]. This is probably not the case for the adverse effects of prenatal maternal smoking, which we also identified as a risk factor for respiratory symptoms in the offspring in the present study (Chapter 6). Noticeable in this respect is that although a somewhat smaller proportion of German mothers (26.7\%) than Dutch mothers $(33.4 \%)$ reported smoking during the first trimester of pregnancy, the proportion of mothers that smoked during the second (and also third) trimester of pregnancy was substantially smaller in Germany $(18.2 \%)$ than in the Netherlands $(30.8 \%)$. In wero tobacco smoke exposure is thought to cause pathological and functional alterations in the airways [43], leading to reduced respiratory function in infancy [44] and childhood [43], thereby predisposing for asthma [45]. Environmental tobacco smoke, on the other hand, can act as a trigger of wheeze attacks rather than as an asthma inducer [45], thus deteriorating disease and leading to more severe symptoms in persons with already established disease. In the case of tobacco smoke exposure it therefore seems rewarding to implement tobacco smoke reduction both as primary and as secondary prevention.

Breastfeeding has been advocated as an important factor protective against atopic disease. However, in the present study no protective effect of breastfeeding was observed: breastfeeding was a risk factor for recent wheeze and for persistent asthmatic symptoms in atopic children and was unrelated to symptoms in nonatopic children (Chapter 7). Breastfeeding has been shown to protect against lower respiratory tract infections during the first months of life, and in the light of the hygiene hypothesis can thus be viewed as a risk factor for respiratory symptoms for which atopics might be more susceptible [17]. Alternatively, breastfeeding has been promoted as reducing the risk of atopy, and this might have selectively induced atopic mothers to breastfeed their child, however, in the present study we found no evidence for this supposition (Chapter 7). Other early life events included in the study, such as specific infections and vaccinations, also did not show a protective effect on neither respiratory symptoms nor allergic sensitisation. In contrast, we found some infections and $B C G$ vaccination to present a risk for allergic sensitisation. 
Although certain vaccinations and infectious diseases might provide insight into the mechanisms responsible for the development of atopic manifestations, at this point they cannot be used for prevention purposes as such, because for one the benefits of vaccination far outweigh their possible adverse influence on atopic disease [46]. One possible exception might be the Mycobacteria, as the therapeutic potential of Mycobacterium vaccae has been subject of a number of recent studies. However, the clear efficacy of mycobacterial treatment seen in animal studies has thus far not been convincingly reproduced in human asthma [47].

\section{Dutch-German differences}

The organisation of healthcare differs between Germany and the Netherlands and has probably resulted in some of the differences in risk factor patterns found between German and Dutch children, such as for vaccination and infection rates (Chapters 4 and 5). From the comparison of these systems, valuable clues may emerge for improving prevention. In the Netherlands, for instance, trained asthma nurses visit families with asthmatic children at home and give advice on preventive measures that can be undertaken. In Germany there is no equivalent for these Dutch asthma nurses and better information delivery (adjusted to the home situation of each respective family) to Dutch families may have contributed substantially to the observation that Dutch parents more often than German parents changed the furnishing of the child's bedroom and more often removed a pet from the home because of the respiratory complaints of the child [34]. On the other hand, information about the harmful effects of smoking during pregnancy seems to have been more efficient in German mothers (see above). In Germany, women attend a gynaecologist very early in pregnancy, whereas Dutch women visit an obstetrician or midwife for the first time around the $15^{\text {th }}$ week of pregnancy. Consequently, one obvious difference is that information about smoking cessation simply reaches Dutch women later in pregnancy than German women.

From these examples it becomes clear that prevention should not be uniform for the German and Dutch regions, but rather be tailored to the specific regional situation or perhaps even tailored to specific groups in society. The necessity for intensifying or adjusting prevention measures to the needs of specific groups is also reflected in the findings that (1) risk factor patterns for asthmatic symptoms differed between atopic and non-atopic children (Chapter 7) and (2) socio-economic status was found to influence the presence of respiratory symptoms (Chapter 6).

The intent of the Municipal Health Services was to improve respiratory health on community level. On the one hand Municipal Health Services can monitor the respiratory health situation in their region with relatively simple means and identify certain groups (from disease or from risk factor point of view) in need of prevention or information delivery adjusted to their specific situation. On the other hand, Health Services have the capacities to coordinate and optimise the flow of information for their region and to mediate between the responsible institutions (e.g., parents, physicians, consultation offices, municipalities, schools). 


\section{RECOMMENDATIONS AND FURTHER RESEARCH}

At present, greater understanding is needed into the natural course of allergic sensitisation and of asthmatic symptoms and the factors influencing these processes, eventually leading to better strategies to prevent sensitisation and asthma, especially as primary prevention. Also, there is fierce debate about potentially beneficial effects of allergen avoidance measures as primary prevention tools. However, secondary prevention remains important in asthma management and can still be improved [35] as the results from the present study also suggest. Municipal Health Services can provide important information on the respiratory health situation for their region, as is illustrated by the example of the Municipal Health Service Westelijke Mijnstreek in Chapters $2 \mathrm{a}$ and $2 \mathrm{~b}$. These periodic surveys could be extended to:

- Other Dutch regions and adjoining German and Belgian regions using the same study design and instrument

- Other issues of interest such as, severity of asthmatic symptoms and other related atopic conditions such as eczema and atopic rhinitis (from 2001 on already included in the Westelijke Mijnstreek survey), more detailed information on environmental factors of influence, diagnostics and medication use, social consequences of disease, delivery of information concerning prevention, and the processing of this information (for instance problems encountered when implementing these prevention measures into daily household routine).

- Randomised controlled trials (RCT) could be incorporated within the existing framework, for instance RCTs investigating efficiency of (new) interventions. These RCTs could benefit from routinely collected information (when children are between 4 and 19 years of age) for instance when studying possible long-term effects of interventions.

Many intervention trials have used a high-risk approach, identifying a group of children at high risk of developing asthma. The results from the periodical surveys can be used to identify high-risk groups from disease point of view or from exposure point of view, for instance identifying groups or regions with high frequency of risk factor(s) for respiratory symptoms. Alternatively, depending on the nature of the risk factor, a population-based approach would be suited for incorporation in Municipal Health Service practice.

To improve secondary prevention, as a first step, an inventory (if not already available) should be made of all information about prevention from all possible sources available to the parents of affected children living in the region. A second step should investigate accessibility of this information for these parents, and what barriers they encounter when implementing these prevention measures. Important knowledge can be gained from comparing the Dutch and German situation and from this comparison national or regional asthma prevention strategies can be improved (see above). As mentioned before, there is no consensus in international literature about the benefits of certain primary prevention measures, although for 
smoking during pregnancy a clear picture has emerged in this respect. Municipal Health Services could play an active role in preventing smoking during pregnancy on communal level. However, for all future intervention measures it is important to evaluate the effectiveness. Well-defined endpoints should be formulated (such as changes in severity of symptoms or medication-use), as well as determining compliance with and practicability of the intervention and determining costs and benefits.

\section{REFERENCES}

1. Remes ST, Pekkanen J, Remes K, Salonen RO, Korppi M. In search of childhood asthma: questionnaire, tests of bronchial hyperresponsiveness, and clinical evaluation. Fhorax $2002 ; 57(2): 120-6$

2. Jenkins MA, Clarke JR, Carlin IB, Robertson CF, Hopper JL, Dalton MF et al. Validation of questionnaire and bronchial hyperresponsiveness against respiratory physician assessment in the diagnosis of asthma. Im J Epidewhol 1996;25(3):609-16.

3. Pekkanen J, Pearce $\mathrm{N}$. Defining asthma in epidemiological studies. Eur Respir J $1999 ; 14(4): 951-7$.

4. Florey C du V, Leeder SR. Methods for cohort shidies of chronic ainflow limitation. WHO Regional Publications European Series. London, United Kingdom, 1982.

5. Brunekreef B, Groot B, Rijcken B, Hoek G, Steenbekkers A, de Boer A. Reproducibility of childhood respiratory symptom questions. Eur Respir J 1992;5(8):930-5.

6. Bumey PG, Laitinen LA, Pendrizet $S$, Huckauf $H$, Tattersfield $A E$, Chinn $S$ et al. Validity and repeatability of the IUATLD (1984) Bronchial Symptoms Questionnaire: an international comparison. Eur Respir J 1989;2(10):940-5.

7. Mommers M, Detkx R, Jongmans-Liedekerken AW, Mertens P. Steup A, Weishoff-Houben M et. al. Respiratory symptoms in children in the regions Heinsberg (Gernany), Midden-Limburg and Westelijke Mijnstreek (the Netherlands). RWTH-Aachen, Germany, 2000.

8. Riess S, Mommers M, Ostrowski $R$, Dott W, Weishoff-Houben M. Indoor exposure to moulds and respiratory symptoms in German and Dutch children. Umweltmed Fonsch Prax $2003 ; 8(4): 193$.

9. wan der Wal MF, Uitenbroek $\mathrm{DG}_{*}$ Verhoeff AP. Toegenomen percentage basisschoolkinderen met astmatische klachten in Nederland, 198485-1994-95; een literatuuronderzock. Ned Tijdschir Geneeskd 2000;144(37):1780-5.

10. RIVM. Nationale Atlas Volksgezondheid. www rivm.nl . 2004.

11. Einbrodt HJ, Dot W, Weishoff-Honben M, Engler A. Ondercoek naar de huchtwerontreinging en effecten op de gezondheid in bet Duts-Nederlandse grensgebied. RW THI-Aachen, Germany. 1995.

12. Anderson HR, Ruggles $R_{*}$, Strachan DP, Austin JB, Burr $M$, Jeffs $D$ et al, Trends in prevalence of symptoms of asthma, hay fever, and eczema in 12-14 year olds in the British 1sles. 1995 2002: questionnaire survey. BMJ 2004:328(7447):1052-3.

13. Braun-Fahrlander C, Gassner M, Grize L, Takken-Sahli K, Neu U, Stricker T et al. No further increase in asthma, hay fever and atopic sensitisation in adolescents living in Swizerland. Eu Respir $J 2004: 23(3): 407-13$.

14. Robertson CF, Roberts MF, Kappers IH. Asthma prevalence in Melbourne schoolchildren: have we reactied the peak? Med I A ust 2004;180(6):273-6.

15. Toelle BG, Ng K, Belousova E, Salome CM, Peat JK. Marks GB. Prevalence of asthma and allergy in sehoolchildren in Belmont, Australia: three cross sectional surveys over 20 years. BMI 2004;328(7436):386-7.

16. Martinez FD, Helms PJ. Types of asthma and weezing. Eur Respir $/ 5$ wpp/ 1998:27:35-8s 
17. Taussig LM, Wright AL, Holberg CJ, Halonen M, Morgan WJ, Martinez FD. Tucson Childrerts Respiratory Study: 1980 to presert. J Allergy Chin Immwnol 2003;111(4):661-75.

18. Anderson HR, Butland BK, Strachan DP. Trends in prevalence and severity of childhood asthma. BMJ 1994,308(6944):1600-4.

19. Anthracopoulos $M_{3}$ Karatza $A$, Liolios $E_{*}$ Triga $M$, Triantou $K$, Priftis $K$. Prewalence of asthma among schoolchildren in Patras, Greece: three surveys over 20 years. Thoran 2001;56(7):56971 .

20. Nystad $W$, Magnus $P$. Gulswilk $A$, skarpaas $U$, Carlsen $K H$. Changing prevalence of asthma in school children: evidence for diagnostic changes in asthma in two surveys 13 yrs apart. Eur Respir J 1997;10(5):1046-51.

21. Peat JK, wan den Berg RH, Green WF, Mellis CM, Leeder SR. Woolcock AJ, Changing prevalence of asthma in Australian children. $B M J 1994,308(6944): 1591-6$.

22. Braback L, A ppelberg d, Jansson U, Kalvesten L. Changes in prevalence and severity of asthma among schoolchildren in a Swedish district between 1985 and 1995. Acta Paediatr $2000 ; 89(4) ; 465-70$.

23. Kuehni CE, Dawis A, Brooke AM, silverman $M$. Are all wheezing disorders in very young (preschool) children increasing in vrewalence? Lancet 2001;357(9271):1821-5.

24. Ng Man Kwong G, Proctor A, Billings $C$, Duggan $R$, Das $C$, Whyte MK et al. Increasing prewalence of asthma diagnosis and symptoms in children is confined to mild symptoms. Thorax 2001;56(4):312-4.

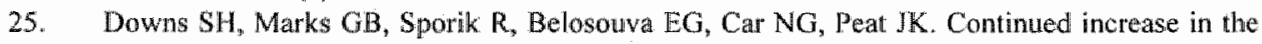
prevalence of asthma and atopy. Arch Dis Child 2001;84(1):20-3.

26. Dirksen WJ, Geijer RM, De Haan $M$, De Koning G, Flikweent $S$, Kolnaar BG. NHG-Standaard Astma bij Kinderen (eerste herziening). Huisarts Wet 1998;411(3):130-43.

27. Stivoro. Www.stivora.nl. 2004.

28. Junge B, Nagel M. [Smoking behavior in Germany]. Gesundheitswesen 1999;61 Spec No:SI21-SI25.

29. Kemp AS. Do allergens play a role in early childhood asthma? Med J Aust 2002;177 Stuppl:S52-S54.

30. Brunekreef B, Smit J, de Jongste I, Neijens H, Gerritsen J, Postma D et al. The prevention and incidence of asthma and mite allergy (PIAMA) birth cohort study: design and first results. Pediat Allergy Immunol 2002,13 Suppl 15:55-60.

31. von Mutius E. Towards prevention. Lancet 1997;350 Supp 2:14-7.

32. Murray $\mathrm{AB}$, Morrison $\mathrm{BJ}$. The decrease in severity of asthmat in children of parents who smoke since the parents have been exposing them to less cigarette smoke. I Allergy Clin Immuol 1993:91(1 Pi 1):102-10.

33. Strachan DP, Cook DG. Health effects of passive smoking. 6. Parental smoking and childhood asthma: longitudinal and case-control studies. Thorax 1998;53(3):204-12.

34. Mommers M, Derkx R, Hahn A, Jongmans-Liedekerken AW, Mertens P, Steup A et al. Similar respiratory symptoms in Dutch and German children with different indoor exposure. Proceedings of Indoor Air 99 The $8^{\text {th }}$ International Conference on Indoor Air Quality and Cimate. Construction Research Communications Ltd., 1999, pp 489-94.

35. de Blay $\mathbf{F}$, Birba $\mathrm{E}$. Controlling indoor allergens. Curr Opin Allergy Clin Immunol $2003 ; 3(3): 165-8$

36. Hirsoh T, Hering M, Burkner K, Hirsch D, Leupold W, Kerkmann ML et al. House-dust-mite allergen concentrations (Der $\mathbb{f}$ ) and mold spores in apartment bedrooms before and after installation of insulated windows and central heating systems. Alergy 2000;55(1):79-83.

37. Ownby DR, Johnson CC, Peterson EL. Exposure to dogs and cats in the first year of life and risk of allergic sensitization at 6 to 7 years of age. $J A M A 2002 ; 288(8): 963-72$.

38. Naftad P. Magnus $\mathbb{P}$, Gaarder PI, Jaakkola JJ. Exposure to pets and atopy-related diseases in the first 4 years of life. Allergy $2001 ; 56(4): 307-12$. 
39. Remes ST, Castro-Rodriguez $\mathbb{A}$ A, Holberg Cl, Martinez FD, Whight AL. Dog exposure in infancy decreases the subsequent risk of frequent wheeze but not of atopy. Allergy $\mathrm{Clm}$ Immunol 2001;108(4):509-15.

40. Hesselmar B, Aberg N, Aberg B, Eriksson B, Bjorksten B. Does tarly exposure to cat or dog protect against later allergy development? Cim Exp Allergy 1999:29(5):611-7.

41. Bacharier LB, Strunk RC. Pets and childhood asthma-how should the pediatrician respond to new information that pets may prevent asthma? Pediatrics 2003; 112(4):974-6.

42. van Schayck CP, Knotmerus A. Can the 'hygiene hypothesis' be explained by confounding by behaviour? IClin Epidemiol 2004;57(5):435-7.

43. Gilliland FD, Berhane K, McConnell R, Gauderman WJ, Vora H, Rappaport EB et al. Maternal smoking during pregnancy, environmental tobacco smoke exposure and childhood Hung function. Thorax 2000;55(4):271-6.

44. Stick SM, Burton PR, Gurrin L, Sly PD, LeSouef PN. Effects of matemal snoking during pregnancy and a family history of asthma on respiratory function in newborn infants. Laucet $1996 ; 348(9034): 1060-4$.

45. Gilliland FD, Li YF, Peters JM. Effects of matemal smoking during pregnancy and environmental tobacco smoke on asthma and wheezing in children. Am J Respir Crir Care Med $2001 ; 163(2): 429-36$.

46. Gruber $C$, Nilsson L, Bjorksten B. Do early childhood immunizations influence the development of atopy and do they cause allergic reactions? Pediatr Allergy Immunol $2001 ; 12(6): 296-311$.

47. Walker C, Sawicka E, Rook GA. Immunotherapy with mycobacteria. Cur Opin Allergy Clin Immunol 2003;3(6):481-6. 
120 


\section{Summary}

In the early nineties, the Dutch Municipal Health Services Westelijke Mijnstreek and Midden-Limburg identified childhood respiratory disease as an important health issue in their region. At that time only limited information was available about the extent of this problem and the risk factors for developing respiratory symptoms in children specific to the Dutch-German borderland. From literature many potential risk factors emerge that may play a role in onset and progression of respiratory symptoms and related allergic conditions, however for many of these factors their exact role is still unclear (Chapter l). This lack of information as well as incomparable results from previous studies resulted, in spring 1994, in the formation of a group consisting of representatives from Dutch and German Municipal Health Services (GGD Westelijke Mijnstreek, GGD Midden-Limburg and Gesundheitsamt Kreis Heinsberg) and University (RWTH-Aachen). In 1995 this cooperation resulted in the Dutch-German study, part of its results are presented in this thesis.

First, prevalence of respiratory symptoms and diagnosis was studied in two consecutive surveys. Parents of all 7201 children (who were born between November $30^{\text {th }} 1989$ and December $1^{\text {st }} 1990$ ), living in the study area at the time the study was conducted, were asked to complete a short questionnaire on respiratory health for their child in 1995 (when the children were aged 5-6 years) and in 1997 (at age 7-8 years). Following these surveys, in a case-control setting, risk factors for respiratory symptoms were investigated. All (781) children with respiratory symptoms and an equal number of children without respiratory symptoms were invited to participate in the case-control study, including blood sampling for immunological analyses, urine sampling, and completion of a detalled parental questionnaire. In addition, a subsample of 240 children was selected (120 cases and 120 controls) for detailed investigation of the homes. The schools of these children were described using checklists.

Besides participating in this Dutch-German study, the Municipal Health Service Westelijke Mijnstreek, every four years, continued to monitor the prevalence of respiratory symptoms in their region. In Chapters $2 a$ and $2 b$ the results from these periodical surveys are described. Combining the survey with the physical examination (PGO), routinely performed by the youth health care section on all schoolchildren aged 5-6 years and 8-9 years, ensured high response rates $(>95 \%)$ in each survey (in 1989, 1993, 1997 and 2001, respectively). In 1989, 3176 children, in 19933491 children, and in 19974776 children participated. These three surveys included both 5-6-year-old children and 8-9-year-old children, in 2001 only 8-9year-olds (1102 children) were included. In each survey, the same methods and respiratory symptom questions were used.

Noticeably, in contrast to other studies, in the Westelijke Mijnstreek the prevalence of wheeze decreased between 1989 and 2001 , whereas during the same time period (until 1997) the prevalence of other respiratory symptoms increased. Among 8-9- 
year-old children, the prevalence of recent wheeze declined from $13.4 \%$ in 1989 to $9.1 \%$ in 2001 ( $\mathrm{p}_{\text {trend }}=0.001$ ). This decrease was also apparent among 5-6-year-olds (from $22.1 \%$ in 1989 to $18.3 \%$ in 1997 , $\mathrm{p}_{\text {trend }}=0.002$ ). Stratification according to sex in 8-9-year-olds, showed that this decline was most pronounced among boys, while the prevalence of recent wheeze among girls remained fairly stable.

Among 8-9-year-old children with recent wheeze, the proportion of children using medication (last month) for their complaints, among boys increased from $42.9 \%$ in 1989 to $64.8 \%$ in 2001 ( $\mathrm{p}_{\text {trend }}=0.003$ ), but among girls this increase was not statistically significant. Accordingly, school absence in the last 12 months decreased among wheezy boys from $25.0 \%$ in 1989 to $3.7 \%$ in 2001 , with an especially large decline between $1997(23.1 \%)$ and 2001 (3.7\%). Among wheezy girls this decline was not seen, and, with $20.0 \%$ in 2001 , remained much higher than among boys.

In contrast to wheeze, the prevalence of other asthmatic symptoms, i.e., recent shortness of breath and recent shortness of breath with wheeze, increased between 1989 and 1997, both in 5-6 and 8-9-year-olds. During the same time period, the proportion of children with asthmatic symptoms, at home exposed to environmental tobacco smoke (from $60.8 \%$ in 1989 to $48.5 \%$ in 1997 ) or to pets (from $55.1 \%$ in 1993 to $47.0 \%$ in 1997), decreased.

Chapter 3 describes differences in asthma diagnosis and treatment between German and Dutch children at 5-6 and 7-8 years of age. Parents of 4462 children participated in both the 1995 and 1997 survey. Of these 4462 children, $341(7.6 \%)$ had recent asthmatic symptoms at 5-6 years of age (in 1995), $240(5.4 \%)$ at $7-8$ years of age and 465 children had asthmatic symptoms either at 5-6 or 7-8 years of age, or at both ages. Parents of 317 of these 465 children completed the elaborate questionnaire, which included questions about respiratory symptoms, treatment, and indoor environment. Large differences in asthma diagnosis and treatment were observed between Dutch and German children. At age 5-6 years, $52.2 \%$ of the Dutch children with recent asthmatic symptoms, had ever been given an asthma diagnosis, among German children this was $21.2 \%(p<0.01)$. Two years later, at age $7-8$ years, the difference was smaller but still present. Bronchitis was diagnosed in almost all 5-6-year-old German children with recent asthmatic symptoms (95.2\%), among Dutch children $65.7 \%$ had been diagnosed with bronchitis $(\mathrm{p}<0.01)$. These differences probably resulted from differential labelling of symptoms; German physicians may have preferred the label 'bronchitis' over the label 'asthma'. In the German region bronchitis seems to encompass symptoms ranging from mild coughing to more severe asthmatic complaints, given the fact that in the present study over $40 \%$ of the German children not reporting any respiratory symptom, had been diagnosed with bronchitis.

Most German ( $80.7 \%)$ and Dutch $(80.0 \%)$ children with recent asthmatic symptoms had been using medication for their complaints in the past year, but there were differences in the kind of medication that was used. More of the Dutch children than of the German children used inhaled $\beta_{2}$-agonists $(67.3 \% v 45.6 \%, \mathrm{p}<0.01)$ and 
inhaled corticosteroids $(38.9 \% \vee 7.0 \%, \mathrm{p}<0.01)$ for their complaints. Instead, proportionally more German than Dutch children used sodium cromoglycate or nedocromil as maintenance treatment $(42.1 \%, 11.5 \%, \mathrm{p}<0.01)$. Inhaled $\beta_{2}$-agonists were used by $26.5 \%$ of the Dutch children and $15.8 \%$ of the German children as monotherapy. Combined with anti-inflammatory medication (corticosteroids or sodiumcromoglycate/nedocromil) inhaled $\beta_{2}$-agonists were used by $40.7 \%$ of the Dutch and $29.9 \%$ of the German children. Taken together these results may implicate undertreatment of German asthmatic children with corticosteroids.

Besides differences in diagnosis and treatment, differences in prevalence of various risk factors for respiratory symptoms were observed between German and Dutch children. Next to variation in exposure to indoor environmental risk factors, differences in German and Dutch vaccination programmes resulted in differences in vaccination status and prevalence of a number of childhood infectious diseases between German and Dutch children.

In Chapter 4, we investigated the role of vaccination in the development of respiratory symptoms and allergic sensitisation, using a subsample of the children (510 cases and 510 controls) selected for participation in the case-control study. For $775(76.0 \%)$ of these 7-8-year-old children a questionnaire was available, for 638 children specific IgE data was available, and for 572 children a complete vaccination status, a questionnaire and specific IgE data (although for one child IgE analysis was incomplete) were available. Contrary to the hypothesis stating that vaccination may promote allergic disorders, we found no evidence in favour of an inverse association between respiratory symptoms or allergic sensitisation and vaccination against pertussis, measles, rubella or Haemophilus influenza type b. BCG vaccination showed an increased risk for sensitisation, in particular for sensitisation against house dust mite allergens ( $\mathrm{OR}=2.28,95 \% \mathrm{CI}$ : 1.05-4.96). Indication for BCG vaccination (subjects from regions with high tuberculosis prevalence or close contact with persons at risk) may selectively have identified a subgroup of children with characteristics differing from the rest of the population. Factors other than BCG, such as exposure to higher levels of house dust mite allergens, may explain at least part of the positive association with house dust mite sensitisation.

As part of the study described above, the relationship was studied between a number of childhood infectious diseases and wheeze and allergic sensitisation at age 7-8 years (Chapter 5). No association was found between wheezing at age 7-8 years and the respective childhood infectious diseases (measles, mumps, rubella, varicella and scarlet fever). Scarlet fever increased the risk of allergic sensitisation $(\mathrm{OR}=2.82,95 \% \mathrm{Cl}: 1.40-5,72)$, in particular of sensitisation against grasses $(\mathrm{OR}=3.00,95 \% \mathrm{Cl}: 1.35-6.69)$. Varicella also increased the risk of sensitisation against grasses ( $\mathrm{OR}=1.88,95 \% \mathrm{CI}$ : 0.99-3.58). The results showed increasing risk of allergic sensitisation and sensitisation against grasses with increasing number of 
infections. This trend was not found for wheeze. When only viral infections were included in the analysis, the same trend was observed.

No evidence was found for a protective effect of childhood infections on wheeze or allergic sensitisation, as has been proposed by the hygiene hypothesis. In contrast, scarlet fever and varicella presented an increased risk of allergic sensitisation.

The relations between a number of indoor environmental factors and respiratory symptoms are presented in Chapter 6 . The parents of $1191(76.2 \%)$ children participated in this part of the study. Interestingly, the distribution of indoor environmental risk factors was found to differ substantially between German and Dutch households; more homes of German than of Dutch children had wall-to-wallcarpeting, on the other hand in Dutch households more often gas was used for cooking and in more Dutch homes a gas geyser (for water heating) was present, than in German homes. Exposure to tobacco smoke in the indoor environment as well as in utero, presence of an unvented gas geyser (as marker for $\mathrm{NO}_{2}$ exposure), exposure to mould or damp spots, or to pets in the home, increased the risk of respiratory symptoms in these children. Presence of wall-to-wall carpeting was inversely associated with respiratory symptoms, as was also the case with insulation measures (double glazing or door and window seals), which in particular reduced the risk of asthmatic symptoms.

In Chapter 7 we investigated whether risk factor patterns for asthmatic symptoms differed between atopic and non-atopic 7-8-year-old children. Children were defined as atopic if at least one specific $\operatorname{lgE}$ tested positive $(\geq 0.35 \mathrm{kU} / 1)$ and as nonatopic if negative for all specific IgE tested. For 267 asthmatic children $(57.4 \%)$ and 485 control children $(62.1 \%)$, complete specific $\operatorname{IgE}$ data and a questionnaire were available.

In general, atopic children had more severe asthmatic complaints, had more often used medication in year preceding the study, and more often also had eczema or hay fever, compared to non-atopic children with asthmatic symptoms. Male sex $(\mathrm{OR}=3.22,95 \% \mathrm{Cl}: 1.53-6.76)$ and maternal asthma $(\mathrm{OR}=21.79,95 \% \mathrm{Cl}: 2.55-$ 185.99) were significant risk factors for asthmatic complaints in atopic children but not in non-atopic children $(\mathrm{OR}=1.57,95 \% \mathrm{Cl}: 0.92-2.65$ and $\mathrm{OR}=2.22,95 \% \mathrm{Cl}$ : $0.77-6.42$, respectively). Breastfeeding increased the risk of persistent asthmatic symptoms later in life in atopic children $(\mathrm{OR}=2.75,95 \% \mathrm{Cl}: 1.14-6.65)$ but not in non-atopic children $(\mathrm{OR}=0.95,95 \% \mathrm{CI}: 0.40-2.25)$. The same risk factors were related to recent wheeze at age 7-8 years in atopic children. Presence of mould or damp spots (OR=3.81, 95\% CI: $1.23-11.84)$ was positively associated with asthmatic symptoms in non-atopic children. Recent wheeze was, in non-atopic children, positively associated with exposure to environmental tobacco smoke in the first two years of life ( $\mathrm{OR}=2.63,95 \% \mathrm{Cl}: 1.11-6.27$ ), gas cooking with irregular use of cooker hood (OR=7.42, 95\% CI: $1.55-35.58)$ and lower socio-economic status ( $\mathrm{OR}=4.44,95 \% \mathrm{Cr}: 1.42-13.91)$. 
It thus appears that with the atopy-definition used in the present study, two subgroups of children with asthmatic symptoms can be distinguished that differ in severity of complaints and in risk factor pattern.

In Chapter 8 methodological aspects of the study are discussed, as well as public health consequences of the findings. Both the Dutch-German study and the periodical surveys conducted in the Westelijke Mijnstreek, were initiated and (partly) conducted by the Municipal Health Services. Main goals of the DutchGerman study were (1) to gain insight in the prevalence of respiratory symptoms, asthma diagnosis and treatment for the region, (2) to identify preventable risk factors for respiratory symptoms specific to the region, which are modifiable at an age the Municipal Health Services have access to the children and (3) to use the resources of the Health Services to implement new or improve existing preventive measures. The consequences of these aims on design and results of the study (for instance, the choice of identifying a cohort of children at age 5-6 years, the use of questionnaires, response rates and respiratory symptom definitions) are discussed.

The high prevalence rates, in the late eighties and early nineties observed for the Westelijke Mijnstreek, were found to be comparable to the prevalence rates of respiratory symptoms in the adjoining regions, Midden-Limburg and Heinsberg. An explanation for the high regional symptom prevalence as well as for the temporal differences observed for the Westelijke Mijnstreek is complicated by the fact that many factors play a role. Differences in risk factor pattern were observed between German and Dutch children. These differences may, at least partly, have resulted from differing healthcare systems and from comparison of these systems valuable clues may emerge for improving asthma prevention. Municipal Health Services can with relatively simple means provide important information on the respiratory health status in their region, as well as identify certain groups in society needing preventive activities adjusted to their specific situation. On the other hand Municipal Health Services have the capacities to coordinate and optimise the flow of information for their region as well as mediate between the responsible institutions.

Better understanding into the natural course of atopic conditions, such as asthma, and factors influencing these processes is essential for improving prevention, especially for improving primary prevention of asthma. Municipal Health Services can provide important information, for instance by conducting periodic surveys as is illustrated by the example of the Westelijke Mijmstreek. These surveys can be extended (1) to other (Dutch, German or Belgian) regions or (2) to other issues of interest, for instance related atopic conditions or to asthma therapy. On the other hand this system could serve as framework to investigate how accessible information on asthma prevention is for the parents and what problems are encountered when implementing this information. Also, intervention trials studying efficiency of (new) interventions could be conducted within the existing framework. This has the additional benefit that, independent of the trial, information on respiratory status of these children is routinely collected by the Municipal Health 
126

Service at different time point when the children are between 4 and 19 years old and long term effects can relatively easy be investigated. 


\section{SAMENVATTING}

Begin jaren '90 werd door de GGD'en Westelijke Mijnstreek en Midden-Limburg onderkent dat luchtwegklachten op kinderleeftijd een belangrijk gezondheidsprobleem vormden in de regio. Op dat moment was slechts weing informatie beschikbaar over de omvang van het probleem en de factoren die regionaal een rol speelden bij het ontstaan van deze luchtwegklachten. In de literatuur worden vele mogelijke risicofactoren voor het ontstaan en verergeren van luchtwegklachten en aanverwante allergische aandoeningen besproken, maar voor een groot aantal van deze factoren is hun rol in dit proces nog verre van eenduidig (Hoofdstuk 1). Het ontbreken van informatie en het niet vergelijkbaar zijn van de wel aanwezige informatie leidde in het voorjaar van 1994 tot het formeren van een werkgroep, waarin GGD'en uit Nederland en Duitsland (GGD Midden-Limburg, GGD Westelijke Mijnstreek en Gesundheitsamt Kreis Heinsberg) en Universiteit (RWTH-Aachen) vertegenwoordigd waren. Deze samenwerking leidde in 1995 tot de Duits-Nederlandse studie waarvan in dit proefschrift een deel van de resultaten wordt gepresenteerd.

Allereerst is in twee op elkaar volgende vragenlijstonderzoeken de prevalentie van luchtwegklachten en van diagnose bestudeerd. De ouders van alle 7201 kinderen, die ten tijde van het onderzoek in het studiegebied woonden en die geboren waren tussen 30 november 1989 en 1 december 1990, werden in 1995 (wanneer het kind 5-6 jaar oud was) en in 1997 (wanneer het kind 7-8 jaar oud was) gevraagd een korte vragenlijst over luchtwegklachten voor hun kind in te vullen. Vervolgens zijn risicofactoren voor het voorkomen van luchtwegklachten bij deze kinderen bestudeerd in een patiënt-controle studie. Daarvoor werden alle (781) kinderen met luchtwegklachten en evenveel kinderen zonder luchtwegklachten uitgenodigd voor deelname aan de patient-controle studie, waarbij bloed werd afgenomen voor immunologische analysen, urinemonsters werden verzameld en de ouders gevraagd werd een uitgebreide vragenlijst voor hun kind in te vullen. Daarnaast werd een subgroep van 240 kinderen uitgekozen (120 cases en 120 controles) voor een gedetailleerd onderzoek van de woningen en het beschrijven van de scholen van deze kinderen aan de hand van een checklist.

Naast deelname an deze Duits-Nederlandse studie is de GGD Westelijke Mijnstreek de prevalentie van luchtwegklachten bij kinderen van schoolleeftijd voor hun regio, elke vier jaar, blijven monitoren. In Hoofdstuk $2 a$ en Hoofdstuk $2 b$ worden de resultaten van deze periodieke metingen beschreven. Het vragenlijstonderzoek werd in elk onderzoeksjaar (1989, 1993, 1997 en 2001 resp.) gekoppeld aan het periodiek geneeskundig onderzoek (PGO), door de afdeling Jeugdgezondheidszorg uitgevoerd bij schoolkinderen van 5-6 en 8-9 jaar oud. Door deze koppeling werd in alle onderzoeksjaren een hoge respons behaald $(>95 \%)$. In 1989 namen 3176 kinderen deel, in 1993 waren dat 3491 kinderen en in 19974776 kinderen. In deze drie onderzoeksjaren werden zowel 5-6 jarigen als 8-9 jarigen volgens exact dezelfde methode en met hetzelfde meetinstrument (vragen over 
luchtwegklachten) onderzocht. In 2001 was dit alleen het geval voor de 8-9 jarigen (1102 kinderen).

Opvallend was dat in tegenstelling tot andere studies, de prevalentie van de klacht piepen op de borst in de Westelijke Mijnstreek daalde tussen 1989 en 2001. terwijl de prevalentie van de overige luchtwegklachten steeg tot 1997. Voor 8-9 jaar oude kinderen daalde de prevalentie van recent piepen op de borst van $13.4 \%$ in 1989 naar $9.1 \%$ in 2001 ( $\mathrm{p}_{\text {trend }}=0.001$ ). Deze daling werd ook gezien bij de 5-6 jarige kinderen (van $22.1 \%$ in 1989 naar $18.3 \%$ in 1997 , p prend $=0.002$ ). Wanneer bij $8-9$ jarige kinderen onderscheid naar geslacht werd gemaakt, bleek deze daling met name veroorzaakt te worden door een daling van de prevalentie bij jongens terwijl bij meisjes de prevalentie min of meer constant bleef.

Binnen de groep 8-9 jarige kinderen met recentelijk piepen op de borst bleek de proportie kinderen die in de laatste maand medicijnen voor hun luchtwegklachten gebruikt had bij jongens toe te nemen van $42.9 \%$ in 1989 naar $64.8 \%$ in $200 \mathrm{I}$. ( $p_{\text {trend }}=0.003$ ), terwijl bij meisjes deze stijging niet statistisch significant was. Dienovereenkomstig daalde het schoolverzuim (in de laatste 12 maanden) bij jongens met recent piepen op de borst van $25.0 \%$ in 1989 naar $3.7 \%$ in 2001 , waarbij met name de afname tussen $1997(23.1 \%)$ en $2001(3.7 \%)$ opvalt. Bij meisjes met recent piepen op de borst is deze afname niet terug te vinden en blijft in 2001 met $20.0 \%$ zelfs veel hoger dan bij jongens.

In tegenstelling tot de klacht piepen op de borst werd voor prevalentie van de overige astmatische klachten, recente kortademigheid en recente kortademigheid met piepen op de borst, een stijging gezien tussen 1989 en 1997, zowel bij 5-6 als bij 8-9 jarigen. Tegelijkertijd daalde de proportie kinderen met astmatische klachten die in de woning werd blootgesteld aan sigarettenrook (van $60.8 \%$ in 1989 naar $48.5 \%$ in 1997) en aan huisdieren (van $55.1 \%$ in 1993 naar $47.0 \%$ in 1997).

In Hoofdstuk 3 worden verschillen in astma diagnose en behandeling tussen de Duitse en Nederlandse kinderen op 5-6 en op 7-8 jarige leeftijd beschreven. Ouders van 4462 kinderen namen zowel deel aan het vragenlijstonderzoek in 1995 als aan het vragenlijstonderzoek in 1997. Van deze 4462 kinderen hadden 341 (7.6\%) kinderen recente astmatische klachten op 5-6 jarige leeftijd (in 1995), 240 (5.4\%) op 7-8 jarige leeftijd (in 1997) en 465 kinderen hadden klachten op 5-6 of 7-8 jarige leeftijd of op beide leeftijden. De ouders van 317 van deze 465 kinderen voldeden vervolgens aan het verzoek een uitgebreide vragenlijst met vragen over luchtwegklachten, behandeling en binnenmilieu in te vullen.

$\mathrm{Er}$ werden grote verschillen in prevalentie van astma diagnose en -behandeling gevonden tussen de Duitse en Nederlandse kinderen. Op 5-6 jarige leeftijd was bij $52.2 \%$ van de Nederlandse kinderen met recente astmatische klachten ooit een astma diagnose gesteld, bij de Duitse kinderen was dit $21.2 \%(\mathrm{p}<0.01)$. Twee jaar later, op 7-8 jarige leeftijd, was dit verschil kleiner maar nog steeds aanwezig. Bronchitis daarentegen was bij bijna alle Duitse kinderen met recente astmatische klachten op 5-6 jarige leeftijd (95.2\%) als diagnose genoemd, bij de Nederlandse kinderen was dit $65.7 \%(p<0.01)$. Deze verschillen zijn waarschijnlijk terug te 
voeren op differentiële labelling van symptomen, waarbij Duitse artsen het label "bronchitis" prefereren boven het label "astma". In het Duitse gebied lijkt "bronchitis" een scala aan luchtwegklachten te omvatten, warièrend van milde hoestklachten tot ernstigere astmatische klachten, getuige het feit dat in de huidige studie meer dan $40 \%$ van de Duitse kinderen die geen enkele luchtwegklacht rapporteerden wel een artsdiagnose bronchitis hadden.

Hoewel de meeste Duitse $(80.7 \%)$ en Nederlandse $(80.0 \%)$ kinderen met astmatische klachten medicijnen gebruikten, waren er enige verschillen in de aard van de gebruikte medicatie. Nederlandse kinderen gebruikten vaker dan Duitse kinderen inhalatie $\beta_{2}$-agonisten $(67.3 \%, y, 45.6 \%, \quad \mathrm{p}<0.01)$ en inhalatie corticosteroïden $(38.9 \% \vee 7.0 \%, \mathrm{p}<0.01)$ voor hun klachten. Meer Duitse kinderen. daarentegen gebruikten sodium cromoglycaat of nedocromil als onderhoudstherapie dan Nederlandse kinderen $(42.1 \% v 11.5 \%, \mathrm{p}<0.01)$. Inhalatie $\beta_{2}$ agonisten werden door $26.5 \%$ van de Nederlandse kinderen en door $15.8 \%$ van de Duitse kinderen als monotherapie gebruikt. In combinatie met inhalatie anti-inflammatoire medicatie (corticosteroïden of sodium cromoglycaat/nedocromil) werden inlialatie $\beta_{2}$ agonisten gebruikt door $40.7 \%$ van de Nederlandse kinderen en door $29.9 \%$ van de Duitse kinderen. Tesamen genomen lijkt dit een indicatie voor onderbehandeling van Duitse kinderen met astmatische klachten met corticosteroilden.

Behalve de verschillen in diagnose en behandeling, werden er ook grote verschillen in het voorkomen van diverse risicofactoren voor luchtwegklachten gezien tussen Duitse en Nederlandse kinderen. Naast variatie in binnenmilieubelasting, hebben verschillen tussen de Duitse en Nederlandse vaccinatie programma's geleid tot verschillen in vaccinatiegraad en verschillen in prevalentie van een aantal kinderziekten tussen de Duitse en Nederlandse kinderen.

In Hoofdstuk 4 wordt het onderzoek naar de rol van vaccinatie bij het voorkomen van luchtwegklachten en allergische sensibilisatie onderzocht bij een deel van de kinderen (510 cases en 510 controles) die voor het patient-controle onderzoek waren uitgenodigd. Voor $775(76.0 \%)$ van deze $7-8$ jaar oude kinderen waren vragenlijsten beschikbaar, voor 638 kinderen waren specifieke lgE data beschikbaar, en voor 572 kinderen was er zowel een complete vaccinatie status, een vragenlijst en specifieke $\operatorname{IgE}$ data (voor 1 kind was deze IgE meting incompleet) beschikbaar. In tegenstelling tot de hypothese dat vaccinatie het ontstaan van allergische aandoeningen zou kunnen promoten, hebben we in deze studie geen aanwijzingen gevonden voor een inverse associatie tussen het voorkomen van luchtwegklachten of allergische sensibilisatie en vaccinatie tegen resp. kinkhoest, mazelen, rode hond en Haemophilus influenza type b. BCG vaccinatie daarentegen liet een verhoogd risico voor sensibilisatie zien, in het bijzonder voor sensibilisatie voor huisstofmijt allergenen (OR=2.28,95\% BI: 1.05-4.96). Door de indicatie voor $B C G$ vaccinatie (personen afkomstig uit hoog-risico landen of personen die in contact zijn gekomen met personen at risk), is mogelijk selectief een subgroep van kinderen geïdentificeerd waarvan de eigenschappen verschillen van de rest van de 
populatie, en factoren anders dan BCG vaccinatie, zoals bv. blootstelling aan hogere concentraties van huisstofmijt allergenen, kunnen mogelijk (deels) de gevonden associatie verklaren.

Als onderdeel van het hierboven beschreven onderzoek hebben we ook gekeken naar de relatie tussen een aantal kinderziekten en het voorkomen van piepende ademhaling en allergische sensibilisatie (Hoofdstuk 5). Ook hier werd geen associatie gezien tussen het voorkomen van piepende ademhaling op 7-8 jarige leeftijd en de respectievelijke kinderziekten (mazelen, bof, rode hond, waterpokken en roodvonk). Roodvonk verhoogde wel het risico voor allergische sensibilisatie $(\mathrm{OR}=2.82,95 \% \mathrm{BI}: 1.40-5.72)$ en in het bijzonder sensibilisatie voor pollen $(\mathrm{OR}=3.00,95 \% \mathrm{BI}: 1.35-6.69)$. Ook waterpokken liet een verhoogd risico op sensibilisatie voor pollen zien ( $O R=1.88,95 \%$ BI: 0.99-3.58). De resultaten lieten ook een toenemend risico op allergische sensibilisatie en sensibilisatie woor pollen zien met toenemend aantal infecties. Voor piepende ademhaling werd dit niet waargenomen. Als alleen virale infecties in de analysen werden opgenomen werd eenzelfde tendens gezien.

Samenvattend werden er dus geen aanwijzingen gevonden voor een beschermende invloed van de onderzochte infectieziekten op het voorkomen van piepende ademhaling of allergische sensibilisatie, als wordt voorgesteld door de hygiëne hypothese. In tegenstelling, roodvonk en waterpokken leken juist een risico op te leveren voor allergische sensibilisatie.

De relatie tussen diverse binnenmilieu-gerelateerde factoren en luchtwegklachten wordt besclureven in Hoofdstuk 6. Aan dit deel van het onderzoek deden 1191 $(76.2 \%)$ kinderen mee. Opvallend was dat de prevalentie van een aantal binnemmilieufactoren grote verschillen liet zien tussen de Duitse en Nederlandse huishoudens; woningen van Duitse kinderen hadden vaker vloerbedekking dan woningen van Nederlandse kinderen, omgekeerd werd in de Nederlandse huishoudens veel vaker op gas gekookt en was vaker een gasgeiser (voor het verwarmen van water) aanwezig dan bij de Duitse kinderen. Blootstelling aan sigarettenrook in de omgeving zowel als in utero, aanwezigheid van een gasgeiser zonder afvoer (als marker voor $\mathrm{NO}_{2}$ belasting), vocht of schimmelvorming in de woning en de aanwezigheid van huisdieren binnenshuis verhoogden de kans op luchtwegklachten bij de kinderen. De aanwezigheid van vloerbedekking liet een veriaagd risico voor het hebben van luchtwegklachten zien, isolatie voorzieningen (dubbele beglazing en tochtstrippen) verlaagden in het bijzonder de kans op astmatische klachten.

In Hoofdstuk 7 wordt gekeken of het risicofactor patroon voor astmatische klachten verschillend is voor atopische en niet-atopische kinderen op 7-8 jarige leeftijd. Een kind werd als atopisch gedefinieerd wanneer tenminste één van de geteste specifieke IgE's positief was ( $\geq 0.35 \mathrm{kU} / /$ ) en als niet-atopisch wanneer alle geteste specifieke $\lg \mathbb{E}$ 's negatief waren. Voor 267 astmatische kinderen $(57.4 \%)$ en 485 
controle kinderen (62.1\%) waren zowel een volledige specifieke lgE analyse als een vragenlijst beschikbaar.

In het algemeen hadden atopische kinderen erristigere astmatische klachten, hadden ze het afgelopen jaar vaker medicijnen gebruikt en hadden vaker eczeem of hooikoorts dan niet-atopische kinderen met astmatische klachten. Mannelijk geslacht $(O R=3.22,95 \% \mathrm{Bl}: 1.53-6.76)$ en een moeder met astma $(O R=21.79,95 \%$ BI: 2.55-185.99) waren belangrijke risicofactoren voor astmatische klachten bij atopische kinderen maar speelden geen rol bij niet-atopische kinderen ( $O R=1.57$, $95 \%$ BI: $0.92-2.65$ en $\mathrm{OR}=2.22,95 \% \mathrm{BI}: 0.77-6.42$ resp.). Borstvoeding verhoogde de kans op het later krijgen van persisterende astmatische klachten bij atopische kinderen $(\mathrm{OR}=2.75,95 \%$ BI:1.14-6.65) maar niet bij niet-atopische kinderen $(\mathrm{OR}=0.95,95 \% \mathrm{BI}: 0.40-2.25)$. Dezelfde factoren speelden bij atopische kinderen een rol als werd gekeken naar het recentelijk last hebben van een piepende ademhaling. De aanwezigheid van vocht- of schimmelvorming $(\mathrm{OR}=3.81,95 \% \mathrm{BI}$ : 1.23-11.84) betekende een risico voor astmatische klachten in niet-atopische kinderen. Recent piepende ademhaling was in niet-atopische kinderen positief geassocieerd met blootstelling aan omgevingsrook gedurende de eerste twee levensjaren $(\mathrm{OR}=2.63,95 \% \mathrm{Bl}: 1.11-6.27)$, koken op gas met onregelmatig gebruik van de afzuigkap $(\mathrm{OR}=7.42,95 \% \mathrm{BI}: 1.55-35.58)$ en lagere sociaal-economische status $(\mathrm{OR}=4.44,95 \% \mathrm{BI}: 1.42-13.91)$.

Het lijkt er dus op dat met de door ons gebruikte atopie-definitie twee subgroepen van kinderen met astmatische klachten kunnen worden onderscheiden, die verschillen in ernst van klachten en in risicofactor patroon.

In Hoofdstuk 8 worden methodologische aspecten besproken en de belangrijkste resultaten bekeken vanuit public health perspectief.

Zowel de Duits-Nederlandse studie als de periodieke luchtwegklachtenmetingen in de Westelijke Mijnstreek zijn geïnitieerd en (deels) uitgevoerd vanuit de GGD'en. Daarbij waren de belangrijkste doeistellingen, (1) inzicht krijgen in de prevalentie van luchtwegklachten, astma diagnose en behandeling in het gebied, (2) het identificeren van beïnvloedbare risicofactoren die modificeerbaar zijn op een leeftijd waarop de GGD'en toegang hebben tot de kinderen en (3) gebruikmaken van het potentieel van de GGD'en voor implementatie van nieuwe of verbetering van al bestaande preventieve maatregels. De gevolgen die dit heeft gehad voor de opzet en uitvoering van de studie (o.a. de keuze voor het identificeren van een cohort van 5-6 jarige kinderen, het gebruik van vragenlijsten, de respons en de gehanteerde definities voor luchtwegklachten) worden besproken.

De hoge prevalentie van luchtwegklachten, eind jaren ' 80 begin jaren ' 90 gesignaleerd voor de Westelijke Mijnstreek, bleek vergelijkbaar te zijn met de prevalentie in de aangrenzende regio's Midden-Limburg en Heinsberg.

Het verklaren van hoge regionale prevalentie en de temporele verschillen in prevalentie van luchtwegklachten gevonden voor de Westelijke Mijnstreek, is gecompliceerd doordat vele factoren een rol kunnen spelen. Verschillen in risicofactor patroon zijn gevonden tussen de Duitse en Nederlandse kinderen. Deze 
verschillen zijn mogelijk (deels) veroorzaakt door verschillende gezondheidszorgsystemen in beide landen en een vergelijk van beide systemen zou belangrijke aanknopingspunten kunnen opleveren voor de bevordering van astmapreventie. GGD'en kunnen met relatief eenvoudige middelen belangrijke informatie verschaffen over de respiratoire gezondheidssituatie in hun regio, alsmede groepen in de samenleving identificeren, om preventie activiteiten af te stemmen op de specifieke situatie van deze subgroepen. Daarnaast kunnen GGD'en de informatiestroom voor hun regio coördineren en optimaliseren en medieeren tussen de verantwoordelijke instanties.

Beter inzicht in het natuurlijke verloop van atopische aandoeningen, zoals astma en de factoren die van invloed zijn op dit proces is essentieel voor verbetering van preventie, in het bijzonder voor primaire preventie, op dit gebied. GGD'en kumnen belangrijke informatie verschaffen over de respiratoire gezondheidssituatie in hun regio, bijvoorbeeld in de vorm van periodieke onderzoeken zoals dat in de Westelijke Mijnstreek gebeurd. Deze vragenlijst onderzoeken kunnen uitgebreid worden (1) naar andere binnen- of buitenlandse (Belgische of Duitse) GGD regio's of (2) met andere thema's zoals gerelateerde atopische aandoeningen of astma therapie.

Daarnaast zou dit systeem als framework kunnen dienen om te onderzoeken hoe toegankelijk informatie over preventie is voor de ouders en welke problemen zij tegenkomen bij de omzetting hiervan. Ook zou d.m.v. interventie-trials, de efficiëntie van (nieuwe) interventies kunnen worden bestudeerd binnen het bestaande systeem. Doordat door de GGD informatie over de respiratoire status van het kind, routinematig en onafhankelijk wan de interventie trial, kan worden verzameld op een aantal momenten tussen 4 en 19 jarige leeftijd, heeft dit het voordeel dat lange termijn effect relatief eenvoudig kumnen worden bestudeerd. 


\section{APPENDIX 1}

1a. Hoest uw kind gewoonllijk-dat is wel 5 dager per week(bij) bij het opstaan of overdag of 's nachts)?

16. Zo ja; hoest uw kind in perioden wan we: 3 maanden achtereen 20 ?

2a. Heeft uw kind gewoonlijk-dat is wel 5 dagen per weeklast van wolzitten op de borst?

2b. Zoja; heeft uw kind dit in perioden van wel 3 maanden achtereen?

3a. Heeft uw kind gewoonlij - dal is wel 5 dagen per weeklast van opgeven van fiumen (sputtum) bijv. bi] het opstaan of overdag of 's nachts?

3b. Zo ja; heeft uw kind dit in perioden wan wel 3 maanden achtereen?

4a. Heeft uw kind de afgelopen 12 maanden weleens een periode gehad waarin het meer dan gewoonlijk hoestle met opgeven van lluimer (sputum)?

4b. Zo ja: duwrde zo"n periode langer dan 3 weken?

5a. Heeft uw kind de afigelopen 12 maanden wel eens last gehad van pliepen op de borst?

5b. Zo ja; hoe waak heeft uw kind last van piepen op de borst gehad in de afgelopen 12 maanden?

6a. Heeft ww kind de afgellopen 12 maanden last gehad wan aanvallen van kortademigheid met piepen op de borst (aismaraanvalleny?

6b. Zo ja, hoe vaak heeft uw kind zon aanval (giemiddeld per maand]?

7ia. Vindl u dat uw kind de afgelopen 12 maanden wol eens kortademig is geweest?

7b. Zo ja; windt u d al uw kind snellen kortademig is dan leeftijdsgenooljes?

8a, Heeft ww kind de afgelopen 12 maanden wel eens last gehad wan kortademigheid bijtraplopen of speien?

8b. Zo ja; heeft uw hind wel eens las van kortademigheid bij lopen over wak terrein in nomaal tempo?

9a. Heeft ww kind de afgelopen maanden waak last gehad wan een werstopte neus oll loopneusi?

9l. Za ja: heeft uw kind dit in perioden van wel 3 maanden achlereen?

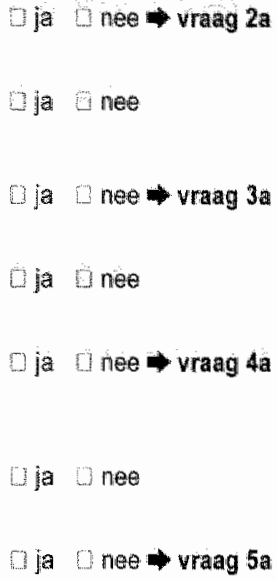




\section{APPENDIX 2}

1. Heeft uw $k$ ind wel ens lasi gehad wan kortademighed

Oja Onee

bij hot butten spelen of bij hel oplopen van de trap?

Indien ja:

2. Heeft uw kind in de laatste 12 maanden last gehad van kortademighed bil het builenspelen of bil het oplopen van de trap?

3. Heeft ww kind wol eens last getheid wan piepen op de borst?

Indien ja

4. Heeft ww kind in de laatste 12 maanden last gehad wan piepen op de borst?

5. Heeft uw kind wel ens aanvallen gehad van kortademigheid met piepen?

Indien $\mathbf{a}$

6. Heett uw kind in de laatste 12 maander aanvallen gehad wan hortademigheid met piepen?

Wa rate

7 ja nes

ja mee

Uja nee

Dja nee

[.] ja nee wimterseizaen?

8. Hoest uw kind meestal overdag of 's naachts, in het najaar- of winterseizoen?

Uja Unee Indien ja:

9. Hoest uw kind zo vitiwel dagelifins wel 3 maanden per

Da la nee 


\section{APPENDIX 3}

21 Heeft uw kind ooit last gehad wan piepen op de borsil?

22 Heeft uw kind in de afgelopen 12 maanden last gehad van piepen op de borst?

23 Hoeveel aanvallen van piepen op de borst heeft uw kind in de afgelopen 12 maanden gehad?

24 Hoe vaak is uw kind gemiddeld wakker geworden door piepen op de borst in de afgelopen 12 maandlen?

25 Was het piepen in de afgelopen 12 maanden ooit zo erg dat uw kind steeds na een of twee woorden moest ademhalen?

Heeft uw kind ooit astma gehad?

27 Heeft uw kind in de afgelopen 12 maanden 's nachts last gehad van een droge hoest zonder dat. het verkouden was of een infectie van longen of luchlwegen had?

28 Heeft uw kind in de afgellopen 12 maanden gewoonlijk lasi gehad van vastziftend slijm of slijm opgehoest tijdens een verkoudheid?

29 Heeft uw kind in de afgelopen 12 maanden gewoonlijk last gehad van vastziltend slijm of slijm opgehoest terwijl hij/zij niet verkouden was?

30 Heefl uw kind last wan vastzittend slijm of hoest uw kind sljjm op, op minstens 4 dagen per week en minstens 3 maanden per jaar?

31 Hoeveel jaar heeft uw kind in deze mate last gehad?

32 Heeft uw kind in de afgelopen 12 maanden last gehad van piepen op de borsil tijdens of na inspanning?

33 Heefl uw kind in de afgelopen 12 maanden last gehad van piepen op de borst zonder dall uw kind zich kort van tevoren ingespannen had?

34 Heeft uw kind in de afgelopen 12 maandlen last gehad van piepen op de borst tijdens een verkoudheidlgriep?

35 Heeft uw kind in de afgelopen 12 maanden last gehad van piepen op de borst zonder dat hij/zij een verkoudheid/griep had?

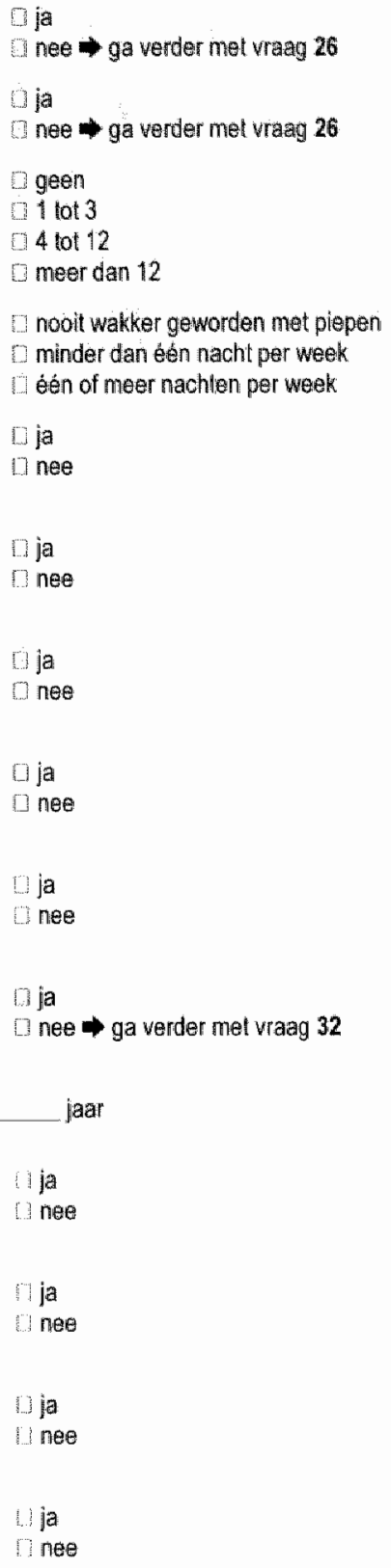


136 


\section{DANKWOORD}

Alweer bijna 8 jaar geleden dat ik de grens overstak om aan de RWTH-Aken te gaan werken aan het "Duits-Nederlandse-project"! Prof. Wolfgang Dott wil ik bedanken voor het bieden van de mogelijkheid deel uit te maken van een project dat niet alleen een Duits-Nederlandse samenwerking betekende, maar ook een samenwerking was tussen Universiteit en Gezondheidsdiensten.

Het idee de gegevens van deze studie in proefschrift-vorm te gieten is echter pas in de zoner van 2001 concreet geworden. Het was toen dat ik, aangespoord door Paul Mertens, contact opnam met Gerard Swaen. En zo leidde het een tot het ander. Paul, op deze plek dan ook; Dank je wel!

Verder will ik mijn promotor, Onno van Schayck en mijn co-promotoren, Gerard Swaen en Michaela Weishoff-Houben bedanken voor hun prettige en deskundige begeleiding. Onno, jouw enthousiasme en altijd opbouwende kritiek heb ik als zeer motiverend ervaren. Gerard, je directheid heb ik erg op prijs gesteld. Je kordate manier van optreden heeft me er menigmaal van overtuigd dat een artikel ook echt af was en niet tot in alle eeuwigheid als concept bleef voortbestaan. Michaela, vanaf het begin hebben we intensief samengewerkt en ik vind het dan ook heel speciaal dat je nu mijn co-promotor bent. Als Nederlandse in Duitsland werken, dat is nog niet zo eenvoudig. Maar je hebt me prima wegwijs gemaakt. Niet alleen heb ik mijn weg leren vinden in het Universitäts-Klinikum dat een erg hoog doolhof-gehalte heeft, maar ook heb je geduldig en begripvol, keer op keer dezelfde taalfouten uit mijn Duitse teksten gevist. Daarnaast heb je mij kennis laten maken met een veelheid aan Duitse gewoonten, gerechten en uitspraken. $\mathrm{lk}$ wil je dan ook ontzettend bedanken voor de jaren van fijne samenwerking, voor je vertrouwen en voor je steun.

Maar bij een project als dit zijn natuurlijk veel meer personen betrokken. Op de eerste plaats alle ouders en alle kinderen die aan de studie hebben deelgenomen. Centraal stond ook de projectgroep bestaande uit Ron Derkx. Prof. Wolfgang Dott, Gonnie Jongmans-Liedekerken, Paul Mertens, Michaela Weishoff-Houben en Bernd Ziemer als de 'harde kern' en Monique de Kok, Ralf Minkenberg, Almut Haln en Achim Steup als tijdelijke leden. Door de vele enthousiaste discussies in deze projectgroep heeft de studie zijn uiteindelijke vorm gekregen en werd tijdens de veldfase alles in goede banen geleid. Meer op de achtergrond was er de stuurgroep, bestaande uit de GGD directeuren, Herr Dr. K.H. Feldhoff van het Gesundheidsamt Kreis Heinsberg, dhr. F. Schreurs van de GGD Midden-Limburg en dhr. F. Keysers en dhr. A. Bovens van de GGD Westelijke Mijnstreek en Prof. W. Dott van het Institut fir Hygiene und Umweltmedizin van de RWTH-Aachen, die toezicht hield op de gang van zaken.

Het waren 'maar' 6 weken en 'maar' 2 landen-warin 1500 kinderen moesten worden onderzocht en 240 huisbezoeken moesten uitgevoerd........... 
Mijn dank gaat uit naar de mensen die dit alles mogelijk hebben gemaakt. Huub Creemers en de medewerkers van de afdeling Jeugdgezondheidszorg van de GGDWestelijke Mijnstreek, Hermann Freund en de andere medewerkers van de afdeling Jeugdgezondheidszorg van het Gesundheidsamt Kreis Heinsberg, Quinta de Creme, Bettie Hutjes en de medewerkers van de Bloedbank Zuid-Limburg, hebben zorg gedragen voor het uitwoeren van de onderzoeken, de bloedafname en de controle van de vragenlijsten. Ook de onderzoeksassistenten Willy Dubois, Arianne Geervliet, Maria Gehlen, Claudia Hildner, Annabelle Hoogers, Elke Körner, Beate Pawelczyk, Karin Vogl, Harm-Jan Weevers en Antje Weyh wil ik bedanken voor hun onmisbare hulp in de veldfase-tesamen zijn we één keer de wereld rondgereisd! Ook dank ik Prof. H.F. Merk en zijn team van de Hautklinik van het Universitätsklinikum Aachen voor het snel en accuraat uitvoeren van de immunologische bepalingen. Miriam Jennissen van de GGD Westelijke Mijnstreek will ik bedanken voor de ondersteuning bij het verplaatsen van talloze afspraken van kinderen die wel wilden maar niet konden komen op de afgesproken dag.

En nadat we de gegevens verzameld hadden, moest alles ook nog in de computer! Onmisbaar daarbij was de deskundige hulp van Alexander Gaß. Alex voor jou 'gab es keine Probleme nur Lösungen', al heb ik nooit begrepen wat er dan opgelost moest worden. Helaas kan je het me niet meer uitleggen...

Torsten Rahms, Maria Gehlen, Sandra Schultz en Willy Dubois wil ik bedanken voor de vele vele uren van data invoeren. Ralf Minkenberg, Almut Hahn en Achim Steup voor het controleren van de gegevensbestanden en de statistische ondersteuning.

Ron, bedankt dat je me destijds de mogelijkheid hebt geboden mee te werken aan het luchtwegklachten monitoringsproject van de GGD Westelijke Mijnstreek. Ik blijf het een uniek project vinden. Cindy en Huub, jullie ook bedankt voor de plezierige samenwerking en jullie bijdrage aan de publicaties.

Mijn familie en vrienden wil ik bedanken voor niet-afiatende interesse en steun.

Pap en mam, op jullie kan ik altijd rekenen. Al vinden jullie dat allemaal vanzelfsprekend, dat is het natuurlijk niet! Bedankt voor alles.

Cécile, gelukkig hoeft een grote plas water een vriendschap niet in de weg te staan, ik ben blij dat je mijn paranimf wil zijn. Bedankt voor alle "transatlantische" discussies, opmerkingen en oplossingen over welk onderwerp dan ook. Shirley, mijn andere paranimf, ik ben erg blij dat jij mij tijdens mijn promotie terzijde wilt staan. En het thuisfront, Ronald, Karlijn en Fleur, jullie zullen me waarschijnlijk niet meer geloven maar - wat zullen we straks eens met al die vrije tijd gaan doen? 


\section{CURRICULUM VITAE}

Monique Mommers werd geboren op 1 september 1966 te Heerlen. In 1985 behaalde zij het Atheneum-B diploma aan het Stedelijk Lyceum te Maastricht. Van 1985 tot en met 1991 studeerde zij Biologie aan de Rijksuniversiteit Utrecht, met als afstudeerrichting medisch gerichte biologie en als hoofdvakken embryologie en neurochemie. $\mathrm{Na}$ haar afstuderen is zij enige tijd werkzaam geweest aan de Rijksuniversiteit Limburg (de huidige Universiteit Maastricht) bij de vakgroep Neuropsychologie en Psychobiologie. Daar werd haar interesse voor epidemiologisch onderzoek gewekt, wat in 1995 leidde tot het volgen van de Postdoctorale opleiding Epidemiologie van het EMGO Instituut (Vrije Universiteit van Amsterdam). Onderdeel van deze opleiding was een onderzoeksstage welke zij verricht heeft bij de GGD Westelijke Mijnstreek te Geleen. Na het behalen van het diploma heeft zij naast haar vrijwilligerswerk voor de GGD Westelijke Mijnstreek, als onderzoeksassistente voor een tweetal projecten gewerkt. Begin 1997 werd zij aan de RWTH Aachen (Duitsland) aangesteld als projectcoördinator voor het DuitsNederlandse onderzoek naar luchtwegklachten bij kinderen, dat de basis vormt voor dit proefschrift. Daarnaast is zij betrokken gebleven bij het luchtwegklachten monitoringsproject van de GGD Westelijke Mijnstreek. Vanaf Juli 2002 is zij bij het Institut für Hygiene und Umweltmedizin van de RWTH Aachen als epidemioloog bij diverse projecten betrokken geweest. Sinds Juni 2004 is zij werkzaam bij de capaciteitsgroep Epidemiologie van de Universiteit Maastricht. 